\title{
MOBILE AGING: A RANDOMIZED TRIAL OF MOBILITY TRANSITION COUNSELING FOR HIGH-RISK OLDER ADULTS
}

A Dissertation
presented to
the Faculty of the Graduate School
at the University of Missouri-Columbia
In Partial Fulfillment
of the Requirements for the Degree
Doctor of Philosophy

by

JAMES STOWE

Dr. Teresa Cooney, Dissertation Supervisor

DECEMBER 2014 
The undersigned, appointed by the dean of the Graduate School, have examined the dissertation entitled

\section{MOBILE AGING: A RANDOMIZED TRIAL OF MOBILITY TRANSITION COUNSELING} FOR HIGH-RISK OLDER ADULTS

presented by James Stowe,

a candidate for the degree of doctor of philosophy,

and hereby certify that, in their opinion, it is worthy of acceptance.

Professor Teresa Cooney

Professor Lawrence Ganong

Professor Angela Curl

Professor Thomas Meuser 
My wife, Becky, and our children, Parker and Sadie, have given of themselves to support this effort and always drew me back to what was most important. My PhD has been a family pursuit.

Wayne and Beverly Williams, my grandparents, encouraged a life of the mind and were the first to inspire me to seriously consider aging.

The warm, kind, and supportive people of Compass Evangelical Free Church of Columbia were a constant refuge and facilitated personal growth that will endure for a lifetime.

All of these individuals have smoothed my path considerably, and I dedicate this scholarship to them. 


\section{ACKNOWLEDGEMENTS}

I acknowledge first and foremost the mentoring that I have received from my Committee Chair, Dr. Teresa Cooney, and other committee members, Drs. Lawrence Ganong, Angela Curl, and Thomas Meuser. Dr. Cooney gave frank criticism and sound advice at every point of my doctoral path. She also showed me how a scholar maintains integrity, cares for students, and continually grows professionally. Dr. Ganong introduced me to intervention trials among older adults, writing large grants, administering multiple projects, and delegating important tasks. Dr. Curl demonstrated how to work collaboratively, break into new areas of inquiry, and never failed to have actionable, sage advice. Dr. Meuser is a master of the craft, and without his guidance, this project would have never left the ground. He demonstrated that a scholar is incomplete without family support, friendship, and that one's work should never consume more than its rightful share.

Additionally, Dr. Marla Berg-Weger has been instrumental in my understanding of transportation and aging and project administration. She and Dr. Meuser welcomed me in to the field at an early stage in my career development, and I am extremely grateful for the opportunities they set in motion.

The faculty and staff of the Frank L. Mitchell Jr., MD Trauma Center were continually supportive, offered constructive and open criticism and helped throughout the research process. Catherine Munger knew more about the IRB and recruitment than I ever will. Paulette Martel was a tireless referrer of high-risk patients to this trial, and I am grateful for her efforts to help patients and researchers. Dr. Greg Petroski offered advice on research design and statistical methodology. 
The Missouri Department of Transportation, The Eastern Association for the Surgery of Trauma Foundation, and State Farm insurance contributed resources that funded this project and others that were created as a result of it. Dr. Leanna Depue is an unparalleled leader of people, and caused me to resolve that in every contact I had with her, I would try to learn how to do things as she did. Jackie Rogers demands excellence and is tenaciously focused on tasks, yet is one of the easiest people to work with that I know. The Transportation and Aging Interest Group of the Gerontological Society of America made it clear that the field of aging and mobility is important, fruitful, and collaborative. The Greater Missouri chapter of the Alzheimer's Association was helpful throughout this project. The leadership of this organization cares about people and relieving problems; they take little notice of bureaucracy or administrative obstacles.

The contributions of my research assistants and student nurses at the University of Missouri Hospital cannot be overestimated. Colter Snethen, Nicholas Schmidt, Mark Swierczek, Sarah Tannehill, Bailey Wolfe, Caitlin Johnson, and many others were a privilege to work with.

Finally, the volunteer participants of this trial deserve many thanks. 


\section{TABLE OF CONTENTS}

ACKNOWLEDGEMENTS ................................................................................

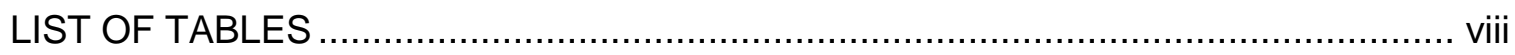

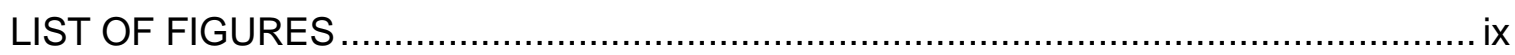

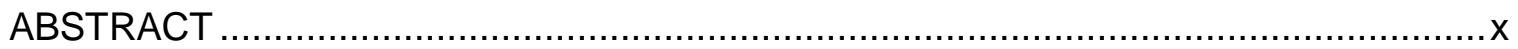

Chapter

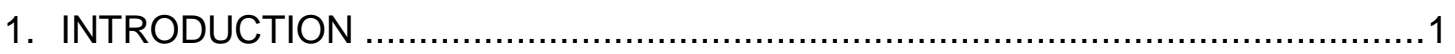

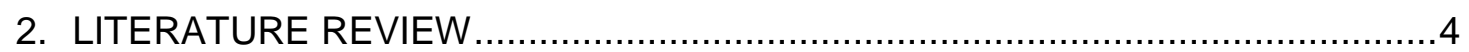

Aim 1

Transition Planning

Impact of mobility on health outcomes

Theory

Pre-decision phase

Decision phase

Post-cessation phase

Combating anosognosia

Trial Objectives and Hypotheses

Hypotheses

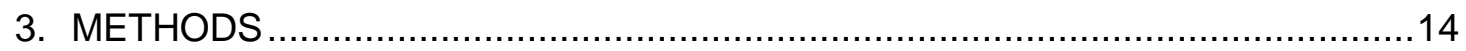

Trial Design

Participants

Informant participation

Peer participation

Rationale

Peer training and intervention process 
Assuring quality peer interventionists

Medically impaired older adult participation

Intervention group

Attention control group

Ethics

Beneficence

Respect for persons' autonomy

Justice

Assessment of safety

Data Handling and Recordkeeping

Protection of privacy

Protection of confidentiality

Selection of subjects

Participant recruitment

Exclusion criteria

Inclusion criteria

Power analysis

Randomization allocation sequence

Allocation concealment

Treatment of subjects

Intervention session I

Intervention session II

Sustained contact

Assessment of Treatment Efficacy

Outcomes 
Primary outcome measure

Secondary outcomes measures

Enrollment questionnaire

Carr's screening measure

Owsley's Driving Habits Questionnaire (DHQ)

Subjective Health Status (SHS)

Self-reported days in bed due to injury or illness

Manchester Driving Behavior Questionnaire (DBQ)

Fitness-to-Drive Screening (FTDS) measure

Data Screening

4. RESULTS

Statistical Analyses

Hypotheses

Approach

Preliminary Analyses

Individual and group differences over time

Participants

Hypotheses Testing

Hypothesis 1

Hypothesis 2

Hypothesis 3

Results Summary

5. DISCUSSION.

Implications

Policy Implications 
Practice Implications

Limitations

Recruitment

Internal resistance

Administrative involvement

Sensitive topic

Lack of time

Expanded sites

Measurement

Peer and research staff differences

Future Research

APPENDIX

A. PEER HANDBOOK AND PROFILE SUMMARIES USED FOR INTERVENTION SESSIONS..

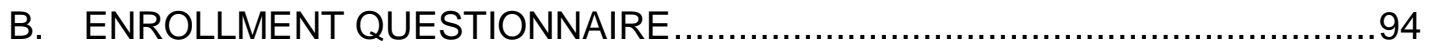

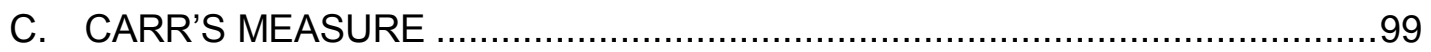

D. DRIVING HABITS QUESTIONNAIRE (DHQ) ..................................... 103

E. OLDER AMERICANS RESOURCES AND SERVICES - SUBJECTIVE HEALTH STATUS ITEMS …............................................................ 105

F. SELF-REPORTED BED DAYS DUE TO ILLNESS OR INJURY ..................106

G. MANCHESTER DRIVING BEHAVIOR QUESTIONNAIRE (DBQ) ............... 107

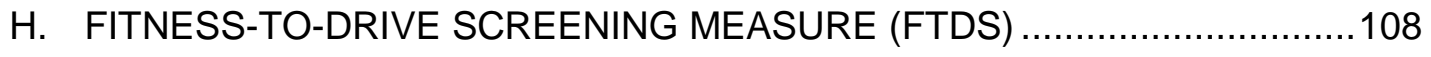

I. ASSESSMENT OF READINESS FOR MOBILITY TRANSITION (ARMT) .....110

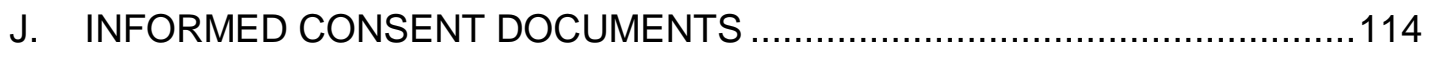

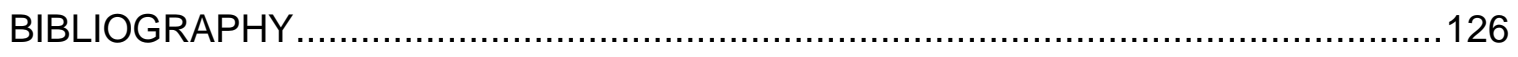

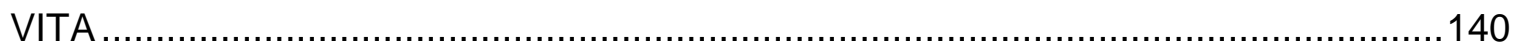




\section{LIST OF TABLES}

Table

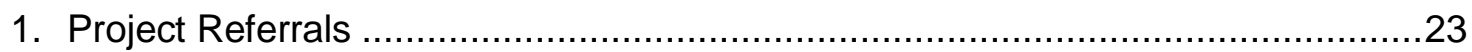

2. Demographic Characteristics and Group Comparison ( $N=39$ ): Means (SD) or

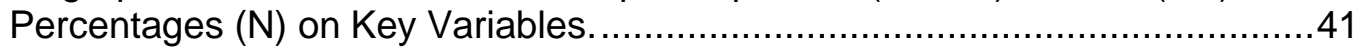

3. Medical Impairment Characteristics and Group Comparison ..............................42

4. Outcome Means (SD) by Measurement Period ……….................................44 


\section{LIST OF FIGURES}

Figure

1. Randomized Controlled Trial Flowchart of MobileAge Study .....

2. Group Comparisons on Mean ARMT Scores (Hypothesis 1)

3. Group Comparisons on Mean DBQ Scores (Hypothesis 2)

4. Group Comparisons on Mean FTDS Scores (Hypothesis 2)......

5. Group Comparisons on Mean DHQ Scores (Driving Space Subscale; Hypothesis 2)

6. Group Comparisons on Mean SHS Scores (Hypothesis 3). .50

7. Group Comparisons on Mean Days of Illness or Injury (Hypothesis 3) .51 


\title{
MOBILE AGING: A RANDOMIZED TRIAL OF MOBILITY TRANSITION COUNSELING FOR HIGH-RISK OLDER ADULTS
}

James Stowe

\author{
Dr. Teresa Cooney, Dissertation Supervisor
}

\begin{abstract}
Older adults with medical conditions that impair function are at the highest risk for driving retirement. This Randomized Controlled Trial investigated the efficacy of an intervention that facilitated planning for a likely driving transition among medicallyimpaired elders - those with vision, cognitive, or psychomotor impairment. A 2-to-1 allocation ratio resulted in comparisons between 26 intervention and 13 attention control $(n=39)$ group members who were recruited from health care sites. The intervention consisted of two sessions of facilitated planning in which the participant's health, transportation alternatives, attitudes/emotions regarding a change in mobility, and actions to ensure continued safe mobility were discussed. Moreover, all participants received supportive phone calls during the 6 month intervention period. Results showed that when compared to the control group, the intervention group had significantly better subjective health, fewer high-risk driving behaviors, and drove less distance on excursions from home at follow up. Simple repeated measures analyses were not significant. Results suggest that facilitated planning may help ease the transition to driving retirement among some high-risk older adults.
\end{abstract}




\title{
1. Introduction
}

\author{
Mobile Aging: A Randomized Trial of \\ Mobility Transition Counseling for High-Risk Older Adults
}

It is commonly known that the world's population is aging rapidly. Less well understood is the challenge of maintaining safe mobility for many older people. As an entire population ages, medical conditions and impairments associated with the aging process become more common. Regrettably, a consequence of some health conditions is an impaired ability to drive safely. In societies that rely on the personal automobile for most mobility needs (Staplin \& Freund, 2013), losing the ability to drive safely is a crisis for many older adults.

Attempting to maintain safe mobility in aging involves two competing factors. The first is that older adults with medical impairments are more likely to experience a vehicle crash. Certain classes of medical impairments have emerged as predictive of crashes, such as cognitive disorders like Cerebrovascular Accident (e.g., stroke; McGwin, Sims, Pulley \& Roseman, 2000; Salzberg \& Moffat, 1998) and memory impairments (e.g., dementia; Carr \& Ott, 2010; Tuokko, Tallman, Beattie, Cooper, \& Wier, 1995; Zuin, Ortiz, Boromei, \& Lopez, 2002). Even common movement impairments (e.g., arthritis), if sufficiently severe, can impact the ability to drive safely (McGwin et al., 2000). Similar to severe arthritis, Parkinson's disease impacts movement in some older drivers (Meindorfner et al, 2005). Finally, vision impairments (e.g., glaucoma, macular degeneration, and cataracts) are detrimental to driving safety (Owsley, McGwin, \& Ball, 1998). Other disorders outside of these classes, such as diabetes mellitus (Cox et al., 2003; Hansotia \& Broste, 1991; Koepsell, Wolf \& McCloskey, 1994; Staplin, Lococo, Steward, \& Decina, 1999) has emerged as important due its potential impact on 


\section{MOBILE AGING}

alertness and consciousness, as well as through side effects of medication used to treat the disease.

The second competing factor is that ceasing to drive puts an older adult at risk for declines in health and well-being (Curl, Stowe, Cooney, \& Proulx, 2014; Edwards, Perkins, Ross, \& Reynolds, 2009; Freeman, Munoz, Gange, \& West, 2006; Marottoli et al, 1997; 2000). Many of these studies were longitudinal and controlled for other potential confounding factors, so that driving cessation was identified as an independent predictor of the observed declines. Therefore, older adults' maintenance of the ability to drive without severe impairments is critical to avoiding unnecessary health declines caused by driving cessation.

One method of identifying medical problems that contribute to driving problems is screening - usually at license renewal - all adults at a certain age viewed to be at higher risk for impairment (e.g., 75+). Mandating screening for all older drivers based on chronological age has proved to be ineffective, while penalizing healthy, safe older drivers (Langford, 2008). An approach that targets only those known to be at the highest risk for crashes is the best practice because it reduces premature driving cessation by healthy older adults (Dickerson et al., 2007; Haddon, 1968; Siren, Hakamies-Blomqvist, \& Lindeman, 2004). An example of this type of approach would be if license office staff screened for observable impairments (e.g., confusion that appeared to indicate dementia), and then referred the license applicant for a full evaluation by medical personnel (Stowe, Niewoehner, Meuser, \& Berg-Weger, 2013). Likewise, in this scenario, health care professionals would carry a portion of the responsibility for identifying patients with conditions that impaired driving, and make appropriate referrals and reports to licensing authorities. Standard evaluations of all older license applicants would not occur, as only those who presented some type of meaningful impairment would be selected for additional evaluation. 


\section{MOBILE AGING}

Although generally a safe group of drivers, older adults (age 60+) do exact a tremendous cost through traffic crashes (IIHS, 2007; Cicchino \& McCartt, 2014a; 2014b). In 2005, for example, the total lifetime cost (i.e., the dollar estimate of the cost of crash aftermath, from the collision, to rehabilitation and lost work opportunities) of older adult crashes was $\$ 2.47$ billion (Naumann et al., 2010). Best estimates suggest a rate of older driver crashes of double the 2005 rate by 2030 (Lyman et al., 2002), resulting in a total lifetime cost of over $\$ 5.12$ billion. Moreover, most of these costs are not absorbed by those involved in the crash, but by society (Naumann et al., 2010). Although older driver involved crashes remain a substantial problem, recent evidence (Cicchino \& McCartt, 2014a; 2014b) suggests that the older driver crash rate and the severity of those crashes is below expectations considering the rate of aging in the population. This evidence suggests that an aging population affects crash and injury rates differently than expected. Regardless of these trends, scholars and practitioners should strive to eliminate serious injury and fatal crashes altogether.

This study examines the efficacy of an intervention trial designed to facilitate transitions in transportation mobility (e.g., driving cessation) among older adults who have a medical impairment that is associated with crash risk. Given that crash risk among older drivers appears to cluster around those with medical impairments (Staplin, 2012), targeting this high-risk subpopulation is important to organizations, governments, and societies that aim to reduce the burden of traffic related injuries and fatalities. Arguably, focusing on the greatest problem area for a highway safety issue ensures maximum efficiency when expending limited resources. 


\section{Literature Review}

One way to avoid vehicle crashes is for older adult drivers to plan for a transition from driving to alternative forms of transportation. The benefits of planning are commonly accepted in many realms of life, but older adults rarely plan for being unable to drive (Kostyniuk, Shope, \& Molnar, 2000). Consequently, when medical and functional challenges arise, some continue to drive despite elevated crash risk (Wong, Smith, \& Sullivan, 2012). Medically-impaired older drivers are dangerous because they often do not realize their own level of impairment, and make major driving errors (Wong et al., 2012). Ceasing to drive can result in poor health, and planning for the possibility of driving cessation may help avoid negative health consequences.

Marottoli et al. found that older former drivers were more likely to experience depression (Marottoli et al., 1997) and reduced out-of-home activity (Marottoli et al., 2000) than older drivers. Similarly, older adults who stop driving have greater rates of institutionalization and mortality than their driving counterparts (Edwards, Perkins, Ross, \& Reynolds, 2009; Freeman et al., 2006). Other research shows that driving cessation reduces productive engagement when conceptualized as paid work, formal volunteering, and informal volunteering (Curl, Stowe, Cooney, \& Proulx, 2014). In that same study, driving cessation was shown to amplify decreases in social engagement over time, albeit some degree of decline was noted among the entire sample. Furthermore, within couple dyads, driving cessation impacts a spouse's engagement in that the negative influence of driving cessation spills into partners in the couple dyad (Curl, Proulx, Stowe, \& Cooney, in press). For wives who are driving, a husband's driving cessation reduces the likelihood of employment (although the effect does not hold over time), as well as the likelihood of informal volunteering. For husbands, a wife's cessation reduces the 


\section{MOBILE AGING}

likelihood of employment and formal volunteering. Thus, continued mobility, rather than simply maintaining driving, is a key to older adults maintaining good health.

Targeting medically impaired older drivers for transitions to safer mobility has become a hallmark of older driver safety research, because of the variability of driving ability among older adults (Warnes \& Fraser, 1993). Recently, Staplin and colleagues (2012) produced a classification system for at-risk older drivers using specific medical impairments, in order to aid health care and other professionals in engaging with this subpopulation. Helping older adults successfully make mobility transitions will improve outcomes and prevent declines associated with immobility. Therefore, this study's overall goal was to evaluate the efficacy of an intervention designed to assist older adults in mobility transition planning. The study's specific aim addressed evaluation of the intervention's efficacy:

\section{Aim 1}

To test the impact of mobility counseling on readiness to make a mobility transition, traffic-related behavior, and health outcomes for older adults with medical impairments known to affect driving performance.

The rest of this chapter provides the background literature for the development of this program and that which informs its evaluation.

\section{Transition Planning}

A few interventions have targeted older drivers with specific medical impairments known to impact driving performance. Baird and colleagues were among the first to screen older hospital patients for diseases and symptoms that impair driving, and $20 \%$ of patients were found to fail screening tests that identified driving-related vision, cognitive, or psychomotor impairments (Baird et al, 2010). This was among a sample $(N=397)$ of legally licensed drivers. 


\section{MOBILE AGING}

A recent, rigorous intervention study (Liddle et al., 2014) attempted to alter older adults' adjustment to driving cessation by improving community mobility through the Australian UQDRIVE program. The UQDRIVE program focused on a group intervention delivered to older adults who self-identified as being in or near the process of driving cessation. One of the primary goals of the intervention was to increase participants' episodes away from the home and use of alternative transportation. Although the study suffered from high attrition, it was successful in immediately increasing community mobility (i.e., episodes away from the home), and had a more lasting effect on improving satisfaction with transportation (i.e., three months post intervention). Additionally, although the group intervention sessions of the UQDRIVE program were facilitated by a health care professional and peer leaders, participants were recruited from the community, not a health care facility.

Importantly, this study failed to focus on those who may have had high-risk medical impairments, but did not self-identify as being in or near driving cessation. Those who self-identify as being in or near driving cessation may be further along in the driving cessation process, and possibly less at risk of failing to cease to drive at a critical point. Therefore, it is important to address patients who have high-risk impairments who may have not yet self-identified as nearing driving cessation, as they may pose the greatest risk for a poor driving outcome or a crisis mobility transition.

Additional evidence regarding planning for driving cessation comes from studies comparing retired and retiring drivers (Liddle, Reaston, Pachana, Mitchell, \& Gustafsson, 2014). Those who were already retired reported greater self-efficacy and greater use of alternative transportation - perhaps indicating that retired drivers had mastered alternative forms of transportation. The authors suggest that preparing older adults for the use of alternative transportation, and encouraging and supporting them when they do use it, may help ease the transition to full driving cessation. Furthermore, they 


\section{MOBILE AGING}

suggest that higher ratings of self-efficacy have been linked to positive gains in areas typically diminished by driving cessation (e.g., mental health), and therefore may be a good focal point for counteracting declines after cessation. Finally, this study revealed that drivers in the midst of the cessation process are not apt to change their mode of transportation, but simply the frequency and volume of trips by car. Therefore, shifts to alternative transportation may only happen after full driving cessation.

In another of the few experimental interventions, Logan et al. (2004) conducted a Randomized Controlled Trial (RCT) of Occupational Therapy rehabilitation sessions for stroke victims $(N=168)$ that assessed outcomes related to outdoor mobility. At both four and 10 months post intervention, individuals in the intervention group more often reported that they "got out of the house as much as they wanted," and reported more journeys outdoors than the control group. At four months post intervention only, the intervention group reported significantly higher instrumental activities of daily living than the control group (as measured by the Nottingham extended activities of daily living).However, it is difficult to draw conclusions about driving from this trial, as mere "movement outdoors" was reported rather than trips by specific modes of transportation (e.g., walking or driving). Moreover, this intervention did not assist the older participants in planning for increased mobility, but rather focused on occupational therapy sessions and the provision of a brief "leaflet" on alternative transportation. Person-centered planning may overcome this limitation by focusing on what the older adult can do to adapt rather than upon what is done to the older adult by medical staff.

Owsley, Stalvey, and Phillips (2003) similarly conducted an intervention trial focused on a specific impairment. The authors studied 365 visually-impaired older drivers who were legally licensed to drive and had a crash in the prior year. The intervention was an educational curriculum (delivered in 2, one-on-one sessions at an eye health clinic) that addressed the risks of vision impairment and how drivers could 


\section{MOBILE AGING}

effectively avoid challenging driving situations that were aggravated by vision impairment (e.g., left-hand turns). The initial study found that the intervention group reported greater awareness of visual impairment as well as fewer high-risk driving maneuvers. Follow-up studies (Owsley, McGwin, Phillips, McNeal, \& Stalvey, 2004) revealed no difference between the intervention and control groups on police-reported crashes during a twoyear period. Historically, interventions that provide education only, without emphasizing an "action" (either by the target or an entity in authority over the target) have failed to substantially impact driving safety among any age group (NHTSA, 2013). Moreover, addressing a broader range of impairments (e.g., include psychomotor and cognitive impairment) may increase the efficacy of interventions on reducing crash rates.

Overall, the transition away from driving has not been fully investigated, especially through rigorous RCT designs. The need is great in acute-care facilities. Older adults often must cease driving due to medical crises that culminate in a hospital stay. Mobility Transition Counseling (MTC; Meuser, 2011), the proposed intervention, responds to literature that calls for crash prevention through personalized approaches (Dickerson et al., 2007). Importantly, this method is in contrast to the popular, yet ineffective, approach of age-based screening at licensing offices (Langford, 2008). MTC helps to ensure intervening with high-risk older drivers in an individualized manner (Berg-Weger, Meuser, \& Stowe, 2013). Individualized, facilitated planning for driving cessation may serve to increase the rate of driving cessation in an impaired subpopulation of older adults, and also may help improve outcomes following the completion of the cessation process. Moreover, in contrast to the previously mentioned efforts, this process avoids a prescriptive, medically-oriented intervention, and attempts to give the elder the ability to choose "what is done" to improve mobility and safety. 


\section{MOBILE AGING}

\section{Impact of mobility on health outcomes}

Although the etiology of re-hospitalization is complex, scholars have identified problems in mobility and transportation as a key determinate of poor health outcomes. Patients' ability to follow the care provider's recommendations and meet basic needs is dependent upon transportation (Strunin, Stone, \& Jack, 2007), and successful discharge interventions consider "transportation needs as of paramount importance" (Sinclair, Conroy, Davies, \& Bayer, 2005, p. 341). Given these conclusions about the significance of mobility to positive health outcomes after hospitalization, the intervention protocol evaluated herein is expected to impact health outcomes of participants by optimizing individual mobility.

\section{Theory}

Transportation and aging is a fairly recent area of specialization, and strong theory only started emerging in the 1970's with Lawton and Nahemow's seminal development of the Ecological Model of Adaptive Aging (1973). The model attempted to explain person-environment interactions and the effect that they have on various individual outcomes. Transportation mobility was one of the areas that received attention from this model, but momentum waned due to few high-quality studies and a shift in focus to the built environment (Oswald et al., 2007; Scheidt \& Norris-Baker, 2003; Wahl, Iwarsson, \& Oswald, 2012).

A more recent development is theory that revolves around individual decisions and the ability (and willingness) to change. As with any major life transition, driving cessation typically requires an individual response (adaptation) to facilitate positive outcomes. Prochaska and DiClemente's (1983) Transtheoretical Model of Behavioral Change explored the issue of changes in behavior during major life transitions, applying their model to the act of smoking cessation. The model explained behavior change through phases of decisions made by the individual. Others built upon the phased 


\section{MOBILE AGING}

behavior change model during life transitions, including transportation and aging scholars. Using an in-depth qualitative analysis, Liddle, Turpin, Carlson, and McKenna (2008) developed a three-phase explanation for the experiences of older adults undergoing a transition to driving cessation. Two of the phases occur during the cessation process (decision phase, and post-cessation phase), and one phase occurs before the elder has fully confronted his or her inability to continue driving (the predecision phase), but, to a certain extent, may have recognized a decline in ability. The following description of the phases discovered by Liddle and colleagues helped to guide development of the intervention protocol tested in this study.

Pre-decision phase. In this phase of driving cessation, the individual does not intend to cease driving, and no plans for cessation have been made. Losses or changes, such as retirement, relocation, health problems, and financial changes may be occurring, but the individual has not yet tied them to the possibility or necessity of driving cessation. During this phase, family members and health professionals will often only reluctantly address driving cessation (e.g., "urgently required" action is needed [p. 382]), and raising the issue of driving cessation is not well-accepted by the older adult. During the latter end of this phase, some individuals begin to self-restrict driving and have awareness of the impact of health conditions on the ability to drive safely. Others remain unaware of impairment and make no driving changes throughout the entirety of this phase oftentimes resulting in a sudden, crisis transition.

Decision phase. During this phase, the older adult decides to cease driving. Commonly, they will seek advice and counsel from peers and trusted individuals who reside within a support network. Moreover, seeking information about transportation alternatives is common during this phase. Safety and health concerns are understood by the driver in some cases, and licensing or health care authorities revoke driving privileges in other cases. Importantly, Liddle, Reaston and colleagues reported that all 


\section{MOBILE AGING}

drivers in their sample reported making the personal decision to stop driving, even if evidence suggested that an authority figure revoked the driving privilege, or a health care professional reported the driver to a licensing agency. The authors suggest that even in the case of forced driving cessation, older adults reconstructed their personal narrative to reflect having made a personal decision.

Post-cessation phase. The post-cessation phase involves attempting to successfully adapt to driving cessation. Following driving cessation, many older adults report continuing in previous roles (e.g., through alternative transportation), changing the location of activities, or engaging in new roles. Additionally, coping and adapting to multiple losses is characteristic of this phase as is the ability to identify benefits of driving cessation (e.g., "financial, reduced stress, and some social gains..." [Liddle et al., 2008, p. 384]). Overall, this phase is highly individualized, and requires the older adult to actively attempt to adapt.

Combating anosognosia. Related to these phases of driving retirement, and of particular importance to this intervention study are medical conceptualizations of awareness of impairments. Anosognosia is a "...lack of awareness of impairments" (Starkstein et al., 2006, p. 719), and the related condition of anosodiaphora is a lack of concern regarding acknowledged impairment (Pachana \& Petriwskyj, 2006). Starkstein et al. (2006) investigated anosognosia in patients with Alzheimer's disease (AD) and found that those with the condition were more likely than healthy controls to engage in dangerous behaviors (including dangerous traffic-related behaviors). Individuals with anosognosia present one of the greatest challenges to safe mobility as they may continue to drive with impairment. The intervention described in the current study specifically addresses anosognosia through timing - participants will already be certain of a medical diagnosis with implications for driving (beyond the building awareness component of the pre-decision phase). Individuals with anosodiaphora are likely to be 


\section{MOBILE AGING}

unaffected by an intervention short of one conducted by law enforcement or licensing authorities.

In contrast to anosognosia common in older adults with $A D$, older people with Mild Cognitive Impairment (MCl) tend to "hyper-report" problems with cognition. These individuals may present a special opportunity for intervention because they are keenly aware of limitations produced by a medical condition. Clinical studies indicate that within six years of diagnosis of $\mathrm{MCl}$, up to $80 \%$ of individuals will have $\mathrm{AD}$ (Petersen et al., 2001). If anosognosia encumbers a successful mobility transition, $\mathrm{MCl}$ may facilitate it at a critical point in the progression of impairment. Prevalence estimates from a Scandinavian sample suggest that over $5 \%$ of the general population of adults $60-76$ have MCI (Hanninen et al., 2002).

Pachana and Petriwskyj (2006) are some of the few scholars to review measurement of anosognosia in relation to safety of older drivers. Nearly all of the research on awareness of deficits related to driving is based on samples of elders with $A D$, and no studies (or measures) focus on other impairments, such as visual deficits. Therefore, outside of the specific realm of $A D$, more research is needed regarding the impact of anosognosia on older drivers' safety or behavior.

The current study builds from the platform of phased behavior change and adaptation during life transitions, and targets individuals who are close to the decision phase due to the presence of health conditions that impair the ability to drive. Several principles of the theory drove design and training considerations for this trial. First, timing of recruitment was designed to coincide with a health care encounter for noticeable, and often serious, health impairments among participants; therefore, many of the participants had conditions with undeniable symptoms that may have helped prime them to confront driving cessation. 


\section{MOBILE AGING}

Next, mobility transition counseling was selected for its ability to facilitate positive, person-centered adaptations by being responsive to where the individual is at in the process of change. For example, the intervention material, peer and research staff training, and overall planning process was intended to encourage movement from one phase to another. This was accomplished primarily through honest conversation about the participant's current health and mobility status, feasible alternatives, consideration of the future and the promotion of time-specific, actionable planning during the intervention sessions.

\section{Trial Objectives and Hypotheses}

The objective of this study is to test a novel, multi-session intervention protocol for older drivers. Pre-post measures established readiness to move from driving to safer forms of mobility. Health (i.e., subjective health status and self-reported illness), driving behaviors (3 measures), and readiness to cease driving at baseline, one and six months post- test were evaluated to assess intervention effectiveness.

Hypotheses. Previous literature has established relationships between driving cessation and various outcomes. The following hypotheses were created in acknowledgement of the previous literature and the expected impact of an intervention study on relevant participant characteristics.

Hypothesis 1: Mobility counseling will increase readiness to make a mobility transition.

Hypothesis 2: Mobility counseling will reduce risky driving behaviors (e.g., based on an informant's evaluation of driving performance, or aggressive maneuvers). Hypothesis 3: Mobility counseling will impact health outcomes by

a) improving subjective health status.

b) reducing self-reported days in bed due to illness or injury. 


\section{Methods}

\section{Trial Design}

This was a permuted block randomized (2:1), controlled (attention control group), experimental design study conducted at a Midwest research and referral hospital. Thirtynine elders with medical impairments that impact driving performance were recruited to a) experience Mobility Transition Counseling $(n=26)$ or b) random assignment to an attention control group $(n=13)$. Additionally, when a participant was able and willing to name an informant, the informant was asked to complete a measure about the participant's driving, and one measure about the participant's cognitive status (see Informant Measures section). One measure was designed exclusively for an informant to answer, and the other was designed to be answered by an informant or the target participant. Participation was not precluded if the participant was unable or unwilling to name a participant. In total, 18 informants were named and were able to be contacted by research staff.

Participants' medical impairments are derived from a taxonomy developed by transportation and aging scholars who were commissioned by the National Highway Transportation Safety Administration (NHTSA). The targeted medical conditions (Staplin et al., 2012) are: diabetes mellitus, cataracts, glaucoma, macular degeneration, stroke or cerebrovascular accident (CVA), sleep apnea, Parkinson's disease, severe arthritis, or mild to moderate cognitive impairments, or problems with executive functioning (e.g., Alzheimer's disease). Physicians, nurses, and other medical professionals were asked to refer individuals to the study. Beyond the target conditions, which are not exhaustive, specific impairments or combinations of impairments that may impact driving ability were left to their professional discretion. Stapleton (2012) found that clinician "Gestalt" was the 


\section{MOBILE AGING}

most accurate predictor of failure of on-the-road tests, so it is important to not neglect this criterion.

\section{Participants}

Informant participation. Some measures in this trial were designed for an informant to answer rather than the participant. Informants were recruited by the participant, who was asked to find a close family member or friend who was knowledgeable about the participant's driving behaviors and mental status. The identified informant was contacted by study staff via telephone, or interviewed in-person if present at the time of contact. Telephone consent was sought of the informant, and if consent was granted, study staff asked the informant questions about the participant. A Waiver of Documentation of Consent was granted by the University of Missouri Health Sciences IRB for informants. Duration of informant participation was approximately 6090 minutes for the entire project period.

Participants were assured that the informant is merely helping to ensure that high-quality data were collected, and not that the informant was making determinations of fitness-to-drive. Moreover, in the event that a participant could not name an informant, the participant was not excluded from participation, but preliminary analyses were conducted to ensure no differences between those individuals able and unable to name an informant. If no differences emerged, then those without informants would be grouped with those with informants during analyses.

Peer participation. Although peer volunteers have been used effectively for interventions with older adults (e.g., falls reduction [Waters et al., 2011], cardiovascular programs [Kaczorowski et al., 2008; 2011; Truncali et al., 2010], weight loss [West et al., 2011], and planning for home emergencies [Ganong, Coleman, Benson, Snyder-Rivas, Stowe, \& Porter, 2013]), they have never been tested as facilitators of one-on-one mobility counseling. Pillemer and Suitor (2002) found that aging interventions utilizing a 


\section{MOBILE AGING}

peer who had experienced a similar event (e.g., bereavement) improved outcomes compared to non-use of a peer.

Rationale. Interventions intended for broad adoption by healthcare organizations must remain sensitive to resource and staffing limitations (Buerhaus et al., 2007). Testing cost effective alternatives to healthcare professionals for a mobility intervention is a substantial contribution to extant knowledge. Therefore, peers were used as consultants to the participants in this project when possible, and they delivered the intervention. In the event that a peer was unavailable, research staff acted in place of a peer. Peers did not administer study measures; these were only administered by research staff. Differences in effectiveness between the peer intervention group and the study staff intervention group were analyzed. Finally, peers who were unable to drive or travel long distances conducted the intervention over the phone.

Peer training and intervention process. Following recruitment, peers attended the initial project training that lasted four hours (including a lunch), and then received an individual training session that lasted for 1.5 hours. Project training included information about older drivers in general, what groups of older drivers are at risk for a motor vehicle crash, the importance of person-centered solutions in mobility counseling, how to discuss mobility alternatives with other older adults, and the importance of attitudes and emotions in the process of making a mobility transition. Four core principles of interventions with older adults are emphasized in the training materials: 1) building rapport, 2) understanding the heterogeneity of the older adult population (and the need for individualized approaches), 3) methods to focus on the positive aspects of transitions, and 4) methods to emphasize the benefits of planning, especially planning related to mobility transitions. The second training emphasized pragmatic methods for conducting the intervention session, as well as documenting encounters with participants, and what information to bring to research staff. 


\section{MOBILE AGING}

Each peer received information about the intervention, and a simply-written "peer handbook" that describes the sessions between the peer and the participant in lay language (see Appendix A). The peer also reviewed an example profile of a fictitious participant, and subsequent examples of materials/forms that would be produced regarding the fictitious participant during the course of the study. This process helped solidify the logistics of interacting with participants and research staff, and previewed the tasks to be completed during the study.

Individual training reinforced the principal concepts used in the intervention, and methods for successfully engaging participants. During a one-on-one training session, each peer was asked to engage the research staff in role playing a practice intervention session to work through the handbook materials. This allowed immediate feedback and suggestions to be given to the peer and instilled some measure of confidence before the peer met with the first participant in a face-to-face meeting.

Following training, the peer met with an assigned participant to hold the intervention session. The peer handbook provided guidance to the peer on topics that may be relevant to a mobility transition and therefore could be included in the discussions during the sessions. The same peer/participant pairings were maintained for the duration of the study. When research staff acted as a peer, the same research staff member was used for all sessions, whenever possible. The peer handbook underwent several revisions after feedback from peers, participants, research staff, and community agencies (who received training on Mobility Transition Counseling simultaneously to this trial). Revisions mainly focused on creating better plans and ensuring that comprehensive material was available for discussion during the intervention sessions.

The duration of peer's involvement in the study was determined by the peer. Seven older peers were recruited and trained, and two remained with the study long 


\section{MOBILE AGING}

enough to conduct intervention sessions. Five peers did not meet with any participants, citing lack of time, or a perceived poor fit as an interventionist. One peer conducted sessions with a single participant, and the other peer conducted sessions with three participants.

Assuring quality peer interventionists. Although the principles of Mobility Transition Counseling call for individualized approaches to each participant, uniform quality of the intervention session was a priority. To ensure high-quality peer delivery of the intervention, research staff contacted participants following the first intervention session to determine the nature of contact with the peer, and the extent and type of planning activity that occurred. Particularly, staff asked participants to describe their "plan," which was a key component of the intervention sessions. If participants were unable to articulate a plan, or did not report a session that aligned with the principles of Mobility Transition Counseling, staff contacted the assigned peer and re-emphasized the topics that needed to be covered during the sessions. Only one participant who interacted with a peer was unable to articulate a plan, and the peer corrected this shortcoming of the intervention during the following supportive phone call. Moreover, study staff monitored the dates and duration of contact between the peers and participants.

Past interventions led by peers used a similar approach to occasional updates on intervention progress (Chapin et al., 2013). Crane-Okada, Freeman, Ross, Kiger, \& Giuliano (2010) successfully developed peer counselors through continued feedback, group meetings, and an emphasis on giving the peer counselors opportunity to suggest improvements and changes. These components of a successful peer-led intervention were present in the current study.

Medically impaired older adult participation. Following referral from a physician or other medical professional (see "Participant Recruitment"), and consent, the 


\section{MOBILE AGING}

participants were screened for project inclusion. Participants remained in the study for six months (from initial referral to final measures). After consenting, each participant met with study staff at a location of her/his choosing and the baseline measurements were administered. Baseline measurements lasted for 30-45 minutes.

Intervention group. Soon thereafter, participants assigned to the intervention group met with a designated peer or research staff member for the approximately 75 minute "intervention session." The intervention session allowed the participant to discuss the issue of mobility and aging, the participant's strengths and weaknesses, opportunity for support network help with mobility, and work with the peer or research staff member to create a plan for a future mobility transition (i.e., moving from driving to an alternative form of transportation). Participants were asked to ensure that the plans were activated, within a set time period, and reasonable given the participant's interests and resources.

Following the first intervention session, contact between the participant and peer/researcher occurred at least once per month via phone. Peers and research staff were encouraged to contact the participant more frequently if the participant indicated a need or desire for additional contact. In practice, no participant desired to have more regular contact than the monthly phone call. Study staff took time two measurements roughly one month post intervention session one. Time two measurements were at a time/location of the participant's choosing. Roughly six months after the first intervention session, and having maintained contact approximately once per month in the interim period, the peer/researcher and participant met for intervention session two. The content of intervention session two mirrored that of intervention session one, but was updated with any changes in mobility that the participant experienced, successful steps she/he had taken toward alternative mobility, and any new information that has been revealed during the regular phone conversations or measurement periods. Finally, soon after intervention session one, study staff took time three (final) measurements. 
Attention control group. To protect against the confound of mere contact by study staff impacting outcomes, participants randomized to the control group received contact similar to the sustained contact experienced by the intervention group. General conversations about well-being and the participant's current circumstances were covered during the contact made by research staff. Measurements were taken at the same time intervals following enrollment as for participants randomly assigned to the intervention group. Upon completion of the study, the control group was offered the intervention.

\section{Ethics}

Ethical approval for the study was obtained through the University of Missouri Health Sciences Institutional Review Board (IRB \# 1205876). The following ethical principles were applied throughout the course of the study.

Beneficence. This trial strived to maximize participant and scientific benefit while reducing risk of harm to participants. The trial protocol posed minimal risk to participants, and the study design maximized the potential for scientific knowledge creation. There may have been no benefits of participation for individual participants; however, discoveries made during the study may benefit vulnerable elders in the community.

Respect for persons' autonomy. The informed consent documents (see Appendix J) were designed to demonstrate respect for persons' autonomy (namely, full information, un-coerced participation, and the freedom to withdraw at any time). Moreover, the study design excluded individuals with severe cognitive impairment, who may not be considered fully autonomous.

Justice. This trial's inclusion criteria focused on medical conditions, and did not aim to disproportionately recruit any particular demographic group. Furthermore, the counseling process that was tested in this trial was designed to be administered without charge and at a very low cost to aging services providers. The intervention tested during 


\section{MOBILE AGING}

the trial may have been helpful by offering assistance with a difficult task, and all control participants were offered the intervention at the conclusion of the study.

Assessment of safety. The intervention used in this trial posed minimal risk to participants. The possibility of adverse events was emphasized in training of peers and study staff. A list of supportive mobility services to reduce participant stress or discomfort was maintained and was ready to be provided to participants if needed. Although intervention sessions were occasionally emotional, all emotionally-upset participants indicated that they wished to continue the sessions, and none needed or desired to stop participation in the study.

\section{Data Handling and Recordkeeping}

Protection of privacy. The questionnaire data did not contain identifiers, and completed questionnaires were stored in a locked file cabinet within a locked university office. The code key was kept in a separate locked location. Once the data were entered electronically, they were stored on the principal investigator's password-protected computer.

Protection of confidentiality. The informed consent document provided participants with an assurance of confidentiality. Only the principal investigator had access to the file cabinet and computer where data were stored. After the project is finished, the data will remain in secure University of Missouri long-term storage for seven years. Finally, no published results or data will include any identifying information, and any identifying information collected during the study was changed.

\section{Selection of Subjects}

Participant recruitment. Participants were recruited by medical clinicians through convenience sampling at the hospital and clinics over a 13 month period (January 2013 - February 2014). Face-to-face meetings, announcements to staff through hospital management, and e-mail were the primary outreach avenues. A litany 


\section{MOBILE AGING}

of other approaches was also used to increase recruitment, including messages sent by hospital executives to department leaders, passing out holiday treats to hospital staff, and using existing relationships between the principal investigator's department and other departments to encourage referrals. Participants could be identified through physicians, nurses, social workers, or any other hospital staff or faculty. There were two methods of referral to the study:

1. With the potential participant's permission, medical clinicians provided information about the study and research staff contact information. The potential participant then contacted research staff if interested in the study. This method of referral was rarely used by potential participants, and five contacted study staff upon their own volition after hearing about the study from a medical clinician.

2. Medical clinicians informed a potential participant about the study and asked for the potential participant's permission to provide research staff with his or her name. Research staff then contacted the interested potential participant after receiving the name from the referring medical clinician. In total, 115 potential participants were referred to the study. Table 1 (next page) includes information on participant referral and enrollment.

The intervention site was a Midwest research and referral hospital or a location that the participant chose. Hospitalizations, and the immediate period following hospitalization are often physically and emotionally demanding. Therefore, although initial contact and recruitment may have occurred at the hospital, the study was carried out in the community when the participant had recovered. Very few initial encounters with participants occurred while they were in-patients at the hospital. 


\begin{tabular}{lrrr}
\hline Table 1 & & & \\
Project Referrals & Enrolled & Failed to Enroll & $\underline{\text { Total }}$ \\
\hline Department & 12 & 10 & 22 \\
Memory Support Agency & 8 & 5 & 13 \\
Orthopedics (Ortho Trauma) & 6 & 39 & 45 \\
Trauma Services & 8 & 3 & 11 \\
Family Practice & 2 & 0 & 2 \\
Department of Medicine & 1 & 3 & 4 \\
Specialty Clinic & 1 & 1 & 2 \\
Ophthalmology & 1 & 12 & 13 \\
On-campus research trial & 0 & 1 & 1 \\
Surgery & 0 & 2 & 2 \\
Unknown & 39 & 76 & 115 \\
Total & & & \\
\hline
\end{tabular}

As an example of recruitment potential, the intervention site treated over 34,000 adults over the age of 65 annually at the time of the trial. In a typical hospital setting, $20 \%$ (i.e., 6,800 ) of these patients would be expected to fail study screening criteria for visual (i.e., visual acuity and visual fields), psychomotor (i.e., rapid pace walk, range of motion, and motor strength), or cognitive (i.e., trail-making and clock drawing) impairments that would make the patient eligible for the study (Baird et al., 2010). These individuals are at the highest risk for crashes.

Exclusion criteria. Participants were excluded if they had conditions that interfered with the provision of informed consent or study measurement: Severe cognitive impairment (e.g., inability to answer how he/she was doing that day and why he/she was speaking with research staff); severe vision or motor impairment that prevented the participant from seeing or completing measurement instruments; residents of skilled nursing facilities; individuals enrolled in hospice, palliative or comfort care; or individuals who were not currently driving. Study staff asked physicians and medical 


\section{MOBILE AGING}

professionals to not refer patients who they had reported to the Department of Motor Vehicle license review process, as the study was in no way a substitute for a formal evaluation of medical fitness-to-drive.

Inclusion criteria. Participants were referred to the study by hospital or health related community organization staff members (e.g., medical clinicians), if they were: $60+$ years old, current drivers, domiciled in Missouri (Boone and the seven contiguous counties), and had signed the informed consent documents. Peers had to be age $60+$, have signed the informed consent documents, and able to share experiences with limitations in mobility.

Overall, 115 participants were referred from all sources. Of those who chose not to enroll, most could not be contacted after multiple attempts (35), stated that they were not interested in the study or the study topic (16), were ineligible (11), stated that the study would be a burden or that they did not have time (10), or had died (4). See Table 1 for a detailed breakdown of student referral and enrollment.

Power analysis. Prior to the onset of the trial, a biostatistician conducted a power analysis to determine the needed sample size. The power analysis is based on the ARMT, which will be used to gauge primary study outcomes. For the power analysis, a significance level of 0.05 and a power of .82 were assumed, as well as a minimum expected mean difference of .40 between groups on the ARMT total score. Previous research (Meuser et al., 2013) revealed the standard deviation $(\sigma=.64)$ that was used for the power analysis. Due to unknown parameters for a multivariate power analysis, a conservative two-sample $t$ test (one-tailed) was employed for the sample size estimate. The needed sample size was 90 participants (unequal groups: 60 intervention; 30 control), which accommodates an anticipated $20 \%$ attrition rate. This power analysis accounts for statistical tests needed to compare the control and intervention groups. This targeted sample size seemed reasonable given the expected number of older adults 


\section{MOBILE AGING}

admitted to the recruiting hospital and estimated rates of qualifying conditions among older adult hospital patients.

Randomization allocation sequence. Restricted randomization using random permuted blocks (with randomly varied block sizes [blocks of 8,10 and 12] and a 2:1 intervention to attention control ratio) was used to obtain unbiased, yet balanced comparison groups (Schulz \& Grimes, 2002). SAS was used to generate random numbers for the allocation sequence, using publically-available code designed for this task. The program randomly created blocks of participant assignments, and the blocks randomly varied in size so that investigators could not guess which group assignment was more likely if several assignments of any particular group had recently been made. The unit of randomization was the individual.

Allocation concealment. The sequentially numbered, opaque, sealed envelopes (SNOSE) allocation concealment method was used until participant assignment. Envelopes were given group assignment and sealed by a neutral third party who securely maintained the allocation sequence on a password protected computer. Envelopes were opened only after the participant's ID number was written on the envelope; a carbon paper assignment card inside the envelope received the writing.

\section{Treatment of Subjects}

Intervention session I (75 minutes). Peers or research staff assigned to be peers received a profile (See Appendix A) that highlighted findings from the study measures (translated into lay terms) to help identify the participants' strengths and weaknesses. The profile was used to help direct and focus the intervention sessions. Priming statements were developed to guide the conversation about readiness to make a mobility transition so that peers or research staff members were adequately equipped to address this particular issue. 


\section{MOBILE AGING}

Using the profile guideposts, the peer or research staff member collaboratively engaged the specific participant about the process of mobility transitions. The peer and participant discussed the participant's most important car trips and interests that may impact mobility in the future (e.g., a participant may have wished to continue a valued volunteer role). Additionally, an inventory of transportation alternatives was created that included informal support network members (e.g., family and friends), public transportation, and formal alternatives (e.g., transportation provided under the Older American's Act Title III B; OAA, 2006). Following creation of the inventory, the benefits of driving cessation were addressed as well as the benefits that may accompany driving alternatives (e.g., reduced cost, enhanced safety, etc.) Family member participation, if desired by the participant, was encouraged. If family members were involved, they were usually the informant named by the participants. The final step was the creation of a mobility "action plan" that identified steps that the participant could take toward safe and sustained mobility. Previous research indicated that this plan should be organized around trips/outings/events that are socially important to the participant, as focusing on merely instrumental trips (e.g., medical appointments) is a major pitfall of many driving interventions (Davey, 2007).

Intervention session II (75 minutes). The second session was to build upon the participant's knowledge and use of transportation alternatives, planning activities for mobility transitions, engagement of support networks (formal and informal), driver retraining/rehabilitation activities, and attitudes toward mobility transitions. An updated profile, using Time 2 measurements, guided this session.

Sustained contact (monthly, by phone). Regular support of the participant's plan (and any action taken) was provided through monthly phone contact by the peer or assigned research staff. Though study staff offered peers the optional resource of answering questions and suggesting alternative actions if those they had collaboratively 


\section{MOBILE AGING}

created were not feasible, none of them took advantage of this support during the study. Anti-attrition efforts were also made through this regular contact by attempting to keep the participant engaged in the project.

\section{Assessment of Treatment Efficacy}

Outcomes. The primary outcome of interest was attitudes and emotions regarding an individual's readiness to make a mobility transition. Readiness is related to how an individual may cope with a mobility transition - future or in-process (Meuser, Berg-Weger, Chibnall, Harmon, \& Stowe, 2013). Positive coping may lead to adaptive behaviors, such as planning for future mobility needs when one faces decline.

Furthermore, additional measures provided data on the distance of common trips for the participant. Data were also collected on health and behaviors.

Primary outcome measure. The Assessment of Readiness for Mobility Transition (ARMT) (i.e., readiness to cease driving) was used as the primary outcome (Meuser, Berg-Weger et al., 2013; see Appendix I). The ARMT consists of 24 items with responses given on a 5-point Likert scale (e.g., "I avoid thinking about my mobility," and "My future independence hinges on my ability to get myself around.") The ARMT is a reliable measure: Stowe (2011) reported Cronbach's $\alpha=.88$ (pre-test) and $\alpha=.89$ (posttest; $n=69)$, and Meuser et al. (2013) reported Cronbach's $\alpha=.88(n=297)$. Although full validity of new scales can only be established through extensive research use, some evidence of validity for the ARMT has emerged in the literature. Berg-Weger, Meuser, and Stowe (2013) reported concurrent validity for the measure beyond what was reported in the manuscript describing the formation of the measure. As expected, individuals who scored poorly on readiness to make a transition had significantly increased perceived fall risk, demonstrated maladaptive coping behaviors, and reported worse vision and self-rated health. 
Secondary outcomes measures. Secondary outcomes included Owsley's Driving Habits Questionnaire (DHQ; Owsley, Stalvey, Wells, \& Sloane, 1999), the Manchester Driving Behavior Questionnaire (DBQ; for risky maneuvers [Reason et al., 1990]), the Fitness-To-Drive Screening measure (FTDS -- a web-based measure for informants; Classen, 2012), subjective health status (from Older Americans Resources and Services study; Fillenbaum, 1982), and self-reported days in bed due to injury or illness (NCHS, 2012). Though traffic crashes and citations are often used as outcome measures in driving intervention studies (Elder et al., 2011; Russell, Vandermeer, \& Hartling, 2011), they are exceedingly rare events. In an analysis of multiple studies of crash rates and aging, older subjects with normal cognitive function crashed at a rate of .048 /year/individual and those with any level of dementia crashed at a rate of .09/year/individual (Carr \& Ott, 2010). The current study's sample would be expected to experience a small number of crashes over the study period. Thus, these outcomes were not used in this study because multiple years of crash data would have to be collected to discover meaningful group differences on this outcome.

Likewise, hospitalizations and nursing facility admissions, though used by some to assess health functioning (Freeman, Gange, Munoz, \& West, 2006) are relatively rare. Thus, a proxy measure of health, "bed days," from the National Health Interview Survey (NCHS, 2012) was used. The item asked the respondent to recall the number of days during the past month that they stayed in bed for more than half of the day due to illness or injury. If the respondent happened to have been hospitalized during that period, then he or she was asked to include any day spent in the hospital as a bed day.

Enrollment questionnaire. The demographic battery included questions on age, gender, socioeconomic status, mobility satisfaction, etc. (see Appendix B). Additionally, open-ended questions about current mobility problems and anticipated challenges were found by Stowe (2011) to provide a more holistic view of the participant's ambulation 


\section{MOBILE AGING}

status and driving problems that may not be captured by other measures, and were included on the enrollment questionnaire and repeated at subsequent measurement periods.

Carr's screening measure. Carr's screening measure (a measure of cognitive impairment as it relates to driving ability) was used as a covariate (Carr et al., 2011; see Appendix C). Carr's measure was designed to predict failure of on-road driving evaluations by older hospital patients with cognitive impairment. The battery was selected because of simplicity and the fact that it did not require technology (e.g., driving simulators) for administration (Gentzler \& Smither, 2012). Cognitively impaired older adults were of interest because of high risk for poor crash outcomes (Anstey et al., 2005). However, individuals with severe cognitive impairment (unaware of research purpose or unable to say how they were currently feeling) were not included because of possibly invalid responses and risks to vulnerable human subjects. Little evidence for validity is available for Carr's recently introduced screening measure, but the individual components of the battery do have better evidence.

The Clock Drawing Task (CDT) and Trails A (a timed test of an individual's ability to draw a line ["trail"] between sequential numbers, or ordered letters) selected for use in Carr's battery have been shown to be psychometrically sound through extensive use in research over multiple decades. For the CDT, participants were given a blank sheet of paper and asked to draw a clock that shows a time of "10 minutes after 11." Freund's (2005) method for the CDT was selected because of ease of use, and Carr used this scoring method when developing the screen. The CDT is a valid predictor of poor onroad performance (Freund et al., 2005, 2008; Mathias \& Lucas, 2009), and cognitive impairment (Samton et al., 2005; Royall et al., 1999). Traditional scoring was utilized for the Trails A as noted in Appendix C. The third measure included in Carr's screening measure is the AD8 Dementia Screening Interview (AD8). This measure was designed 


\section{MOBILE AGING}

to be completed by an informant or the participant and is included in the "Informant Measures" section below. In cases in which an informant was not named, or could not be contacted, study staff administered the AD8 to the participant, and used these responses to calculate a score for Carr's measure.

Owsley's Driving Habits Questionnaire (DHQ). The 34-item self-report DHQ (see Appendix D) is perhaps the most broadly used measure in older driver studies, and has ample evidence for construct validity (Huebner, Porter, \& Marshall, 2006; McGwin et al., 2005; Owsley, Stalvey, \& Phillips, 2003). Three subscales were used for the current study (19 items): 1) Current driving, 2) crashes and citations, and 3) driving space. The "current driving" subscale consists of nine items with varied response scales related to current driving status, and preferred mode of transport (e.g., "do you currently drive," and " has anyone suggested over the past year that you limit or stop driving?"). The "crashes and citations" subscale consists of four items that asked the participants the number of times an incident has happened during the past year (e.g., "How many accidents have you been involved in over the past year when you were the driver?") Finally, the "driving space" subscale consists of six items with "yes/no" responses (e.g., "during the past year, have you driven to neighboring towns?').

Subjective Health Status (SHS). SHS (see Appendix E) is a three-item measure with varied Likert scale responses (i.e., "How would you rate your overall health at the present time —excellent, good, fair, or poor?", "Is your health now better, about the same, or worse than it was five years ago?", and, "How much do your health troubles stand in the way of your doing the things you want to do - not at all, a little (some), or a great deal?'). This measure is from the Older Americans Resources and Services study's Functional Assessment Questionnaire (OMFAQ; Fillenbaum, 1988). Jang, Poon, and Martin (2004) used "How would you rate your overall health at the present time", "How is your present health compared to five years ago" and "How much do your health 


\section{MOBILE AGING}

troubles stand in the way of your doing the things you want to." Total scores ranged from 0 (negative self-perception of health) to 7 (positive self-perception of health). An acceptable Cronbach's alpha of .63 was reported for the scale. Subjective health status measures are valid independent predictors of mortality (Idler \& Benyamini, 1997) and have been correlated with physical and objective health in samples of older adults (Pinquart, 2001).

Self-reported days in bed due to injury or illness. This measure, drawn from years of use in a national survey conducted by the Centers for Disease Control and Prevention, requires a specific appraisal by the participant of periods of time greater than one half of a day in bed due to illness or injury (within a specific time period; see Appendix F). The instructions for this measure indicate that the participant count any day spent as an inpatient in a hospital as a "bed day," in addition to time spent in bed at home. This measure is more sensitive to nuanced health issues than severe appraisals of health, such as hospital readmissions or skilled nursing facility admissions, which are less likely to occur during the fairly short duration of the current study. To capture intervention effects, various time periods were used when asking participants about bed days due to illness or injury. At baseline and T3, a 6-month time period was used. At T2, a 1-month time period was used (i.e., only the time period following the first intervention session). Although validity trials are unavailable for this specific measure, it may be particularly useful for distinguishing the very ill from the very well.

Among adults $65+$ who are eligible for both Medicare, and Medicaid, the mean number of bed days reported per year is 14 (NCHS, 2012). Van Houtven et al. (2008) explored the impact of specific health conditions on bed days for adults 65 years and older. Although estimates are not available for all of the medical conditions targeted in the current study, older adults with stroke, for instance, can be expected to have 14 more bed days per year than their healthy counterparts. With the fairly substantial impact 


\section{MOBILE AGING}

of health conditions on bed days, some variability on this outcome can be expected, even over the relatively short study period.

Manchester Driving Behavior Questionnaire (DBQ). This 20-item measure emerged from the literature on aggressive driving (to measure "car use choices"; Reason et al., 1990; see Appendix G). The scale is useful beyond aggressive driving as it includes items for other types of driving errors and lapses, and routine violations of driving laws (e.g., "How often do you miss 'Stop' or 'Yield' signs and narrowly avoid colliding with traffic having the right of way?", or "How often do you disregard the speed limit on a highway?') It has been used to assess on-the-road crash risk for a variety of populations (LaJunen, Parker, \& Summala, 2004), albeit the highest reported Cronbach's alpha was for a Finnish sample $(\alpha=.80)$. The measure has been well-validated through repeated use in the literature (Mattsson, 2012).

Fitness-to-Drive Screening (FTDS) measure. The FTDS is a 54 item four-point Likert scale response measure of an informant's assessment of an individual's driving behavior (e.g., "How much difficulty does the person have driving in light rain," or "How much difficulty does the person have keeping up with the flow of traffic?" Classen, Velozo, Winter, Wang and Lanford (2012) reported extensive validity information on the FTDS (see Appendix H). Notably, through rigorous methods, the authors established face, content, and concurrent validity (including an on-the-road driving assessment). The authors also started work on demonstrating construct validity. Dyads were recruited as the FTDS is designed to be completed by a caregiver/family member. Among caregivers or family members (the intended respondent group), the measure achieved a Cronbach's alpha of .98 .

AD8 Dementia Screening Interview (AD8). The AD8 Dementia Screening Interview (AD8; part of Carr's screening measure; Galvin, et al., 2005) has shown promising psychometric validity in clinical samples (Galvin, Roe, Xiong, \& Morris, 2006) 


\section{MOBILE AGING}

and discriminates well between individuals with beginning symptoms of cognitive impairment and those without these symptoms (see Appendix C). The AD8 is designed to be administered to an informant or the target participant, and consists of eight items (e.g., Has there been a change in the last several years of "less interest in hobbies/activities"). The respondent was given three response choices ("Yes, a change," "No, no change," and "N/A, Don't know"). Traditional scoring was utilized for the AD8, as noted in Appendix C.

\section{Data Screening}

To prepare for analyses, the data were checked for integrity and screened for outliers. During screening, $25 \%$ of cases were randomly selected for re-entry of data by a research staff member who did not originally enter the case. Very few minor errors were detected by this process and corrected for the entire dataset, if applicable. Moreover, all data were checked for inappropriate or out-of-range entries for each variable. Again, very few minor data entry errors were detected and corrected.

Univariate outliers were checked using a z-score value exceeding \pm 3.29 (Tabachnick \& Fidell, 2007). One case each for "Days of Illness or Injury" (Time 1[zscore $=4.14$, Time $2[$-score $=5.07]$ and Time $3[$-score $=4.03])$ and "DBQ total score" (Time $1[$ z-score = 3.78]) were excluded.

Due to skewness and kurtosis concerns (score divided by standard error of skewness and kurtosis that was $\geq 3.29$ ), the variables for "Days of IIIness and Injury," "Carr's Battery," and the total score for "Driving Behavior Questionnaire" were log transformed. Moreover, variables were checked graphically for normal distribution histograms were generated for scale variables, and categorical variables were checked using bar charts with overlaid standard curves. Except the variables that required log transformation, each was fairly normally distributed despite the small sample size. 


\section{MOBILE AGING}

Missing data were primarily a concern with regard to informants' responses to the AD8 and Fitness to Drive Screening Measure (FTDS) because fewer informants were recruited than participants (see Results section). Missing responses to the AD8 would have resulted in missing scores on Carr's screening measure as it was one of the measures that comprised this battery. Due to the fact that the AD8 was also designed to be administered to the target participant, all participants were asked to respond to the AD8 at each time point. If available, however, the informant's AD8 score was used in the calculation of Carr's screening measure. The FTDS was designed only for administration to an informant, and therefore, cases with missing data on this measure were excluded from the analyses associated with this measure.

Early in the trial, three participants were asked a single self-rated health item ("How would you rate your overall health?") at baseline rather than the three-item composite measure that was later adopted. The summed score of the three-item scale resulted in categories that resembled the possible responses for the single self-rated health item. For these three cases, a composite score was generated that resulted in a classification similar to the participant's answer to the global item (e.g., if the participant rated his/her overall health as "good" in response to the single-item question, then a composite score of " 4 - Good" was entered for the participant). 


\section{Results}

This chapter describes the overall findings of an intervention study conducted on a sample of medically impaired older hospital patients who were also current drivers. Participants were recruited in the trial over a period of 13 months. The findings are presented in relationship to study hypotheses which guided the study design and analytic strategy. The hypotheses were developed based upon previous literature published in the transportation and aging, injury prevention, and medical sciences fields.

\section{Statistical Analyses}

The following hypotheses were tested by comparing outcome measures of the control and intervention groups. It was expected that the intervention group would experience significantly better outcomes as noted by the hypotheses.

Hypotheses. Among older adults with medical impairments known to impact driving performance:

Hypothesis 1: Mobility counseling will increase readiness to make a mobility transition.

Hypothesis 2: Mobility counseling will reduce risky driving behaviors (e.g., the informant's evaluation of driving performance, or aggressive maneuvers).

Hypothesis 3: Mobility counseling will impact health outcomes by

a) improving subjective health status.

b) reducing self-reported days in bed due to illness or injury.

This intervention study tested a novel protocol in a unique setting with a final sample size that was smaller than planned. Therefore, an alpha level of .10 was chosen to enhance detection of significant test statistics and facilitate continued refinement and testing of the intervention protocol on future samples. Interpretation of results at the 


\section{MOBILE AGING}

chosen alpha level should be done with caution, and clinical relevance of results should be evaluated with prudence.

\section{Approach}

Analyses characterized the results by exploration of individual and group differences over time.

Preliminary Analyses. To reveal potential differences between groups at baseline, independent samples $t$-tests were used to test for differences between the control and intervention groups in participant age, composite SES, satisfaction with mobility, days of illness or injury, and Carr's screening measure. No significant differences between the groups were indicated at baseline. Furthermore, Fisher's exact tests revealed no significant differences between the groups on participant gender, rural versus urban dwelling, living alone, or race. Due to the small sample size (expected frequency of a cell was below 5), Fisher's exact tests were used where Chi square analyses became inappropriate throughout the analyses (Utts \& Heckard, 2012).

Similar tests were run on all outcome variables to test for selection differences between participants who dropped out and those who remained in the study. No significant differences were indicated. Fisher's exact test also revealed no significant difference between participants in the control and intervention groups who left the study. Within group analyses were conducted between those who remained in the study and those who dropped, and no significant differences were found.

It was possible that characteristics of certain peers or the length of contact between peer and participant could impact outcomes. Therefore, descriptive statistics (Mean/Median and $S D$ ) and $t$-tests were used to assess the impact of "peer" or dosage effects related to particular peers or the length and frequency of phone contact between the peer and the participant. Preliminary analyses addressed these possibilities. Pearson's Chi-Square revealed significant differences between research staff members 


\section{MOBILE AGING}

and peer volunteers on length of Call $3(p=.016)$, Call $4(p=.018)$, and total time spent $(p=.002)$ in intervention activities, with peers appearing to spend more time involved with participants. $T$-tests showed a significant difference between scores on the ARMT only for those participants who met with peers versus research staff members at every time point (For time three: $\mathrm{p}=.066 ; M_{\text {peer group }}=2.70[S D=.20] ; M_{\text {research staff }}=3.22[S D=$ .636]. However, participants were not randomly assigned to peers, as peer volunteers required schedule flexibility and convenience. All participants assigned to peers were non-rural; all were female, and all complied with the planning process. Non-compliant participants spent substantially less time speaking with research staff when contacted, and not unexpectedly had fewer issues to discuss regarding the planning process.

Furthermore, a dichotomized variable $($ Peer $=1)$ was created to conduct $t$-tests on differences in total time spent on intervention related activities (time on sessions and calls summed) between peer volunteers and researchers. Peers were clearly indicated as spending more time on intervention activities than were research staff members $(p=$ .002). Notably, the difference in time did not lead to significant differences on any outcome measures.

Individual and group differences over time. For basic assessments of differences between groups following intervention, within group differences were assessed using paired samples $t$-tests, and between group differences were assessed using independent samples $t$-tests.

To evaluate the effect of the program on readiness for a mobility transition (ARMT), driving behaviors (DHQ, DBQ, FTDS), and health (SHS, and self-reported days in bed) from pretest to posttest, a series of simple repeated measures analyses were conducted, controlling for demographic effects (i.e., age, gender and socioeconomic status) and measures of cognitive health (Carr's screening measures). This strategy allowed for the inclusion of participants with fewer than three measurement periods by 


\section{MOBILE AGING}

transposing the dataset (each participant is entered with three rows of data rather than three columns of data for any given measure entered into the dataset software). Time was treated as discrete (nominal scale variable) so that the differences between $\mathrm{T} 1$ and T2, T2 and T3, etc. could be analyzed with a focus on the timeXgroup interaction. The repeated measures analysis allowed for consideration of how readiness for a mobility transition, informant's evaluation of driving performance and aggressive maneuvers, subjective health status, and self-reported bed days changed over time and evaluation of any differences in rates of change between the groups. Bonferroni adjustments were used for the multiple tests. Due to a small sample size, close attention was paid to the differences between groups even if the result was not significant. 


\section{MOBILE AGING}

\section{Participants}

The final sample included thirty-nine participants and 18 informants all recruited from a research and referral hospital (in- and out-patient settings), and health-related community organizations. One third $(n=13)$ of all recruited participants were randomly assigned to the attention control group (see Figure 1 for complete information on participant movement through the trial protocol).

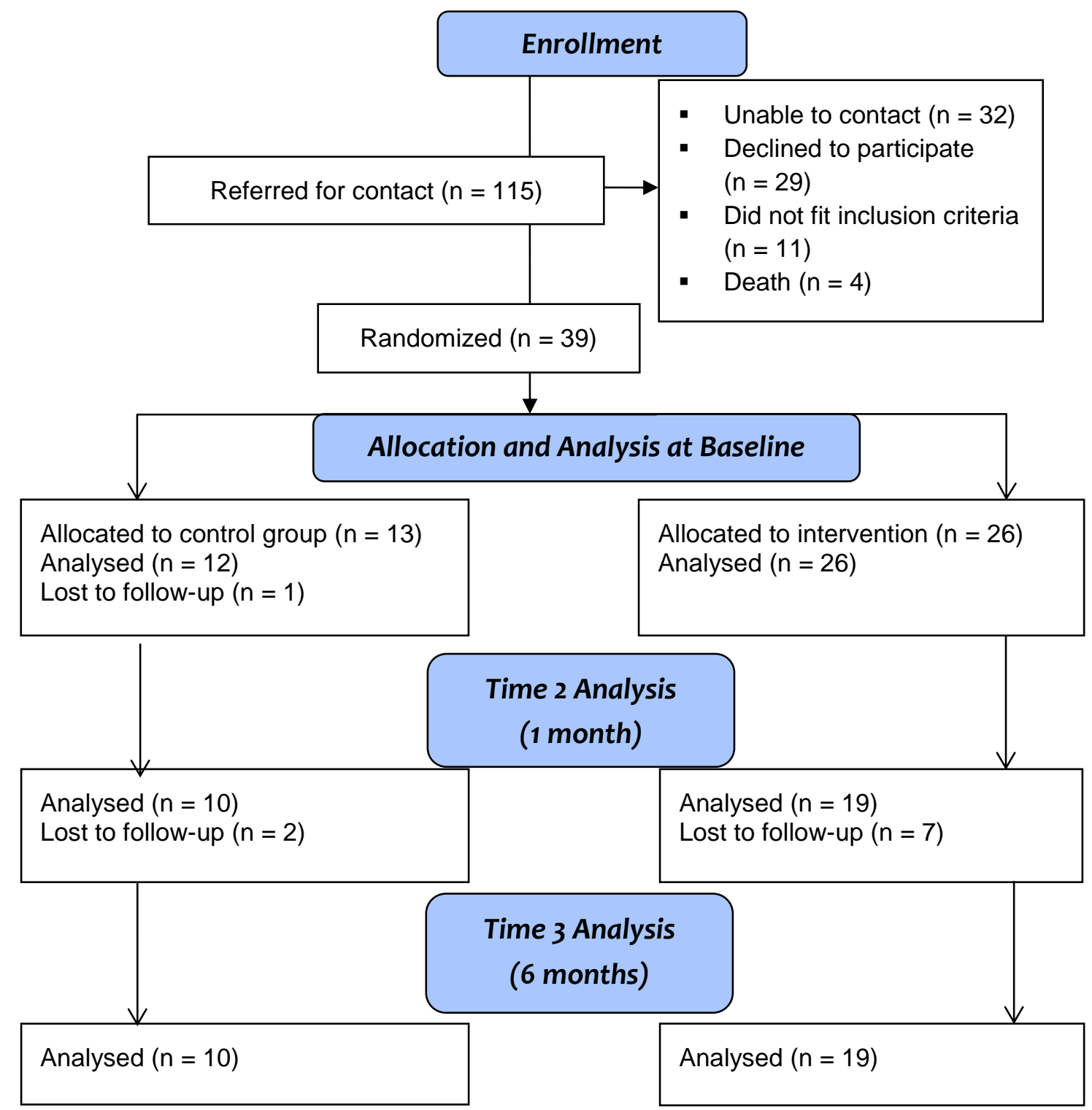

Figure 1. Randomized Controlled Trial flowchart of MobileAge study. 


\section{MOBILE AGING}

Only six participants declined to name an informant. Of the 33 informants that were named, research staff members were able to consent and take at least baseline measures for 23 (Intervention: 14; Control: 9). Those who were not consented could not be reached by research staff members. No informant refused to participate in the study. The most common informant named was a spouse ( $n=16 ; 12$ wives; 4 husbands), followed by friend $(n=3)$, daughter $(n=2)$, son $(n=1)$, and daughter-in-law $(n=1)$.

The average participant was 75.5 years old $(S D=8.1)$. Of the $X$ participants, 21 were women, and 9 lived in a rural area. Ten lived alone, and most were married (29). A composite of socio-economic status (years of education and job title before retirement) indicated that the sample was fairly evenly split between low, medium and high SES (10, 15 , and 14 , respectively). In alignment with regional estimates, 37 were White. Twentynine indicated that they were somewhat or very satisfied with their mobility at baseline. Most (33) reported always wearing a seatbelt when driving, and eight reported that over the past year, someone had suggested that he or she limit or stop driving. No participant rated the quality of his or her own driving as worse than average, and most (21) rated their driving as "good." Three participants reported having had a crash in the past year, and two of those reported that the police were called to the crash scene. Three also reported having received a traffic citation in the past year. Table 2 provides a complete demographic profile for each group and the entire sample.

For participants assigned to the intervention group, mean Session 1 time was 42.11 minutes $(S D=18.95)$, and Session 2 was 37.63 minutes $(S D=17.189)$. 
MOBILE AGING

\begin{tabular}{|c|c|c|c|}
\hline \multicolumn{4}{|l|}{ Table 2} \\
\hline \multicolumn{4}{|c|}{$\begin{array}{l}\text { Demographic Characteristics and Group Comparison }(\mathrm{N}=39) \text { : Means }(\mathrm{SD}) \text { or } \\
\text { Percentages }(\mathrm{N}) \text { on Key Variables. }\end{array}$} \\
\hline Variables & Intervention $(n=26)$ & Control $(n=13)$ & $\underline{M}$ \\
\hline$\overline{\text { Age }}$ & $\overline{74.42(8.63)}$ & $\overline{77.67(6.67)}$ & $\overline{75} .45(8.11)$ \\
\hline Sex $(1=$ female $)$ & $46.2 \%(12)$ & $38.46 \%(5)$ & $43.6 \%(17)$ \\
\hline Rural & $26.9 \%(7)$ & $16.7 \%(2)$ & $23.7 \%(9)$ \\
\hline Live Alone & $30.8 \%(8)$ & $16.7 \%(2)$ & $26.3 \%(10)$ \\
\hline Married & $69.2 \%(18)$ & $84.6 \%(11)$ & $74.4 \%(29)$ \\
\hline \multicolumn{4}{|l|}{$\begin{array}{l}\text { Socio-Economic } \\
\text { Status }\end{array}$} \\
\hline Low & $30.8 \%(8)$ & $16.7 \%(2)$ & $25.6 \%(10)$ \\
\hline Medium & $30.8 \%(8)$ & $53.9 \%(7)$ & $38.5 \%(15)$ \\
\hline High & $38.5 \%(10)$ & $30.8 \%(4)$ & $35.9 \%(14)$ \\
\hline Race (1= White) & $96.2 \%(25)$ & $92.3 \%(12)$ & $94.9 \%(37)$ \\
\hline $\begin{array}{l}\text { Satisfied with } \\
\text { Mobility }\end{array}$ & $65.4 \%(17)$ & $92.3 \%(12)$ & $74.4 \%(29)$ \\
\hline $\begin{array}{l}\text { Informant Available } \\
\quad \text { for Contact }\end{array}$ & $50.0 \%(13)$ & $61.5 \%(8)$ & $53.9 \%(21)$ \\
\hline ARMT & $3.20(.65)$ & $3.16(.43)$ & $3.19(.58)$ \\
\hline $\begin{array}{l}\text { Driving Habits } \\
\text { Questionnaire } \\
\text { (Driving Space } \\
\text { subscale) }\end{array}$ & $4.27(1.46)$ & $3.83(1.36)$ & $4.13(1.46)$ \\
\hline FTDS & $76.08(15.55)$ & $80.22(19.20)$ & $\begin{array}{l}77.60 \\
(16.58)\end{array}$ \\
\hline $\mathrm{DBQ}$ & $.40(.28)$ & $.24(.22)$ & $.35(.27)$ \\
\hline $\begin{array}{l}\text { Subjective Health } \\
\text { Status }\end{array}$ & $4.54(1.45)$ & $4.42(1.83)$ & $4.50(1.56)$ \\
\hline Bed days & 7.62 (15.28) & $.82(1.83)$ & $5.59(13.15)$ \\
\hline
\end{tabular}

Regarding medical risk, 30 reported that a doctor had diagnosed them with cataracts, and of these, 21 reported having had corrective surgery. Another 11 reported a doctor had told them that they had macular degeneration (MD) or Glaucoma. Nine participants reported that a doctor had told them they had severe arthritis, and 3 reported that a doctor had told them they have had a stroke or cerebrovascular accident (CVA) - one of those reported a formal screening for fitness to drive before returning to driving. Eight participants reported having been diagnosed with sleep apnea and of 


\section{MOBILE AGING}

those, five reported having received treatment. Four participants reported that a doctor had told them they had dementia, and three of the four reported that the diagnosis was made more than one year ago. Seven reported diabetes, and eight reported having been told by a doctor that they have some other condition that may impair driving. See Table 3 for group comparisons of medical risk.

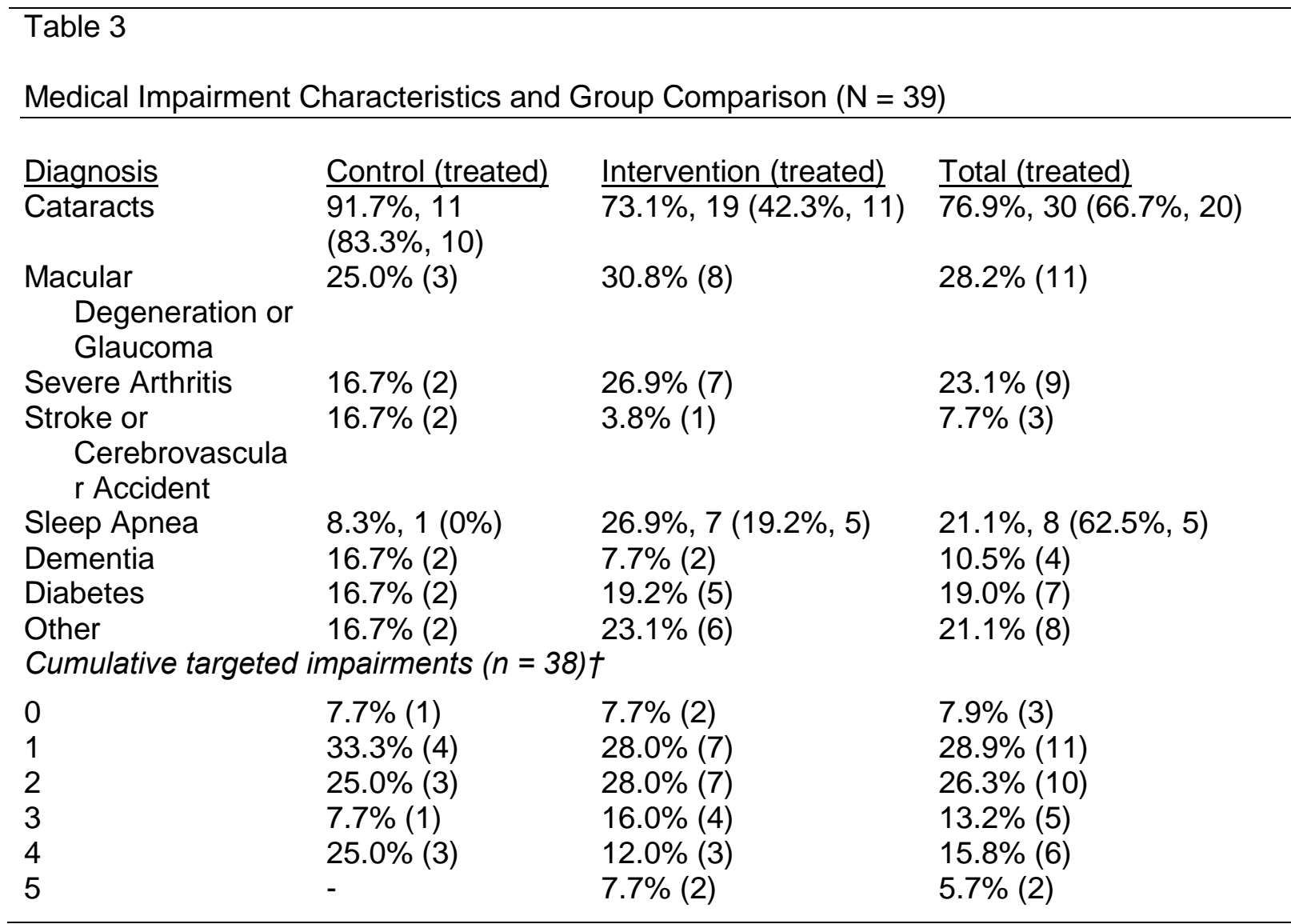

† Note. One participant refused to answer questions about medical impairments. An additional participant had no data collected on medical impairments. 


\section{MOBILE AGING}

\section{Hypotheses Testing}

Between group (i.e., intervention group and control group) differences were tested using independent samples $t$-tests. At baseline, Days of Injury or Illness was significantly different between the groups $(p=.045$ with equal variances not assumed Levene's test $=.047$ ), with the intervention group having significantly more days of illness or injury. This significant difference carried over to the second measurement period $(p=.023$, with equal variances not assumed - Levene's test $=.000)$, but dropped below significance at the final measurement period. At the final measurement period (Time 3), the control group had a significantly higher score on Carr's screening battery ( $p$ $=.023)$ than the intervention group, indicating greater risk of failing an on -the -road driving examination in the control group. Moreover, a significant difference in Subjective Health Status at Time 3, but not at baseline or Time 2 was found between the groups ( $p$ $=.071)$, with the control group reporting lower Subjective Health Status than the intervention group. Table 4 (next page) provides outcome means at each time of measurement for both groups. 
MOBILE AGING

Table 4

Outcome Means (SD) by Measurement Period ( $\mathrm{N}=39$ )

\begin{tabular}{|c|c|c|c|}
\hline Outcome & Control & Intervention & Sample \\
\hline $\begin{array}{l}\text { Assessment of Readiness for } \\
\text { Mobility Transition T1 }\end{array}$ & $3.16(.43)$ & $3.20(.65)$ & $3.19(.58)$ \\
\hline $\begin{array}{l}\text { Assessment of Readiness for } \\
\text { Mobility Transition T2 }\end{array}$ & $3.24(.35)$ & $3.12(.53)$ & $3.16(.47)$ \\
\hline $\begin{array}{l}\text { Assessment of Readiness for } \\
\text { Mobility Transition T3 }\end{array}$ & $3.30(.54)$ & $3.11(.61)$ & $3.17(.58)$ \\
\hline $\begin{array}{l}\text { Driving Behaviors Questionnaire } \\
\text { T1 }\end{array}$ & $.24(.22)$ & $.40(.28)$ & $.35(.27)$ \\
\hline $\begin{array}{l}\text { Driving Behaviors Questionnaire } \\
\text { T2 }\end{array}$ & $.31(.41)$ & $.36(.29)$ & $.34(.33)$ \\
\hline $\begin{array}{l}\text { Driving Behaviors Questionnaire } \\
\text { T3 }\end{array}$ & $.26(.35)$ & $.32(.27)$ & $.30(.30)$ \\
\hline $\begin{array}{l}\text { Fitness-to-Drive Screening } \\
\text { Measure T1 }\end{array}$ & $80.2(19.2)$ & $76.1(15.6)$ & $77.6(16.6)$ \\
\hline $\begin{array}{l}\text { Fitness-to-Drive Screening } \\
\text { Measure T2 }\end{array}$ & $78.3(18.3)$ & $79.6(19.3)$ & $78.9(18.0)$ \\
\hline $\begin{array}{l}\text { Fitness-to-Drive Screening } \\
\text { Measure T3 }\end{array}$ & $73.4(14.1)$ & $72.8(17.7)$ & $73.2(14.9)$ \\
\hline $\begin{array}{l}\text { Driving Habits Questionnaire (Life } \\
\text { Space) T1 }\end{array}$ & $3.83(1.47)$ & $4.27(1.46)$ & $4.13(1.46)$ \\
\hline $\begin{array}{l}\text { Driving Habits Questionnaire (Life } \\
\text { Space) T3 }\end{array}$ & $3.70(1.34)$ & $3.50(1.25)$ & $3.57(1.26)$ \\
\hline Subjective Health Status T1 & $4.42(1.83)$ & $4.54(1.45)$ & $4.50(1.56)$ \\
\hline Subjective Health Status T2 & $3.90(1.85)$ & $4.21(1.47)$ & $4.10(1.59)$ \\
\hline Subjective Health Status T3 & $3.60(1.51)$ & $4.47(1.47)$ & $4.20(1.51)$ \\
\hline Days IIIness/Injury T1 & $.75(1.77)$ & $5.52(11.15)$ & 3.97 (9.43) \\
\hline Days IIIness/Injury T3 & $1.33(3.0)$ & $3.37(7.64)$ & $2.71(6.51)$ \\
\hline
\end{tabular}

Note. Standard deviations appear in parentheses.

Within group differences were tested using paired samples $t$-tests. For the control group, a significant increase in total score on the ARMT appeared between Baseline and Time $2(p=.058)$. A significant decrease in Subjective Health Status between Baseline and Time $3(p=.033)$ was also observed. Additionally, increased risk for failing an on the- road driving examination was noted by significant differences in Carr's screening battery between Times 2 and $3(p=.063$; increased risk) and Baseline and Time $3(p=$ .064; increased risk), however the increase was not significant between Baseline and Time 2. 


\section{MOBILE AGING}

Among the intervention group, a significant decrease in FTDS emerged between Baseline and Time $2(p=.045)$. Additionally, significant decreases in the DBQ were found between Baseline and Time $2(p=.085)$ and Baseline and Time $3(p=.047)$. From Baseline to Time 3, the Driving Space subscale of the DHQ significantly decreased $(p=.015)$.

To assess differences in the groups on outcome measures over time, simple repeated measures were conducted. No significant differences emerged from these analyses, albeit the differences between groups were in the hypothesized direction for Subjective Health Status $\left(p=.382, M_{\text {control }}[4.0], M_{\text {intervention }}\right.$ [4.42], where a higher rating indicates better subjective health). Likewise, differences on the ARMT occurred in the hypothesized direction ( $\mathrm{p}=.705, M_{\text {control }}$ [3.23], $M_{\text {intervention }}$ [3.15], where lower scores indicate greater readiness for a mobility transition).Therefore, explicit full support was not found for any of the hypotheses, but partial support was found in some cases, as outlined below.

Hypothesis 1. Trends in mean differences on the ARMT may be encouraging for potential support of Hypothesis 1 (the intervention increases readiness for a mobility transition; see Figure 2). The intervention group started with higher mean scores on the ARMT and followed a decreasing trajectory over the course of the study. In contrast, the control group started with lower mean scores on the ARMT and followed an increasing trajectory over the course of the study period, which indicates less readiness to make a mobility transition over time in this group. Notably, the clinical relevance of the observed differences between the groups is suspect. The group differences did not amount to movement between, for instance, the high or moderate risk classifications. 
MOBILE AGING

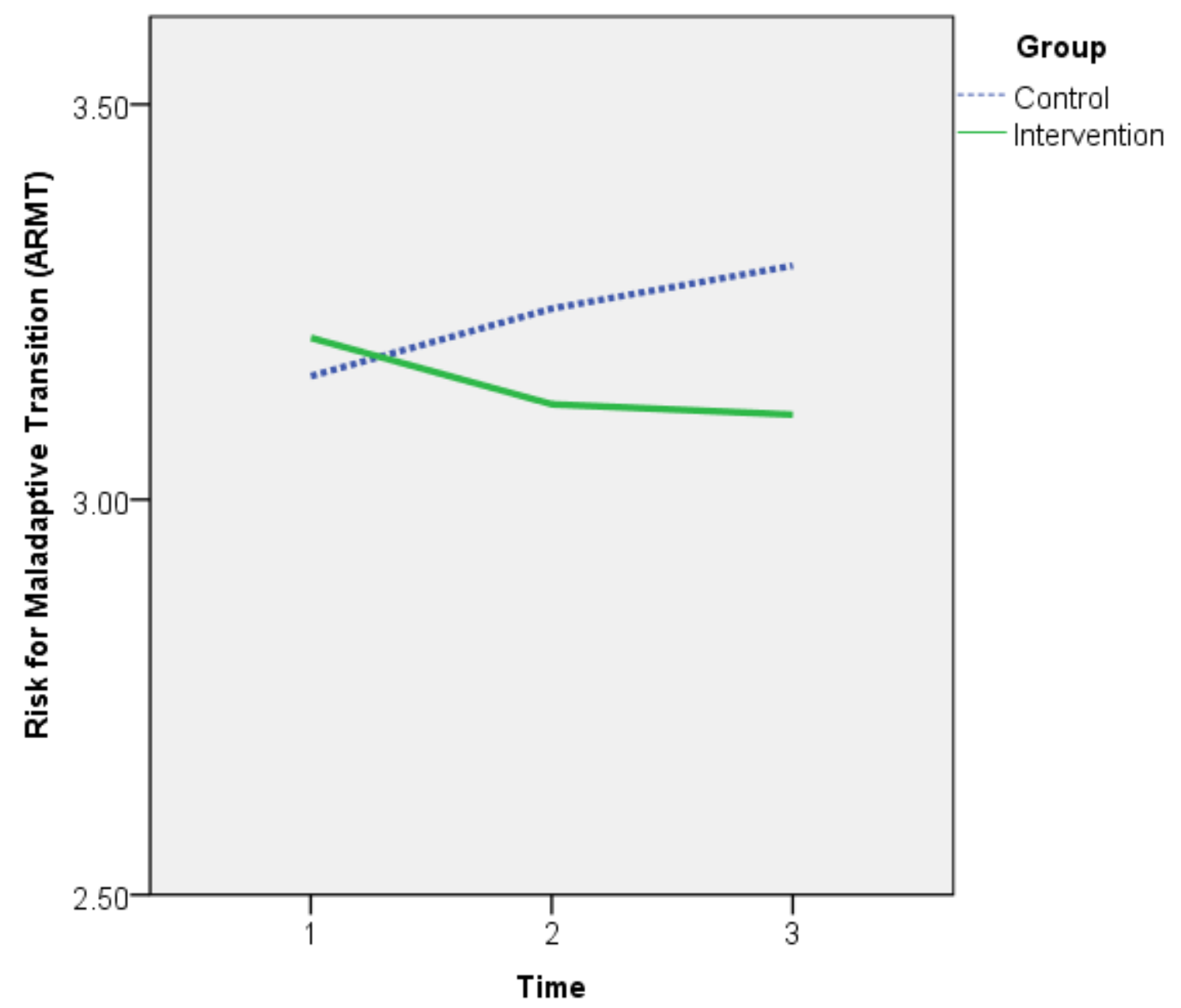

Figure 2. Group comparisons on mean ARMT scores (Hypothesis 1). 


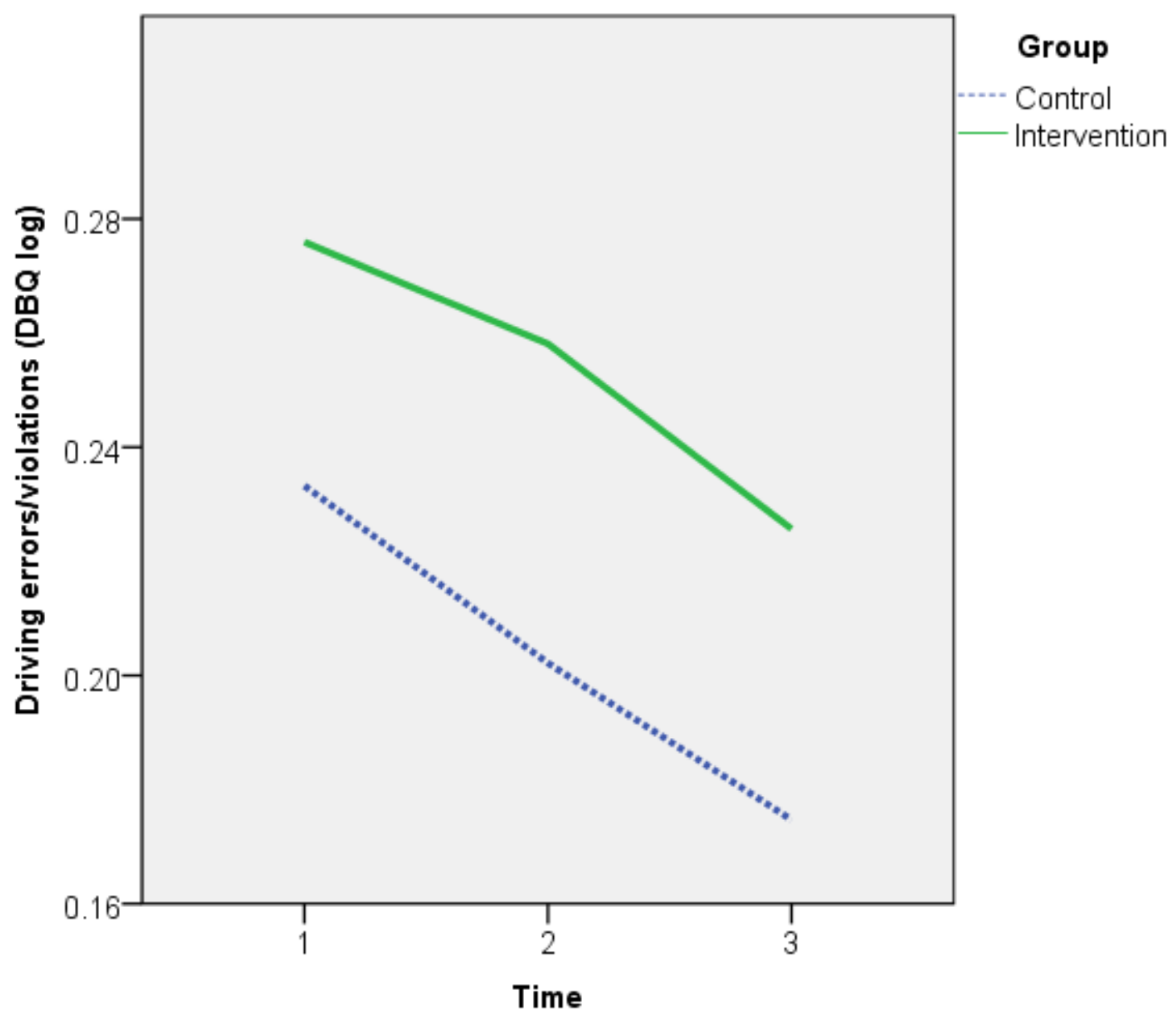

Figure 3. Group comparisons on mean DBQ scores (Hypothesis 2).

Hypothesis 2. That the intervention reduces risky driving behaviors was partially supported by declines in mean scores on the DBQ (driving errors and violations) among the intervention group only. The control group likewise experienced declines in reported errors and violations, but the difference over time was not significant. The second measure used to test this hypothesis, the FTDS (informant rated driving skills), offered little clarity. Both groups decreased over time, indicating worsening evaluations of driving over time by the informant, yet no statistical tests were significant on this measure. Driving space, which refers to excursions of various distances from home, was nearly flat for the control group, but the intervention group did appear to have a reduction in driving space over the trial period (see Figures 3-5). 
MOBILE AGING

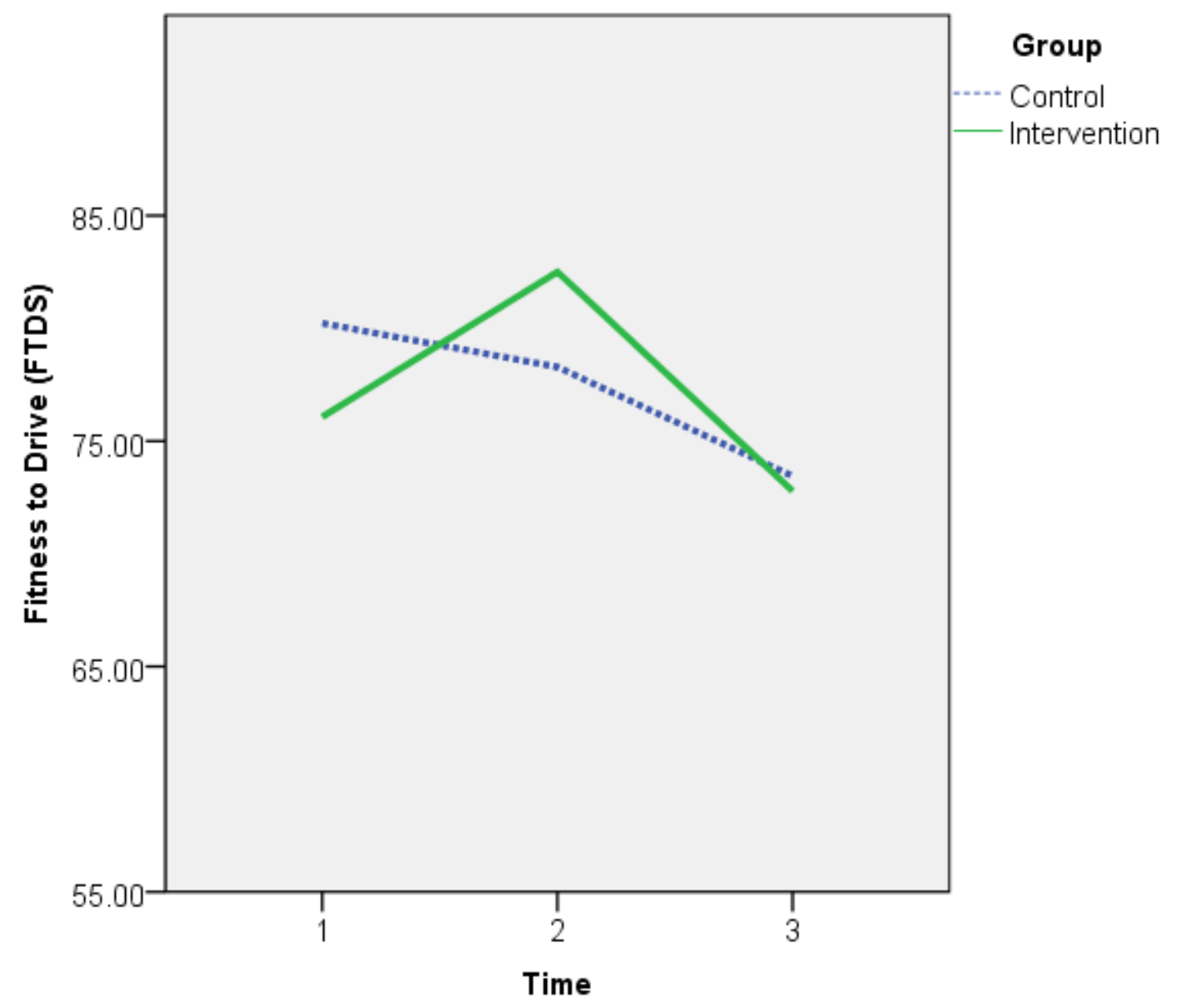

Figure 4. Group comparisons on mean FTDS scores (Hypothesis 2). 
MOBILE AGING

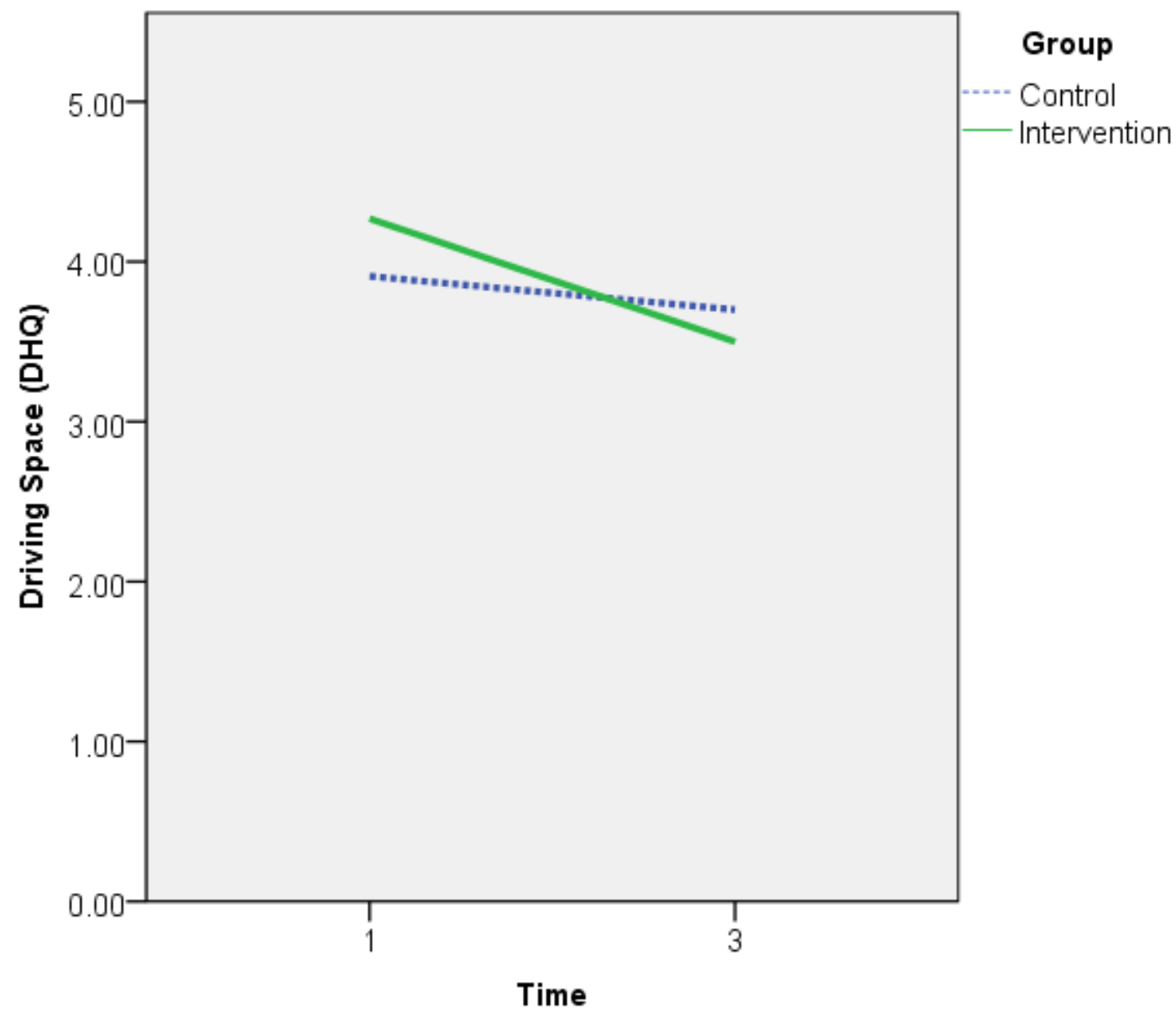

Figure 5. Group comparisons on mean DHQ scores (Driving Space subscale; Hypothesis 2). 


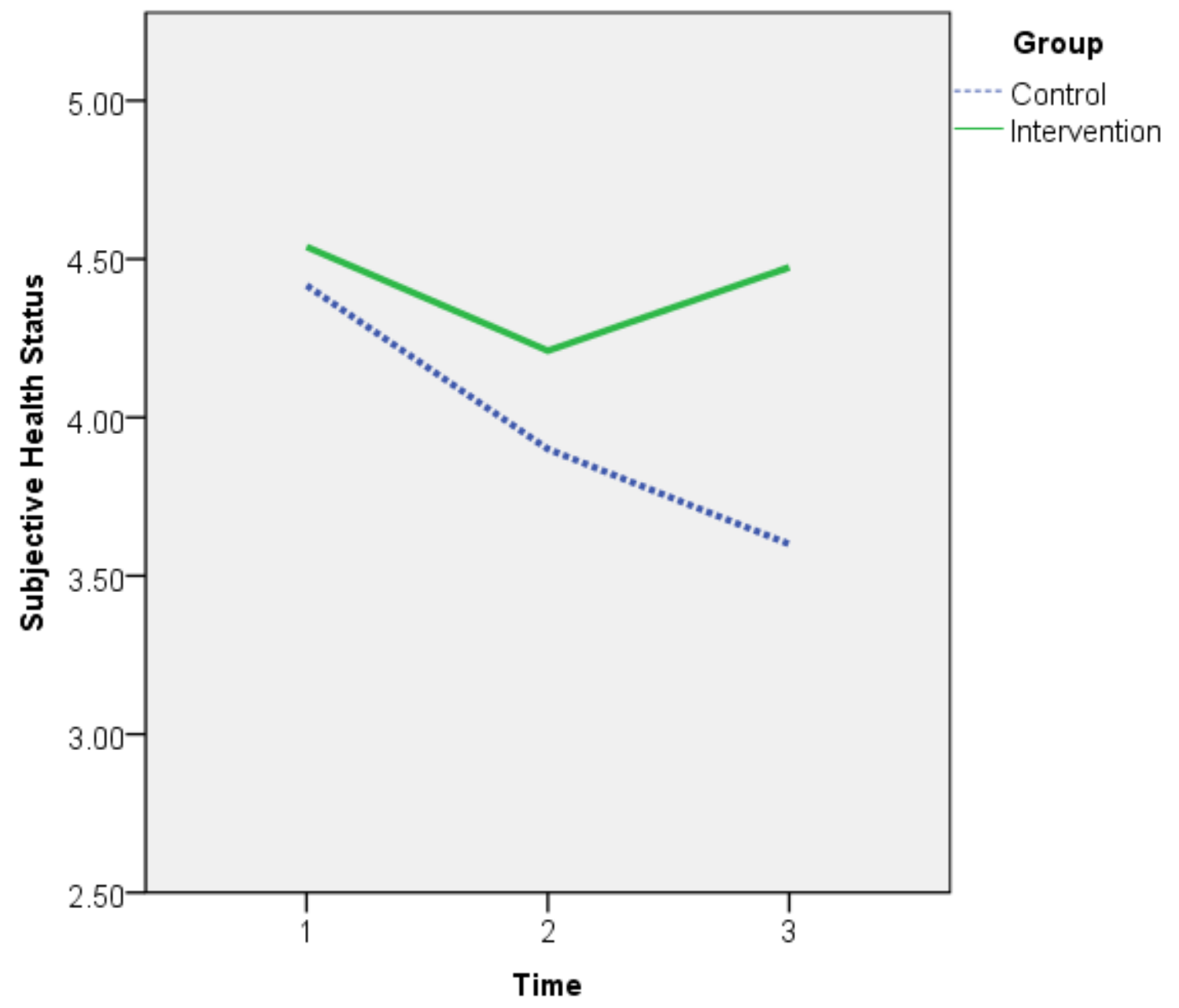

Figure 6. Group comparisons on mean SHS (Hypothesis 3).

Hypothesis 3. Finally, that the intervention impacts health outcomes was partially supported through significant $t$-tests on Subjective Health Status (SHS; see Figures 6-7). Whereas the intervention group experienced an increase in SHS at Time 3, the control group reported a decrease in SHS. Days of Illness or Injury did not offer support of the hypothesis, but the significant difference between the groups at baseline, despite random assignment, must be noted for this measure. Moreover, the pattern of change over time appears to show a sharp drop whereas the control group shows a strong increase. 


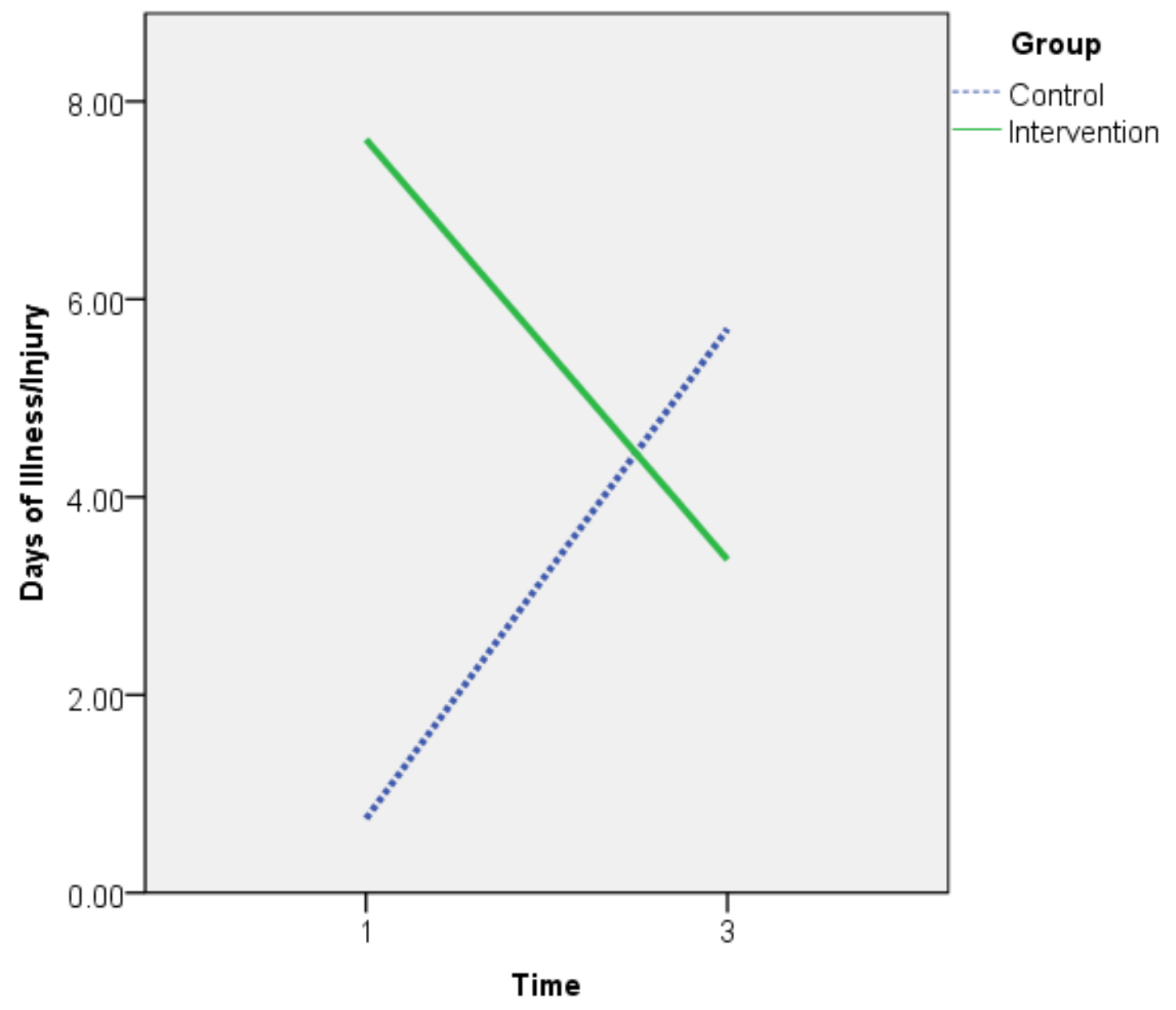

Figure 7. Group comparisons on mean Days of Illness or Injury (Hypothesis 3).

\section{Results Summary}

Results of this intervention trial showed trends in the differences between the group that participated in intervention activities and that receiving attention only (the control) that were in line with the proposed hypotheses. Older at-risk hospital patients who participated in a facilitated mobility transition planning program tended to show improved outcomes over time relative to an attention-only control group, though these group differences were not statistically significant. 


\section{MOBILE AGING}

\section{Discussion}

In this section, support and lack of support for each hypothesis will be considered in light of previous research and limitations of this trial, and the implications of this study for future work will be addressed.

An unexpected component of this trial discovered early in the process was that some participants in the intervention group who would not participate in the planning process. Although no study measures were designed to explicitly capture the reasons for noncompliance with the intervention protocol, research staff discussed these cases at length in an attempt to encourage planning and alternative approaches. Therefore, a general sense of why planning efforts were less successful with this subgroup did become apparent. Almost universal among this group was the sense that driving ability was not yet compromised by a medical impairment, and therefore planning at an "early" stage would not be helpful. The trial's measures could not measure medical fitness-todrive, so it was possible that the identified impairments indeed were not impacting the participant, or that the participant was unaware of the extent of the impairment. Additionally, many of the noncompliant participants, although not all, were younger than 70. Previous research (Dellinger, Sehgal, Sleet, \& Barrett-Connor, 2001) suggests that chronological timing of driving cessation is important to older adults, despite the evidence suggesting cessation be related to functional ability alone (Ball et al., 2006). Research staff members also discovered a general reluctance to plan in any life domain in this group, as several spoke about having to take life and aging "as it comes, each day at a time." These observations are important to keep in mind for future intervention work that involves planning, regardless of the focus of such intervention.

The first hypothesis that readiness for a mobility transition would increase among the intervention group was not supported by statistical tests. However, the trajectory of 


\section{MOBILE AGING}

increased readiness among the intervention group, and a trajectory of decreased readiness among the control group was observed. Tempering any confidence in this result was likely low clinical relevance of the difference between groups (e.g., despite the encouraging trajectories of the measure, movement on the scale did not amount to a change in risk category for the individual participant). In line with previous work on the Assessment of Readiness for Mobility Transition (ARMT), the measure has been found to be quite stable over time (Meuser et al., 2013), even in an interventional setting (Stowe, 2011). Perhaps the ARMT measures a highly stable construct, or interventions to date have not accurately targeted pathways for promoting change on the scale. Alternatively, the measure may not be sensitive enough to detect change if the construct is not stable.

Hypothesis two predicted enhanced driving safety, as measured by driving behaviors, an informant's perspective of a participant's driving skills, and driving habits (distances of driving excursions from home). Here, a decrease in risky driving behaviors over time was reported by both groups, although only the intervention group's decrease at follow up was significant. Importantly, overall categorizations of driving behavior would characterize this sample as low risk (LaJunen, Parker, \& Summala, 2004). Any reduction in high-risk driving behaviors (due to either errors or violations of laws) is positive, but reductions among low-risk older adults may be less meaningful than those among adolescent drivers, for example.

Moreover, informants' assessments of the participant's driving skills, using the accurate Fitness to Drive Screening Measure (FTDS), returned surprisingly positive appraisals of driving performance for a medically-impaired sample. The intervention did not appear to impact informants' perspectives of driving over time, as both groups experienced slightly reduced appraisals by follow-up. The intervention did not aim to improve participant's driving skills, so informant ratings may have been unaffected by 


\section{MOBILE AGING}

other positive impacts of the intervention, such as increased use of driving alternatives. Even if the participant started to use a paratransit service, the informant would continue to rate the participant's driving skill in a similar manner. Measures of driving habits for the control group suggested little change in the distance that these participants travelled from home as a driver. The intervention group, however, experienced a decline in driving space, suggesting that this group may have been self-regulating driving following the intervention.

Self-regulation has become widely regarded as a positive phenomenon among impaired older drivers (Siren \& Meng, 2013), and this intervention may have enhanced this behavior. For instance, an established dialogue between the participant and research staff or peers may have helped sensitize the at-risk drivers to safety issues. Even if these individuals continued driving, they may have reduced longer trips, trips in unfamiliar areas, or in more complex situations. Moreover, some of the plans generated by participants included trying alternative modes of transportation (e.g., a private service bus for medical appointments) for the first time. Inexorably, the use of alternative modes, or becoming a car passenger rather than driver would have reduced driving space.

Finally, the control group experienced significant decreases in Subjective Health Status when tested between groups and within the control group only. The intervention process explicitly addressed health concerns and planning for worsening of symptoms. It may have been that through tangible actions related to participants' plans, anxiety regarding deteriorating health was reduced. Health self-management interventions have been shown to have a positive impact on the similar measure, and identical construct, of Self-Rated Health (SRH; Kate et al., 2001) among participants with chronic illnesses. Perhaps the transition planning process in this trial is akin to self-management of the impact of a medical condition. 


\section{MOBILE AGING}

Additionally, it may have been that the consideration of driving cessation itself buoyed participants' perceptions about subjective health status. Specifically, very few participants in this trial stopped driving, even if only temporarily $(n=3[11.5 \%])$. In the context of a clear marker of health decline (i.e., driving cessation), participants may have realized that if they were healthy enough to continue driving, then their subjective health status may be better than they had previously thought. Indeed, research staff characterized very few intervention participants as in a period of major health decline, despite high-risk health conditions and recent hospitalizations.

Days of illness or injury were significantly different among the control and intervention group at the beginning of the trial, with the intervention group reporting substantially more days of illness or injury than the control group. It is possible that this initial difference is an artifact of a small sample size, and a few participants with a severe illness or injury happened to be assigned to the intervention group. Lacking even one individual with one of the most severe problems would have mattered on this measure for the control group. At follow-up, the control and intervention groups came closer together on this measure, and an additional measurement period would have been helpful for estimating the trajectory of change in both groups.

Clarity of findings was hampered by a small sample size, but overall findings were encouraging, especially with regard to improving Subjective Health Status, and lower risk reported driving behaviors among the intervention group. Moreover, encouraging directions of mean score differences between groups were found on all but the informants' ratings of the participants' driving ability, suggesting that the intervention protocol has promise for effectively working in a group of medically at-risk older drivers.

\section{Implications}

Intervening with at-risk older patients in a health care setting is a logical starting point for facilitated planning that eases a mobility transition. Health care settings 


\section{MOBILE AGING}

commonly treat older adults with impairments that are problematic for driving safety, are well-integrated into the community, and oftentimes have quality relationships with supportive service agencies. Moreover, these settings are particularly well-suited to monitoring changes in health and function that may impact the ability to drive safely. They are likely to encounter older adults who are in Liddle's (2008) decision phase regarding driving cessation because of an obvious impairment, or an injury crash. Few types of professional organizations or agencies concerned with driving safety other than health care providers have regular follow-up or are equipped to monitor medically impaired older adults.

However, the resources of health care settings, including hospitals, are often constrained and focused on the delivery of medical procedures that fix a particular problem. Encouraging staff to take a broader perspective and engage patients on the topic of safe mobility is needed, as this trial exposed reluctance among health care professionals to address issues beyond the specific ailment for which the patient was being seen that day. Although recruitment for this trial was exceptionally challenging, it may be that established teams of volunteers and professionals who are integrated into the health system can receive referrals of at-risk patients. The teams could then specialize in providing mobility transition counseling services, perhaps in addition to procedures such as occupational therapy. It may be that a referral process would help to clarify roles in helping patients with mobility, and also broaden the number and type of providers who were willing to address the issue of driving cessation.

Policy Implications. The current process of driving cessation for medicallyimpaired older adults is fractured and lacks uniformity across providers and health care settings. Some have suggested (Berg-Weger, Meuser, \& Stowe, 2013) the need to normalize discussions about driving cessation so that the topic can be addressed openly and with foresight. Health system policy that addresses how providers approach older 


\section{MOBILE AGING}

drivers with conditions known to impair driving safety may be beneficial. Uniform policy may help avoid the tendency noticed in this trial of provider "champions" who have an interest in driving safety being the only professionals willing to refer older patients to driving related resources. Moreover, without clearly defined policy, health care administrators may be "over-protective" of their valuable revenue stream of older adults, and shield patients from needed discussions about driving transitions due to concern of upsetting them and risking loss of their business.

Among the high-risk sample in this trial, only two reported ceasing to drive at the end of the study period, indicating possibly high levels of anosognosia. The trial included an intense effort to discuss planning, alternatives, risk of crash and injury, and the need to make a decision about driving cessation. It is unlikely that programs broadened and shortened for implementation in health care settings will match the current trial in intensity or duration of interaction with high-risk patients on this topic. Therefore, few high-risk patients would be expected to move from Liddle's (2008) pre-decision phase to a more advanced phase of the cessation process using this intervention protocol alone. Thus, it appears important for health care settings to make a concerted effort to report high-risk patients to licensing authorities for final determinations on medical fitness to drive, whenever severe levels of impairment are encountered during the delivery of care. Policy, either at the public or internal institutional level, should be designed to guide health care providers on when the report to licensing authorities is appropriate, and why it is needed. Further research is needed to determine whether more stringent reporting policies versus concerted efforts to implement mobility transition counseling in health care settings proves more valuable for public safety and the well-being of older adults.

Transportation and mobility is related to geographically-available infrastructure. Rural older adults, or even those in semi-urban areas, may not have access to adequate alternatives to the personal automobile. The peers in this trial often suggested that 


\section{MOBILE AGING}

participants would transition away from driving if they could simply identify a viable alternative. Funding and supporting alternative transportation may be a key to help impaired older drivers make a seamless and appropriately-timed transition to cessation. Adler and Rottunda (2006) reported results from focus groups of elders who had previously ceased to drive, and noted that in addition to the appropriate timing of cessation, appropriate alternatives was one of the most important factors. Notably, the overall utility of the alternative (e.g., it met transportation needs), rather than a certain mode or public versus private provision of the alternative, was most important.

Practice Implications. It is worthwhile to acknowledge that there will be noncompliant patients regardless of risk level or prognosis, and even substantial investments of time and resources may not change outcomes for these individuals. They may remain in a pre-decision phase until a crisis point, and that crisis may involve injury to self or others following a vehicle crash. Therefore, patients who refuse to engage in planning or fail to recognize any reason to cease to drive should likely be referred to state licensing authorities for further medical evaluation of fitness to drive, if condition severity and functional limitation suggests this action.

Moreover, it appears that clinicians would benefit from clearer measures or descriptions of "at-risk" drivers. It may be that reduced visual, cognitive, or psychomotor functioning (or imminent reduced functioning due to recent diagnosis) would serve as a qualifier for Mobility Transition Counseling, or referral for an examination of fitness to drive. This may help avoid intervening with those who remain healthy and safe behind the wheel. As Liddle and colleagues (2014) suggest, it would be helpful to tailor interventions to various points along the driving cessation process continuum, so that elders and family members receive needed support regardless of if they are predecision, decision, or post-decision. This type of approach may have benefited the participants in this study who were labeled as "noncompliant," by better meeting them at 


\section{MOBILE AGING}

an early pre-decision phase. If practice can be enhanced to the point at which full cessation is planned well enough that it results in greater safety as well as continued engagement with the community, then a major task of the field will have been achieved.

\section{Limitations}

Recruitment. Given the challenging nature of recruitment for this trial, the research staff strived to discover and implement effective recruitment strategies. A major challenge of trial recruitment was the duration of the recruitment period (13 months) as well as the expense of the trial when compared to the final number of study participants. These challenges may dissuade future research using similar methodology, especially if large sample numbers are desired. During the recruitment period, research staff members were encouraged to document their experiences with recruitment, and the key characteristics and obstacles to recruitment. What emerged from these notes were the following:

Internal resistance. Research and referral hospitals are usually large entities with occasionally competing and uncommunicative components. For example, an especially relevant clinic reported that "hundreds" of eligible participants were treated every week. After months of contact with several levels of leadership by study staff, no participants were referred from this clinic. At another high-volume clinic, research staff members were directed to a physician medical director who explained that the clinic did not treat older adults. Hospital records retrieved by research staff revealed that this particular clinic had treated approximately 2,400 patients over 60 in the past calendar year. Research coordinators in other departments cited similar recruitment difficulties outside of their home departments. One research coordinator noted that competition for singular enrollment in research trials may have reduced receptivity of other departments. Perhaps research conducted in smaller hospitals, or those with less trial recruitment competition would result in larger samples. 
Administrative involvement. Following the example of other research trials, incentives for referring potential participants who would later be screened by research staff for eligibility and inclusion were offered for a short time and advertised widely in the study site. Much enthusiasm and interest was generated by this approach, and due to referrers having no control over a participant's decision to enroll or eligibility to enroll, the study director assumed that there would be no conflict of interest or ethical concerns. Hospital administration disagreed with this position, suggesting that referring staff would coerce participants into enrolling, and revoked fiscal authority to issue incentives to referring staff. Research staff sensed a loss of trust with clinics and departments who subsequently had to be notified that no incentive for referrals could be offered. Unsurprisingly, no referrals were received from departments or clinics that initially showed interest in the incentives.

Sensitive topic. On numerous occasions, research staff reported that referrers mentioned a general reluctance to address the topic of driving with older patients in any manner. Several contacts mentioned having been fired by older patients after previous conversations about driving cessation, and that the loss of clients was an unacceptable risk. The issue of lost clientele mainly emerged during conversations with physicians, but nurses also mentioned known and potential negative consequences of discussing driving with patients. Many departments could be termed as specialists who only treated certain types of illness or injury. Therefore, they stated that the issue of driving retirement was simply beyond the scope of care that they were willing to provide, and did not want to raise the issue with patients.

Lack of time. On only rare occasions did potential referrers fail to mention a high patient load, lack of extra time, or the inability to spare even a few moments to describe the study. Research staff continued to revise study materials and recruitment techniques to reduce time required to refer. Research staff screened patient lists (IRB approved 


\section{MOBILE AGING}

amendment) for likely eligible participants and notified hospital staff if they were going to soon treat those patients. Moreover, research staff with clinical skills "shadowed" certain providers and offered their skills/assistance to reduce the referrer's workload and free them to speak with potential participants about the study. These tactics resulted in few referrals.

Expanded sites. Recruitment was later expanded to a regional memory support organization, another regional hospital, and a research trial that focused on medicallyimpaired older adults. Despite a cooperative, professional, and friendly relationship, the volume of eligible participants available to the regional memory support organization was relatively low, and the partnership only resulted in a handful of enrollments. The regional hospital was enthusiastic and offered ample participant volume. Scheduled training of this hospital's staff was pre-empted by administrators who reported that they did not participate in studies that they did not "control." Participants from the cooperative research trial had outdated contact information, and were difficult to locate. Most of the referred trial participants had died, stopped driving, or were not interested in participation.

Measurement. Important gains in reduction of injury due to motor vehicle crashes may be best accomplished through directly measuring injury, crash, and fatality outcomes (Cummings, Koepsell, \& Mueller, 1995). Larger studies of longer duration are likely needed to produce tangible variability on these outcome measures, even in samples of medically-impaired drivers.

Peer and research staff differences. Despite training and attempts to standardize intervention sessions, profound differences between peers and research staff occurred on time spent with participants. For this trial, anecdotal evidence presented by both peers and participants suggested that the peers' conversations covered many more topics that may have not been directly relevant to the process of 


\section{MOBILE AGING}

driving cessation (e.g., long-term care insurance). The assumption that peers may have been "less efficient" in addressing topics directly relevant to the intervention is supported by a lack of significant differences on outcomes among participants assigned to peers versus those assigned to the research staff. Greater numbers and more diverse peers as well as and a heightened ability to record peer to participant interactions (e.g., through video recording) are needed to determine the effects and nature of time differences. A thorough understanding of these differences may be critical to scaling the program to higher volume settings.

\section{Future Research}

The results of this trial suggest several paths for future inquiry. Given that this trial had some promising impacts on health outcomes for medically impaired patients, additional work is needed to explore how health care professionals can best be engaged on this issue, and how Mobility Transition Counseling may be better incorporated into routine or specialized care. Future research must better establish how the driving cessation process is tied to health outcomes, including those which impact health systems' revenue (e.g., re-hospitalizations).

Related to engaging health care professionals is the need to understand how expectations regarding changes in mobility, especially as they relate to high-risk medical conditions, can be normalized in the general community. It may be beneficial that upon diagnosis, patients presume that a change in mobility is likely and preparations should begin. Likewise, tools should be tested among family members and caregivers that may help prime for eventual driving cessation, and how to make the transition orderly and without crisis.

Due to the challenges of recruitment into this trial, it is recommended that the core research team include a physician in future trials focused on hospitals and similar health care settings. In clinical settings accustomed to physicians holding the highest 


\section{MOBILE AGING}

decision making authority, a research team member of equal hierarchical stature may be of use for explanation of the study and encouraging referrals for possible recruitment. Moreover, the use of peer counselors is time consuming due to the need for high levels of training, and a general unease among some community members with the idea of addressing the sensitive topic of driving cessation with high-risk patients. Thorough training of select peer counselors may be the best approach, or finding volunteers who are already incorporated into the health care system. Retired Registered Nurses, Social Workers, or other professionals may be valuable to future efforts. Finally, it is assumed that different health care systems and facilities will have varying approaches to research and assisting investigators with recruitment from the patient pool. The overall health system culture will likely strongly impact the efficacy of future research efforts related to the sensitive topic of driving cessation.

Due to the reluctance among some older adults with functional impairment to cease to drive, investigations of assistive vehicle or infrastructure technology that reduces driving risk in spite of impairment is well warranted. Above all, the key to future research agendas must be heightening engagement and mobility of older adults, even after the onset of frailty and impairment, while minimizing the risk of devastating traumatic injury. 
Appendix A

Peer Handbook and profile summaries used for intervention sessions.

Name:

\section{Session 1 Profile Summary}

Phone number: 555.5555

\section{Contact Notes:}

Insert any information that will be helpful for contacting the participant (work schedule, certain days of the week that are preferred, etc.)

\section{Background Information:}

Indicate where the participant lives and how satisfied or unsatisfied he/she is. Indicate any current driving problems they have or expect to have in the future and any other information you feel pertinent about the individual.

Colored Squares:

Cognitive Screen: Feedback is determined by participant's probability of failing an on-the-road driving test using Carr's probability calculator. Follow the guide below in accordance to the score.

\section{Probability score between $\mathbf{0 - 2 5 \%}$ (green square)}

The participant's score indicates a low risk for failing an on-the-road driving assessment.

\section{Probability score between $\mathbf{2 6 - 7 4 \%}$ (yellow square)}

The participant's score indicates a moderate risk for failing an on-the-road driving assessment. This score indicates a cognitive impairment is possible. It is important to discuss driving alternatives in the event their impairment worsens over time.

\section{Suggested Talking Points:}

- Sometimes, individuals with cognitive impairment do not recognize problems with driving. Who can he/she trust to help make a decision about driving in the future?

\section{Probability score between $\mathbf{7 5 - 1 0 0 \% ~ ( r e d ~ s q u a r e ) ~}$}

The participant's score indicates a high risk for failing an on-the-road driving assessment. This person should likely be evaluated for driving safety. However, because of their cognitive impairment, they may be unaware they 
are an at-risk driver. Family members and friends should be encouraged to help this individual make safe mobility choices.

\section{Suggested Talking Points:}

- Sometimes, individuals with cognitive impairment do not recognize problems with driving. Who can he/she trust to help make a decision about driving in the future?

\section{Self-Rated Health:}

Follow the guide below.

\section{Fair or Poor (red square) Total Score: 0-2}

Low ratings of your own health or a high number of days in bed due to injury or illness indicates that health in general may be compromised. Individuals who score low on these indicators should be prepared for health challenges that may make driving safely difficult.

Good (yellow square) Total Score: 3-5

Although he/she believes their health is generally good, a rating of "good" may indicate underlying health issues that may present a challenge to mobility. Most people are very positive when reporting their own health.

\section{Very good or Excellent (green square) Total Score: $6+$}

No problem indicated.

Driving Habits: Feedback will be given for seatbelt use (4), if anyone has suggested they limit or stop their driving (7), their rating of their quality of driving (8), driving crashes (10 \& 11), and driving citations (12 \& 13).

\section{Question 4: Seatbelt use}

Anything other than "always" triggers feedback.

It is always safer to wear a seat belt. Older adults are at high risk for injury in a crash, and a seat belt helps to minimize or avoid injury.

\section{Question 7: Has anyone suggest they limit or stop driving}

Both responses trigger feedback.

\section{If they responded "yes"...}

The participant indicated others have made comments that he/she should limit or stop driving. Having others comment about limiting or stopping driving may indicate serious problems with driving ability.

\section{Suggested Talking Points:}


- Sometimes, it is hard to determine your own ability to drive safely. A doctor and a Certified Driving Rehabilitation Specialist can give sold advice about a person's driving ability.

\section{If they responded "no"...}

The participant indicated others have not made comments that he/she should limit or stop driving. It is a good sign that no one has suggested he/she stop or limit driving.

\section{Suggested Talking Points:}

- It is important to listen to other people about driving. There is even a condition among some people that makes it hard to recognize problems with their own driving. In these cases, someone else's opinion is very important.

\section{Question 8: Quality of Driving}

All responses trigger feedback.

It is normal for people to overstate the quality of their driving and their driving skills. In studies, the large majority of people rate themselves as "excellent" or "good" drivers. In reality only a very few people are excellent drivers, and most are "average."

If the participant rated themselves as "fair" or "poor," then suggest:

$\mathrm{He} /$ she should thoughtfully consider their comfort with driving and why they feel there may be some problems with their driving ability. Oftentimes, being uncomfortable with your own driving signals safety problems that could become dangerous.

\section{Questions 10 \& 11: Crashes}

If they indicated they have been in any car crash...

Crashes are rare, and being involved in one may signal problems with driving. Crashes, and unexplained dents and dings in his/her car can be a red flag about driving safety. Being involved in multiple crashes over a relatively short period of time may indicate very serious problems and high risk for crashing again in the future.

\section{If they indicated they have not been in any car crash...}

Crashes are rare, and not all people who are unsafe to drive will have a crash. The goal is to make positive choices in mobility so that crashes do not happen in the first place.

\section{Questions 12 \& 13: Citations} If they indicated they have been pulled over or received a traffic ticket... 
Being pulled over by the police indicates unusual or unsafe driving behavior, regardless of whether or not they received a ticket. Receiving a ticket or being pulled over may signal an increased chance of being involved in a crash.

\section{Suggested Talking Points:}

- Individuals who are pulled over should carefully evaluate why the stop occurred.

- A doctor or Certified Driving Rehabilitation Specialist (CDRS) can help answer questions about driving safety. If your doctor can't give you an answer, ask to see a CDRS.

Driving Behaviors: Follow the guide below, two scores will be given; one for errors and one for violations.

Violations, items: $6,11,13,14,16,18,20$

Errors, items: 1, 3, 5, 8, 10, 12, 15, 17

Some items excluded from analyses.

Low composite score (green square): Violations mean 0-1.3; Errors mean: 0-2.1

The participant's responses indicate a low risk for hazardous driving behavior.

Moderate Composite Score (yellow square): Violations mean 1.4-3.2; Errors mean: 2.2-4.7

The participant's responses indicate a moderate risk for hazardous driving behavior. Some of their driving behaviors may place them at an increased chance of injury, car crashes, and reduced mobility following a crash.

\section{Suggested Talking Points:}

- What are steps the person can take to have safer driving behavior?

\section{High Composite Score (red square): Violations mean 3.3+; Errors} mean: 4.8+

The participant's responses indicate a high risk for hazardous driving behavior. Other people who report driving behaviors similar to her/him have an increased chance of injury, car crashes, and reduced mobility following a crash.

Suggested Talking Points: (not yet created)

Ready to Make a Transition: Feedback is determined by the participant's total ARMT Score. Follow the guide below in accordance to their responses. 


\section{Total Mean Score of 3.58 - 5 (89 - 120 points) / LOW READINESS}

\section{What does the participant's total score on the ARMT say about them?}

Their score indicates that they are a proud, independent, self-reliant person. The participant appreciates doing things for themselves and being in a position to help others. They cope with age-related declines in health or function by keeping a positive attitude and focusing on what they still do well. While they are open to receiving help from others at times, they prefer solutions that allow them to remain in control and focused on their personal priorities.

When faced with a mobility transition, such as a need to cut back on driving, they prefer a go-slow, wait-and-see approach. They worry about what life will be like if they are less mobile than they are today, and they want to do all they can to avoid negative outcomes for themselves and their family. Having to rely more on others and burden them does not appeal to the participant. The participant would rather not think about declining health and function right now because it makes them worry about your future.

\section{Questions for Consideration \& Discussion}

- What are the biggest concerns about growing older? What could be avoided?

- Think about how it would be to suddenly lose independence and need to rely on others. What are the feelings that arise?

- Is it possible to remain independent and in control, but also rely on others to live a full, meaningful life? How might this look?

- Does retirement from driving mean an end to living well? Is it possible to stop driving and still go to activities and destinations?

Total Mean Score of $2.29-3.57$ (56 - 88 points) / MIXED READINESS

What does their total score on the ARMT say about them?

The participant's score indicates that they are thoughtful, considerate, and realistic. They want to remain as active and mobile as they can, but they also understand that growing older presents some challenges. The thought of facing declines and depending on others does not appeal to them and they much prefer to chart a safe and comfortable course. They worry that their quality of life could be impacted as they age. It is one thing to talk about growing older and quite another to live it. The participant has normal worries about it.

When faced with a mobility transition, such as a need to cut back on driving, they are open to talking about the issues and exploring options. Remaining in control is important to them, so they are likely to respond to pressure from others with caution and even skepticism. This does not mean that they are inflexible or unreasonable. They know that age-related changes in health and function are likely, and so it is good to plan ahead. The participant simply wants to weigh their options and consider solutions that maximize their function and minimize any burden on others. The bottom line is that they want to maintain a good quality of life.

\section{Questions for Consideration \& Discussion}


- What aspects of aging may be the biggest challenge in the future? Are there negative outcomes that can be avoided?

- The ability to get from place to place is important. What aspects of mobility (type of transportation, valued destinations, activities) should be maintained for as long as possible?

- Does retirement from driving mean an end to living well? Is it possible to stop driving and also be able to still go to other places? How might this look?

\section{Total Mean Score of 1- 2.28 (24 - 55 points) / HIGH READINESS}

\section{What does the participant's total score on the ARMT say about them?}

Their score indicates that they are confident, adaptable and open to new experiences. They understand that aging is a process that requires gradual change over time. They have a "cup half full" outlook and appreciate what your life offers in the present, without worrying too much about past or future losses. This is not to say that they ignore the impact of aging. On the contrary, the participant recognizes that planning for the future is the best way to remain active, mobile and engaged in life. Aging does not frighten them so long as they can make decisions along the way.

When faced with a mobility transition, such as a need to cut back on driving, they prefer to face the issue head on and learn their options. They welcome opportunities to talk with people they trust, including family members and professionals, and they appreciate input. The participant is open to accepting help from others and does not view this as causing a burden. If driving the car won't work for them, then they will find other ways to get around. Their quality of life is not dependent on one form of mobility or another. They have a flexible view of independence.

\section{Questions for Consideration \& Discussion}

- What does positive mobility mean? How does the ability to travel, at will, from place to place, contribute to the quality of life?

- Thinking about aging, what aspects of mobility (types of transportation, valued destinations, activities) are important to preserve? What can be lived without?

- What mobility options make the most sense right now?

Driving Rating (by a loved one): Below is a website to input the participant's scores that will indicate which category they fall under. Choose the type of driver and recommendations accordingly.

\section{http://ftds.phhp.ufl.edu/questionnaire.php}

3 Main Groups and General \& Specific Recommendations: 
Basic Driver (red square): (specific) We recommend the driver sees a doctor for a physical exam as soon as possible and not drive until he/she is able to undergo a comprehensive driving evaluation conducted by a Certified Driver Rehabilitation Specialist. Information on the use and access to alternative transportation (other than the personal automobile) may be available from the local Area Agency on Aging. (general) Based on guidelines of The American Geriatrics Society, we recommend an eye exam annually or earlier if there are changes in health or vision.

Routine Driver (yellow square): (specific) We recommend a doctor's appointment to start a conversation about conditions that may impact driving safety. The driver will also benefit from a comprehensive driving evaluation to address safety concerns. We recommend repeating this self-screening annually or when the driver experience changes in health or functional status. (general) The American Geriatrics Society recommends a physical and eye exam annually or earlier when needed. We recommend taking a class for mature drivers, such as those offered by AAA, AARP, or a local driving school.

Accomplished Driver (green square): (specific) It may be helpful to avoid or limit driving situations that are challenging. Based on your ratings, we do not think that a comprehensive driving evaluation is critical at this time. We recommend repeating this self-screening annually or when the driver experiences changes in health or functional status. (general) Additionally, The American Geriatrics Society recommends a physical and eye exam annually earlier when needed. We recommend taking a class for mature drivers, such as those offered by AAA, AARP, or a local driving school. 
Name:

\section{Session 2 Profile Summary}

Phone number: 555.5555

\section{Background Information:}

Indicate any change in the participant's satisfaction with their mobility. Indicate if they have any change in current driving and any other information you feel is pertinent

Colored Squares:

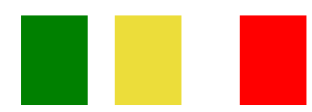

${ }^{* *}$ For each item below, be sure to note if there has been a change and whether that change may be positive or negative. Also, make note if there has not been a change.

Cognitive Screen: Feedback is determined by participant's probability of failing an on-the-road driving test using Carr's probability calculator. Follow the guide below in accordance to the score.

\section{Probability score between $\mathbf{0 - 2 5 \%}$ (green square)}

The participant's score indicates a low risk for failing an on-the-road driving assessment.

\section{Probability score between $\mathbf{2 6 - 7 4 \%}$ (yellow square)}

The participant's score indicates a moderate risk for failing an on-the-road driving assessment. This score indicates a cognitive impairment is possible. It is important to discuss driving alternatives in the event their impairment worsens over time.

\section{Suggested Talking Points:}

- Sometimes, individuals with cognitive impairment do not recognize problems with driving. Who can he/she trust to help make a decision about driving in the future?

\section{Probability score between $\mathbf{7 5 - 1 0 0 \% ~ ( r e d ~ s q u a r e ) ~}$}

*Explain if a person has moved into high risk category after one month, they likely have a progressive impairment

The participant's score indicates a high risk for failing an on-the-road driving assessment. This person should likely be evaluated for driving safety. 
However, because of their cognitive impairment, they may be unaware they are an at-risk driver. Family members and friends should be encouraged to help this individual make safe mobility choices.

\section{Suggested Talking Points:}

- Sometimes, individuals with cognitive impairment do not recognize problems with driving. Who can he/she trust to help make a decision about driving in the future?

\section{Self-Rated Health:}

Follow the guide below.

Fair or Poor (red square) Total Score: 0-2

* If a person changes after the first measurement and now indicates fair or poor health, we should explain it may be due to an illness, injury, etc. - What has caused the change?

Low ratings of your own health or a high number of days in bed due to injury or illness indicates that health in general may be compromised. Individuals who score low on these indicators should be prepared for health challenges that may make driving safely difficult.

Good (yellow square) Total Score: 3-5

Although he/she believes their health is generally good, a rating of "good" may indicate underlying health issues that may present a challenge to mobility. Most people are very positive when reporting their own health.

\section{Very good or Excellent (green square) Total Score: 6+}

No problem indicated.

Driving Habits: Feedback will be given for seatbelt use (4), if anyone has suggested they limit or stop their driving (7), their rating of their quality of driving (8), driving crashes (10 \& 11), and driving citations (12 \& 13).

\section{Question 4: Seatbelt use}

Anything other than "always" triggers feedback.

If the participant has begun to "always" wear their seatbelt and before they didn't, provide positive feedback of their progress.

It is always safer to wear a seat belt. Older adults are at high risk for injury in a crash, and a seat belt helps to minimize or avoid injury.

\section{Question 7: Has anyone suggest they limit or stop driving} Both responses trigger feedback. 


\section{If they responded "yes"...}

The participant indicated others have made comments that he/she should limit or stop driving. Having others comment about limiting or stopping driving may indicate serious problems with driving ability.

\section{Suggested Talking Points:}

- Sometimes, it is hard to determine your own ability to drive safely. A doctor and a Certified Driving Rehabilitation Specialist can give sold advice about a person's driving ability.

\section{If they responded "no"...}

The participant indicated others have not made comments that he/she should limit or stop driving. It is a good sign that no one has suggested he/she stop or limit driving.

\section{Suggested Talking Points:}

- It is important to listen to other people about driving. There is even a condition among some people that makes it hard to recognize problems with their own driving. In these cases, someone else's opinion is very important.

\section{Question 8: Quality of Driving}

All responses trigger feedback.

It is normal for people to overstate the quality of their driving and their driving skills. In studies, the large majority of people rate themselves as "excellent" or "good" drivers. In reality only a very few people are excellent drivers, and most are "average."

If the participant rated themselves as "fair" or "poor," then suggest:

$\mathrm{He} /$ she should thoughtfully consider their comfort with driving and why they feel there may be some problems with their driving ability. Oftentimes, being uncomfortable with your own driving signals safety problems that could become dangerous.

\section{Questions 10 \& 11: Crashes}

\section{If they indicated they have been in any car crash...}

Crashes are rare, and being involved in one may signal problems with driving. Crashes, and unexplained dents and dings in his/her car can be a red flag about driving safety. Being involved in multiple crashes over a relatively short period of time may indicate very serious problems and high risk for crashing again in the future.

* If someone has indicated being in a crash in the past month, stress the rareness of the event, and how it is a strong indicator of a potential problem. If they indicated they have not been in any car crash... 
Crashes are rare, and not all people who are unsafe to drive will have a crash. The goal is to make positive choices in mobility so that crashes do not happen in the first place.

\section{Questions 12 \& 13: Citations}

If they indicated they have been pulled over or received a traffic ticket...

* If someone has indicated being in pulled over in the past month, stress the rareness of the event, and how it is a strong indicator of a potential problem.

Being pulled over by the police indicates unusual or unsafe driving behavior, regardless of whether or not they received a ticket. Receiving a ticket or being pulled over may signal an increased chance of being involved in a crash.

Suggested Talking Points:

- Individuals who are pulled over should carefully evaluate why the stop occurred.

- A doctor or Certified Driving Rehabilitation Specialist (CDRS) can help answer questions about driving safety. If your doctor can't give you an answer, ask to see a CDRS.

Driving Behaviors: Follow the guide below, two scores will be given; one for errors and one for violations.

Violations, items: 6, 11, 13, 14, 16, 18, 20

Errors, items: 1, 3, 5, 8, 10, 12, 15, 17

Some items excluded from analyses.

Low composite score (green square): Violations mean 0-1.3; Errors mean: 0-2.1

The participant's responses indicate a low risk for hazardous driving behavior.

Moderate Composite Score (yellow square): Violations mean 1.4-3.2; Errors mean: 2.2-4.7

* If a person moves to a moderate composite score after a month, explain impairment may be the cause and they may be an at-risk driver.

The participant's responses indicate a moderate risk for hazardous driving behavior. Some of their driving behaviors may place them at an increased chance of injury, car crashes, and reduced mobility following a crash. 


\section{Suggested Talking Points:}

- What are steps the person can take to have safer driving behavior?

\section{High Composite Score (red square): Violations mean 3.3+; Errors mean: $4.8+$ \\ * If a person moves to a high composite score after a month, explain that impairment may be the cause and they are an at-risk driver.}

The participant's responses indicate a high risk for hazardous driving behavior. Other people who report driving behaviors similar to her/him have an increased chance of injury, car crashes, and reduced mobility following a crash.

Ready to Make a Transition: Feedback is determined by the participant's total ARMT Score. Follow the guide below in accordance to their responses. ${ }^{*}$ Report positive feedback if the participant moves to a higher readiness

\section{Total Mean Score of $3.58-5$ (89-120 points) / LOW READINESS}

\section{What does the participant's total score on the ARMT say about them?}

Their score indicates that they are a proud, independent, self-reliant person. The participant appreciates doing things for themselves and being in a position to help others. They cope with age-related declines in health or function by keeping a positive attitude and focusing on what they still do well. While they are open to receiving help from others at times, they prefer solutions that allow them to remain in control and focused on their personal priorities.

When faced with a mobility transition, such as a need to cut back on driving, they prefer a go-slow, wait-and-see approach. They worry about what life will be like if they are less mobile than they are today, and they want to do all they can to avoid negative outcomes for themselves and their family. Having to rely more on others and burden them does not appeal to the participant. The participant would rather not think about declining health and function right now because it makes them worry about your future.

\section{Questions for Consideration \& Discussion}

- What are the biggest concerns about growing older? What could be avoided?

- Think about how it would be to suddenly lose independence and need to rely on others. What are the feelings that arise?

- Is it possible to remain independent and in control, but also rely on others to live a full, meaningful life? How might this look?

- Does retirement from driving mean an end to living well? Is it possible to stop driving and still go to activities and destinations? 


\section{Total Mean Score of $2.29-3.57$ (56 - 88 points) / MIXED READINESS}

\section{What does their total score on the ARMT say about them?}

The participant's score indicates that they are thoughtful, considerate, and realistic. They want to remain as active and mobile as they can, but they also understand that growing older presents some challenges. The thought of facing declines and depending on others does not appeal to them and they much prefer to chart a safe and comfortable course. They worry that the quality of life could be impacted as you they older. It is one thing to talk about growing older and quite another to live it. The participant has normal worries about it.

When faced with a mobility transition, such as a need to cut back on driving, they are open to talking about the issues and exploring options. Remaining in control is important to them, so they are likely to respond to pressure from others with caution and even skepticism. This does not mean that they are inflexible or unreasonable. They know that age-related changes in health and function are likely, and so it is good to plan ahead. The participant simply wants to weigh their options and consider solutions that maximize their function and minimize any burden on others. The bottom line is that they want to maintain a good quality of life.

\section{Questions for Consideration \& Discussion}

- What aspects of aging may be the biggest challenge in the future? Are there negative outcomes that can be avoided?

- The ability to get from place to place is important. What aspects of mobility (type of transportation, valued destinations, activities) should be maintained for as long as possible?

- Does retirement from driving mean an end to living well? Is it possible to stop driving and also be able to still go to other places? How might this look?

\section{Total Mean Score of 1- 2.28 (24 - 55 points) / HIGH READINESS}

What does the participant's total score on the ARMT say about them?

Their score indicates that they are confident, adaptable and open to new experiences. They understand that aging is a process that requires gradual change over time. They have a "cup half full" outlook and appreciate what your life offers in the present, without worrying too much about past or future losses. This is not to say that they ignore the impact of aging. On the contrary, the participant recognizes that planning for the future is the best way to remain active, mobile and engaged in life. Aging does not frighten them so long as they can make decisions along the way.

When faced with a mobility transition, such as a need to cut back on driving, they prefer to face the issue head on and learn their options. They welcome opportunities to talk with people they trust, including family members and professionals, and they appreciate input. The participant is open to accepting help from others and does not view this as causing a burden. If driving the car won't work for them, then they will find other ways to get around. Their quality of 
life is not dependent on one form of mobility or another. They have a flexible view of independence.

\section{Questions for Consideration \& Discussion}

- What does positive mobility mean? How does the ability to travel, at will, from place to place, contribute to the quality of life?

- Thinking about aging, what aspects of mobility (types of transportation, valued destinations, activities) are important to preserve? What can be lived without?

- What mobility options make the most sense right now?

Driving Rating (by a loved one): Below is a website to input the participant's scores that will indicate which category they fall under. Choose the type of driver and recommendations accordingly.

\section{http://ftds.phhp.ufl.edu/questionnaire.php}

3 Main Groups and General \& Specific Recommendations:

Basic Driver (red square): (specific) We recommend the driver sees a doctor for a physical exam as soon as possible and not drive until he/she is able to undergo a comprehensive driving evaluation conducted by a Certified Driver Rehabilitation Specialist. Information on the use and access to alternative transportation (other than the personal automobile) may be available from the local Area Agency on Aging. (general) Based on guidelines of The American Geriatrics Society, we recommend an eye exam annually or earlier if there are changes in health or vision.

Routine Driver (yellow square): (specific) We recommend a doctor's appointment to start a conversation about conditions that may impact driving safety. The driver will also benefit from a comprehensive driving evaluation to address safety concerns. We recommend repeating this self-screening annually or when the driver experience changes in health or functional status. (general) The American Geriatrics Society recommends a physical and eye exam annually or earlier when needed. We recommend taking a class for mature drivers, such as those offered by AAA, AARP, or a local driving school.

Accomplished Driver (green square): (specific) It may be helpful to avoid or limit driving situations that are challenging. Based on your ratings, we do not think that a comprehensive driving evaluation is critical at this time. We recommend repeating this self-screening annually or when the driver experiences changes in health or functional status. (general) Additionally, The American Geriatrics Society recommends a physical and eye exam annually 
MOBILE AGING

earlier when needed. We recommend taking a class for mature drivers, such as those offered by AAA, AARP, or a local driving school. 
MOBILE AGING
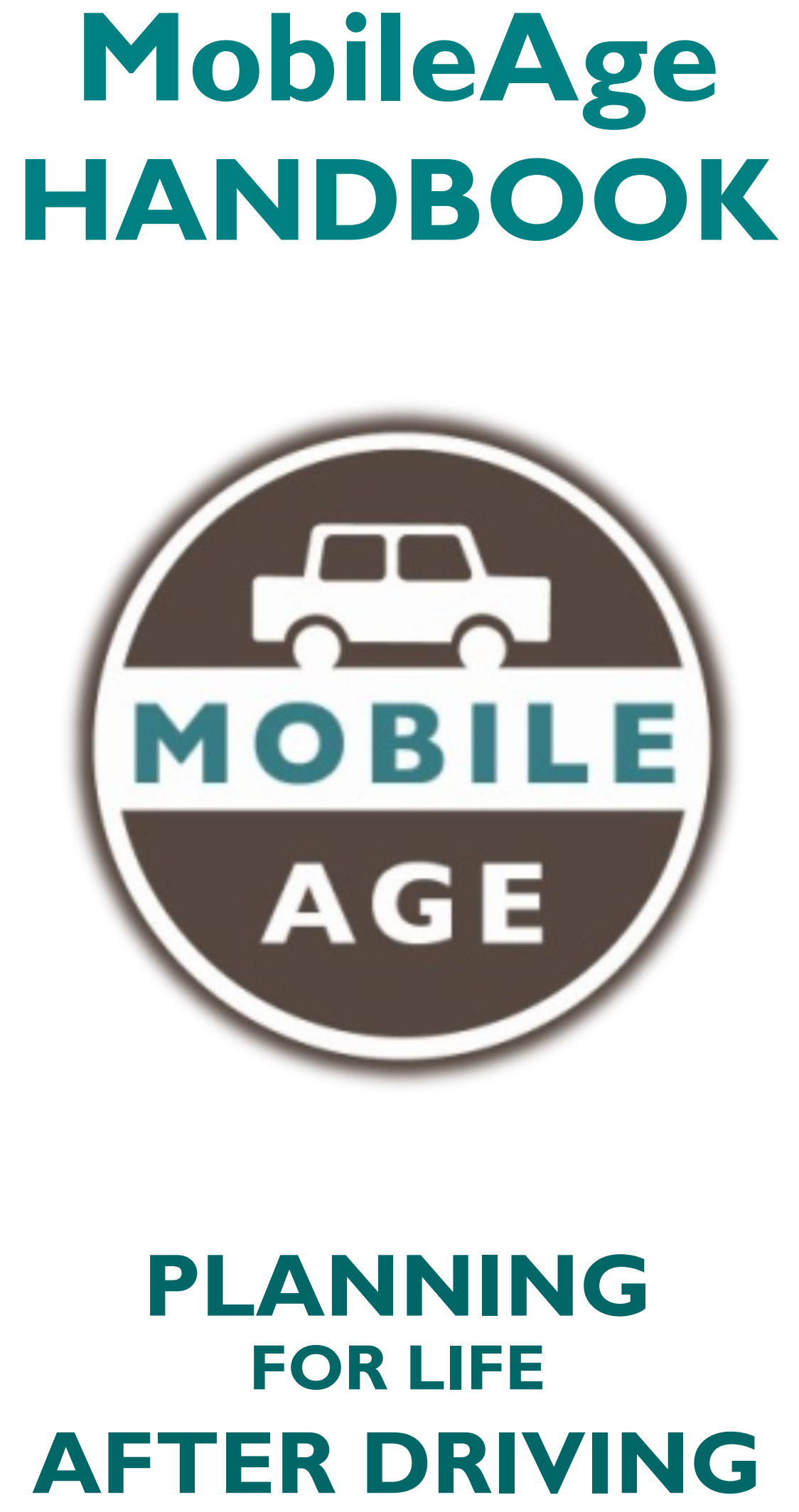


\section{INTRODUCTION}

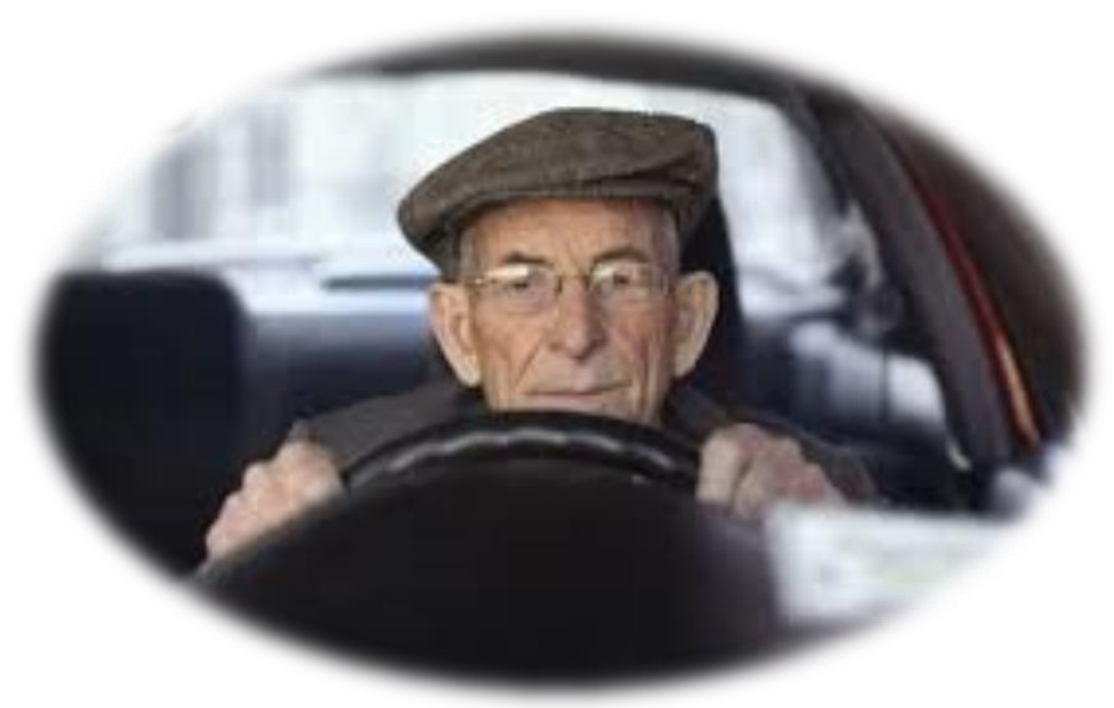

\section{Purpose}

- Show people they can stay mobile and engaged without a car

- Plan for the day when driving is no longer an option

"Mobility" in this handbook means, "The ability to get where you want to, when you need to." For the most part, this means using transportation in the community.

This handbook provides tools for having a "Mobility Transition Counseling" session with the client. The materials are a basic outline, and should be changed according to your needs or specific clients. 


\section{DRIVING \& AGING}

\section{Goal: Inform client about driving and aging}

While older drivers are among the safest drivers on the road, there are some issues to consider:

- As we get older, the risk of health problems increases. Health problems that impact vision, thinking/memory, or movement may impair driving and increase crash risk

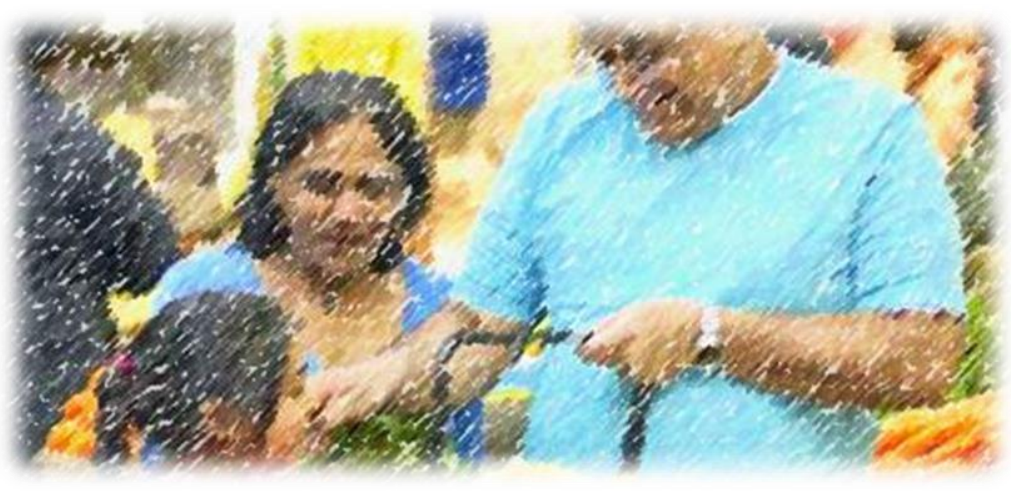

Those over 85 are more likely to die in a crash than any other group

Crashes involving older adults annually cost over $\$ 2$ billion in lifetime costs

But when older adults stop driving, studies show the following outcomes:

Decreased...

- Out-of-home activity

- Productivity

- Social engagement

and increased...

- Depression

- Mortality

- Institutionalization

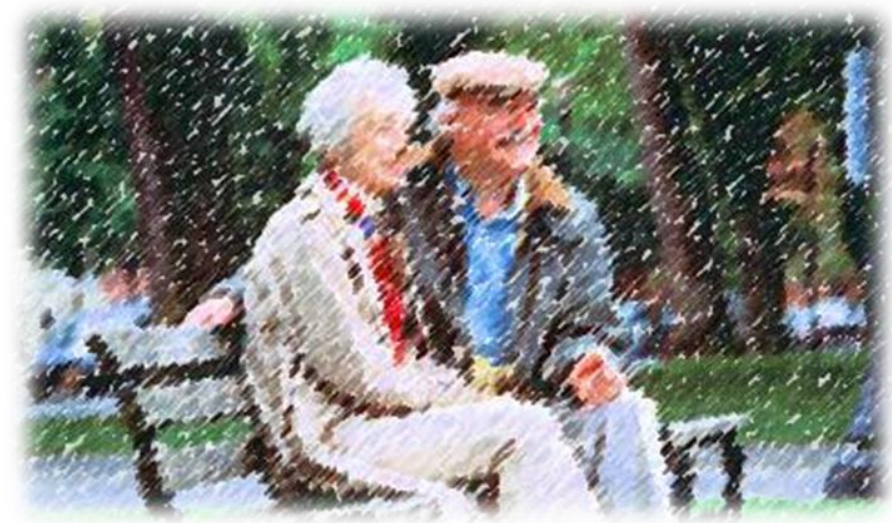

Making a plan for an organized transition may help avoid poor outcomes! 


\section{GOALS}

MobileAge has one primary goal: keeping people safely mobile for the entire life course.

- Your role is to help the person create a clear, thorough plan for the day when they need to stop driving.

\section{Meeting Timeline}

This is the semi-structured order of a Mobility Transition Counseling meeting. Meetings are usually 30-45 minutes long.

\section{Where Are You?}

\section{Making the Plan}

\section{Follow-Up}




\section{WHERE ARE YOU?}

\section{Goal: Understand the other person's needs}

Each person has different backgrounds, personal needs, and resources available to them. Learning a few of these things will help the session work smoothly.

\section{HELPFUL HINTS}

To begin, we suggest free tools available at:

www.mobileage.org

The online tools include a

measure of how ready a

person is for a transition,

and can also help with

discussion questions. If you

need more materials, call us!

(See last page.)

If they have questions about transitions (that is, moving from driving to an alternate/alternatives) and why they are important, share details from the Driving and Aging page. Let them know that a transition is not only possible, but can be beneficial. 


\section{MAKING PLANS}

Goal: Use the Worksheet to develop a personalized transition process

Basic Outline

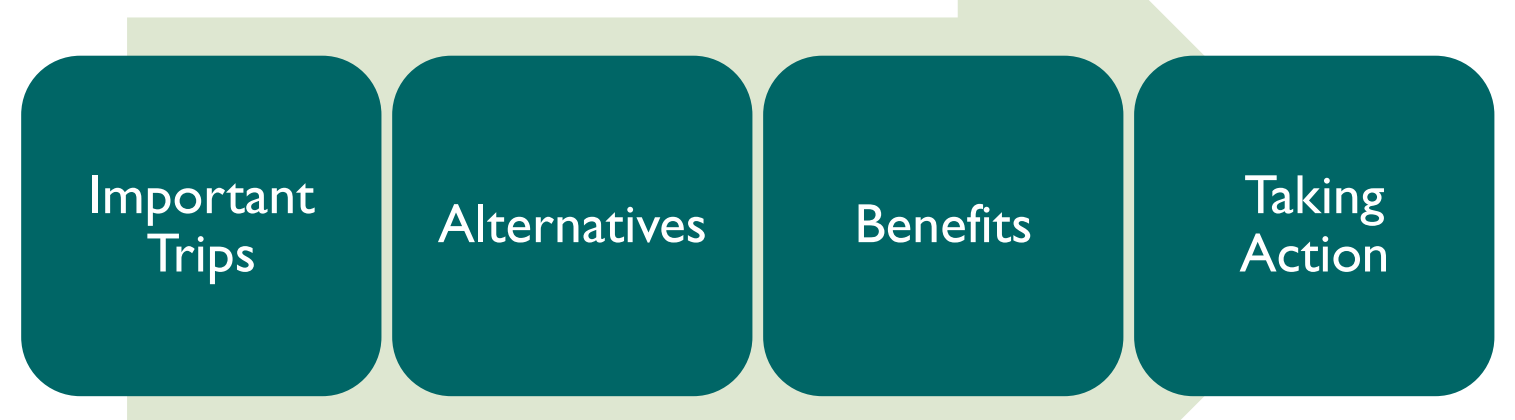

How to use the Worksheet

While each item on the Worksheet is important, individual items may be more or less important than others. Take a look at it before your meeting and see what is needed. FEEL FREE TO BE FLEXIBLE. Decide what is most helpful to the person you are working with! 


\section{IMPORTANT TRIPS}

\section{Goal: Decide which trips are the most important}

Now, for the worksheet: what are three driving trips that they do not want to give up? If they can discover which trips are the most important for them, it will be easier for them to find alternatives later.

\section{Examples}

- Therapy

- Entertainment

- Weekly bridge game

- Family visit

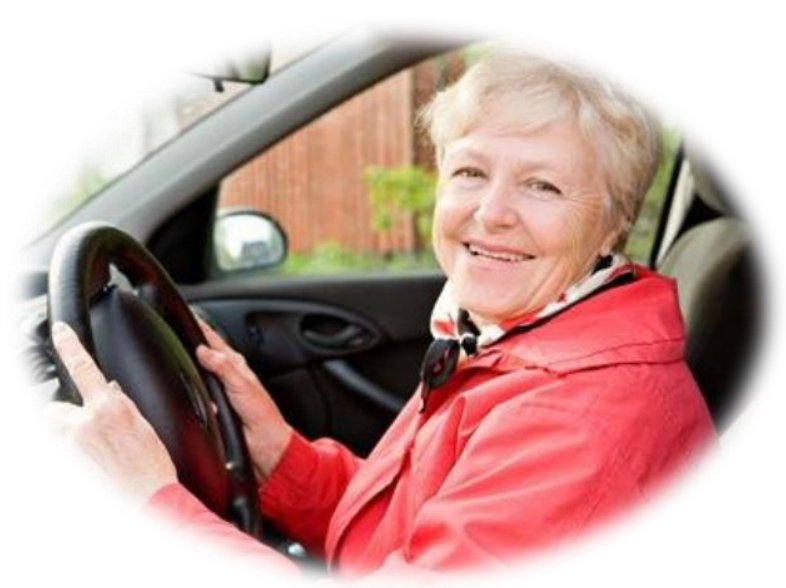

\section{HELPFUL HINTS}

- Ask them the question, "What makes a good day for you?"

- If they can come up with trips they want to take, then it will be easier to find alternatives to trips they need to take 


\section{ALTERNATIVES}

\section{Goal: Find out what other driving transportation options are available}

Occasionally, people already know about the transportation substitutes in their area. However, most are unaware of the options they have.

\section{Ways to Think of Alternatives}

- Be creative! Those in rural areas have to think beyond public transportation

- Find out which family members and friends live near them

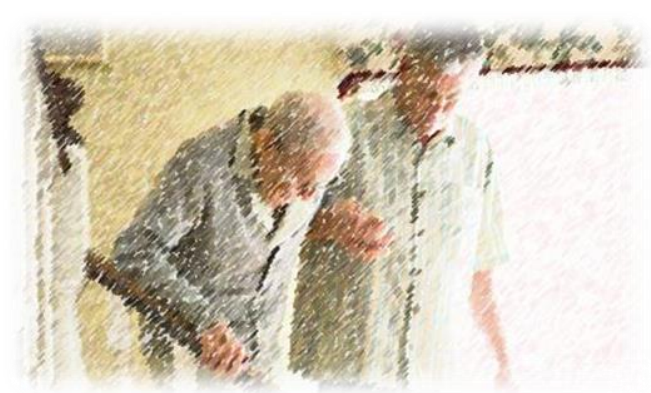

- What are the alternatives most readily available to them? Are public transit systems good options?

\section{LIVING SITUATION}

Sometimes, living situations make anything other than driving very difficult. A suggestion-even as a last resort-could be finding different housing that will support a healthier, safer lifestyle for getting around.

\section{Examples}

- "A co-worker who lives close by might be willing to give me a ride to work"

- "A senior van and the public bus run through my area. Maybe they go by the library?" 


\section{TRANSITION BENEFITS}

\section{Goal: Think of some positive outcomes to the transition}

Often, the hardest step in the process is coming up with positives to driving cessation. The person may view it as very difficult or sometimes impossible, but there are positives to almost any situation.

Help show them these positives! Some are provided, but help them to think of at least one new one, if they can.

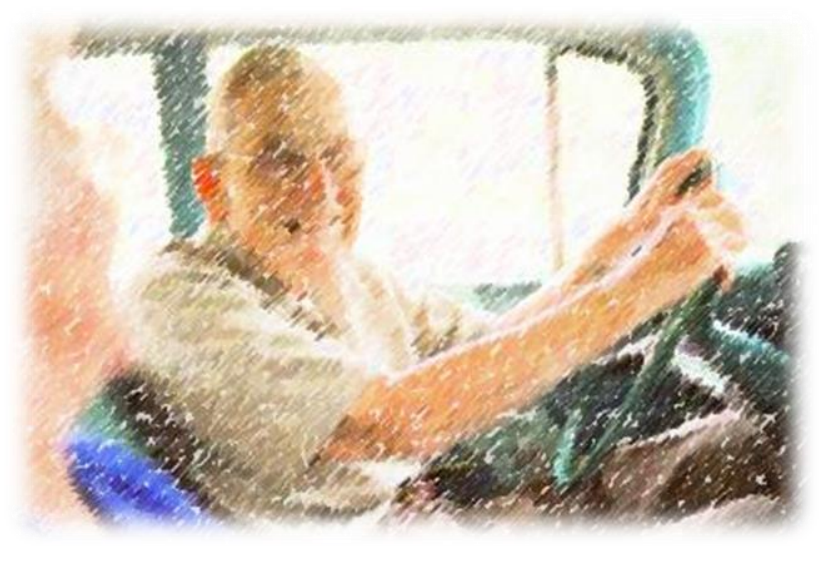

\section{$\underline{\text { Tips }}$}

- Help them to think of counters to their negative views

- If they are worried about being a burden, help them to realize people enjoy helping!

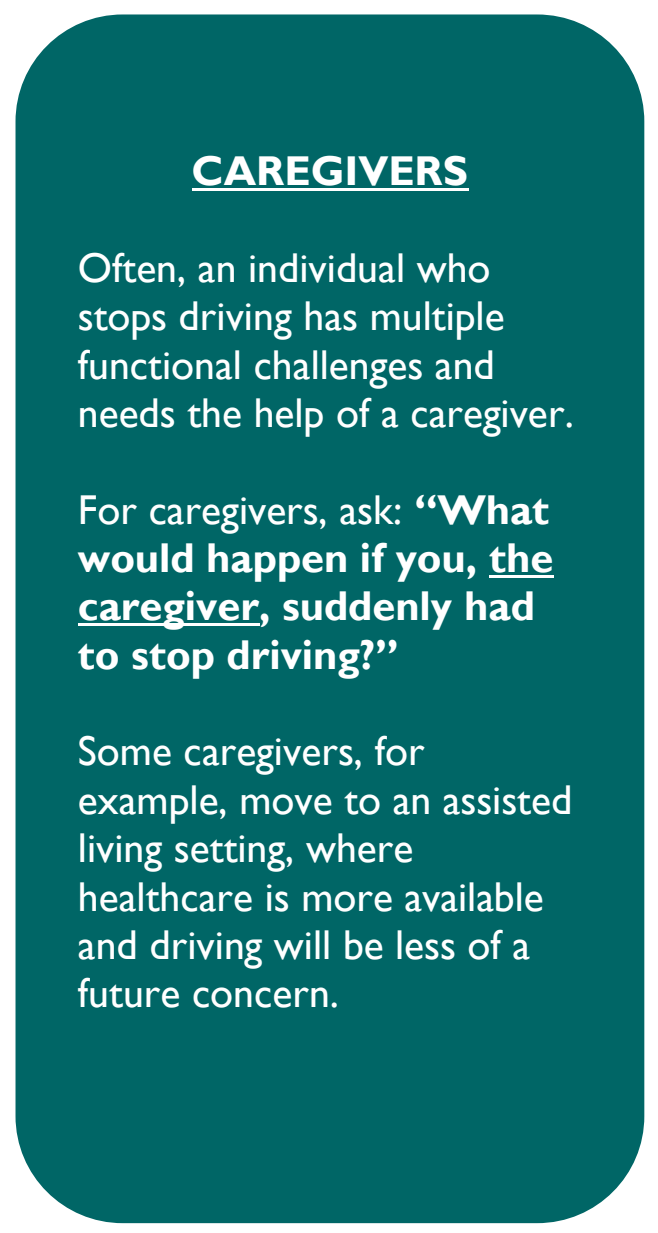




\section{TAKING ACTION}

\section{Goal: Create a concrete step toward a transition}

Now the person can start taking steps towards the change. Some common plans are provided in the Worksheet. The client should try to accomplish as many of them as they feel comfortable doing.

Encourage the client to come up with their own plan - one that is personal to them. The actions in the plan should be active, specific, and within a timeframe (i.e., within the next month).

Poor Action: "I could get a ride with a friend sometime"

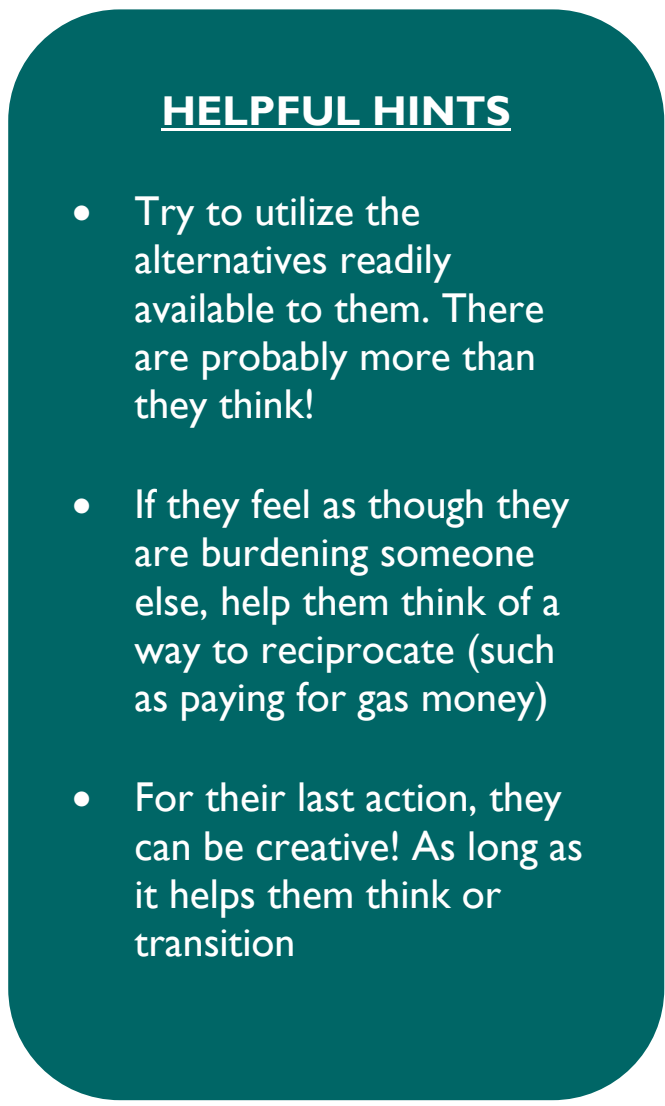

Good Action: "I could ride with my son Jeffrey twice this month to my doctor's appointment and pay him for gas"

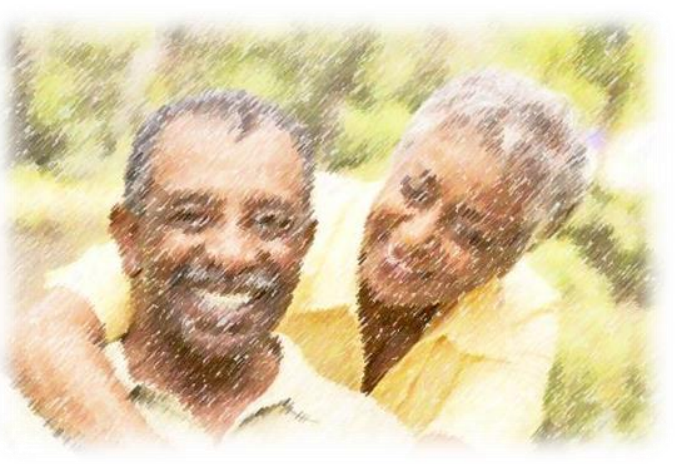




\section{FOLLOW-UP}

\section{Goal: Check in on planning progress}

This is an optional but beneficial step in the process. They've made the plan and gone through the worksheet, so here is a chance to see how far they've gotten!

\section{Things to Talk About}
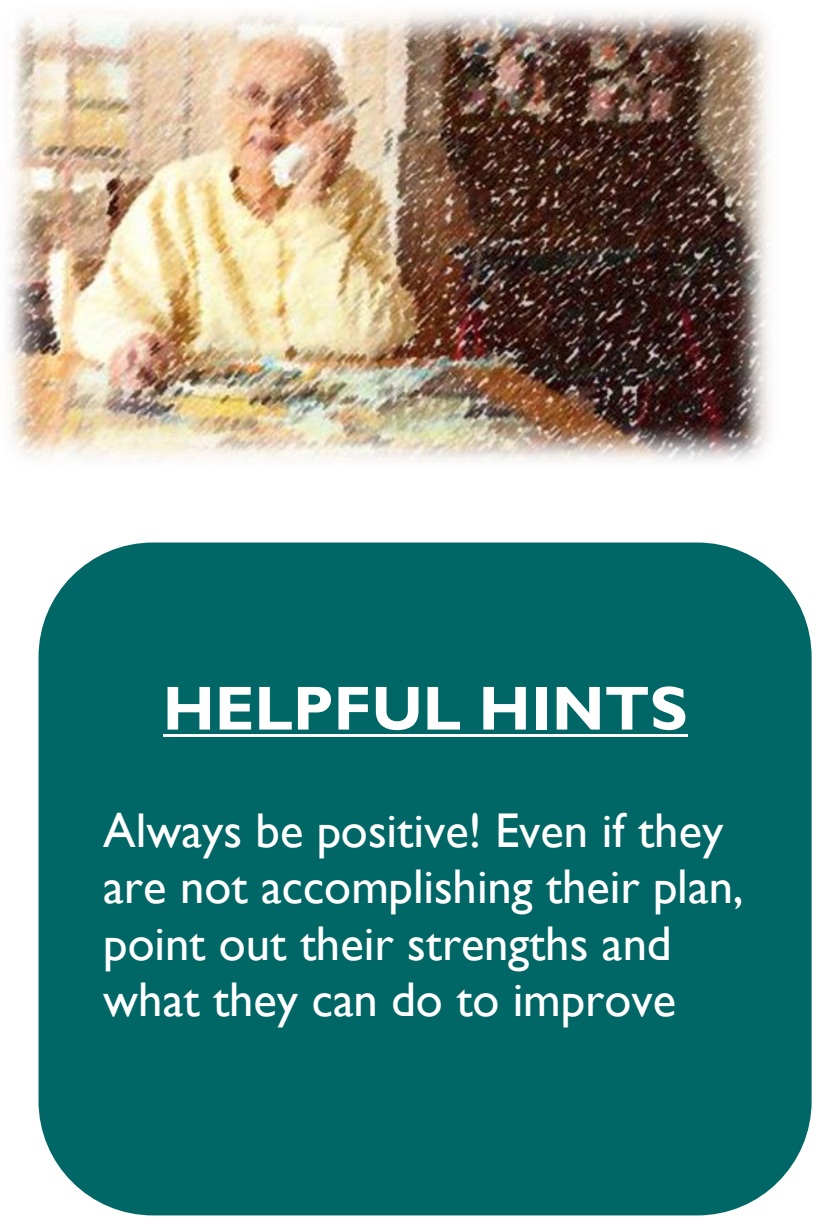

- How are their actions going?

- If they did not follow through with them, ask why. What needs to change so their planned actions become a reality?

- If they did follow through, can they do anything else?

- Are they having doubts, fears, or concerns about the process or the future?

- Do you need to meet again to help with planning? 


\section{TIPS}

\section{Here are some hints for a successful session!}

- It's a conversation with a direction

o It will be easy to just talk, but use the TAKING ACTION worksheet to guide the discussion (next page)

○ Keep the goals of the session in mind

- Each person is different

o What works for one person may not work for another

- Cognitive impairment may make appropriate planning difficult

- Think about the Caregiver in that situation and look to the Transition Benefits page for help

- Focus on the positives

o If a person has to give up driving, think of something new. Replace the loss with a gain.

- What is an activity or hobby they have always wanted to try or improve upon?

- Planning is beneficial

- Even if the person won't stop driving very soon, planning will make that day easier

- Rely on us!

o If you have a problem, let us know! We can work with you. (See last page) 


\section{TAKING ACTION}

Name

Date

Session

To maintain independence and continue doing the things you like to do, it helps to think about the future and driving.

On your own terms, how would you plan for changes in driving mobility?

For some people, these questions help them begin to think about transitions:

Health is the main reason that people have to stop driving. What are your concerns about your present/future health?

When do you believe you will need to stop driving?

If you were to make the decision to stop driving, what are some concerns you have?

Check each of the alternative transportation options you know are available:

$\square \quad$ Public (like the bus)

$\square$ Friend(s)

$\square$ Senior Van

$\square$ Family Member(s)

$\square \quad$ Religious Group

$\square$ Other

Information about alternative transportation is available in every community. For information, which of these groups would you to talk to?

$\square \quad$ Local service (like bus services)

$\square$ Area Agency on Aging

$\square$ Friend or family member

There are benefits to not driving, even if they are hard to see. In your opinion, what are some benefits?

appointments are usually important trips people make. What are some other trips that are very important to you?

I.

2.

3. $\square$ Financial - Less insurance cost

$\square$ Spending time with friends and family

$\square$ Time for other activities/hobbies

$\square$ Safety - for you and others

$\square$ Other 
MOBILE AGING

Whenever you decide to stop driving, it helps to take action now so your decision executes smoothly. Accomplish as many actions as you can within the next month.

$\checkmark$ Call an organization who has information about transportation

Talk to a respected friend about what it was like to stop driving

- What actions did they take?

- What would they have done differently?

Talk to family members and friends about the future

- People thinking about driving changes often do not want to be burdens to their friends or families. Talk to your loved ones about this: do they think it would be a burden? What can you do to make your decision less of a burden?

- Have a discussion with your loved ones about the future. What can they do? What can you do?

Ask a friend for a ride to an appointment or activity

○ Where would you go?

- Who would you go with?

- How many times this month could you go with them?

Now, come up with your own action that could help you make the transition

If you can't come up with any plans, why do you think that is? Who can help you take action?

Name the Person Who Can Help:

Occasionally, the place you live limits your ability to be independent. How does your living situation impact your ability to get where you want to, when you need to? 
MOBILE AGING

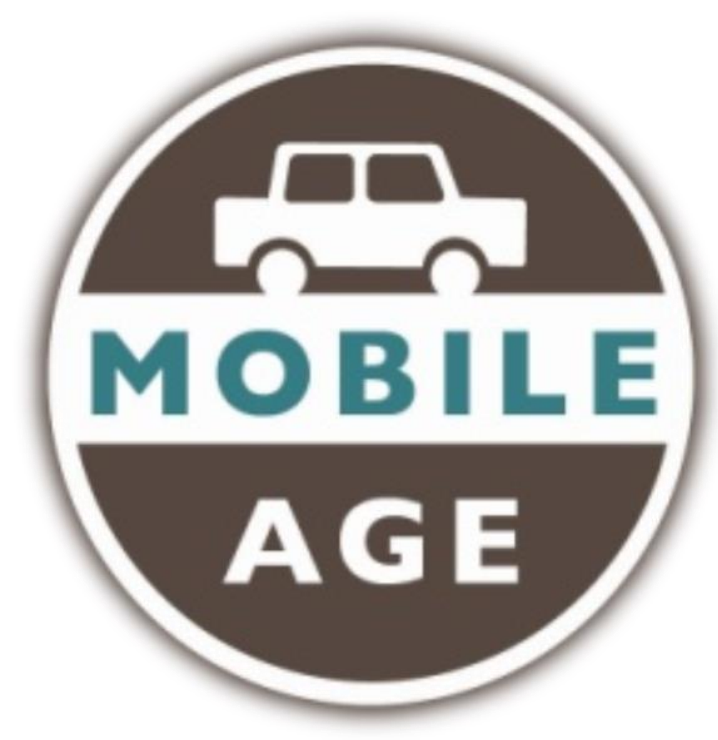

Thank you for participating in MobileAge!

If at any time you have questions, comments, or concerns please call or email:

James Stowe: (573)-884-638 I; stowejd@health.missouri.edu

\title{
University of Missouri Hospital \\ One Hospital Drive, 207 McHaney Hall DC024.00 \\ Columbia, MO 65212
}

\author{
An initiative of the Frank L. Mitchell Jr., MD Trauma Center, with support from: \\ State Farm \\ EAST Foundation \\ Missouri Department of Transportation
}




\section{Appendix B}

Enrollment questionnaire.

1. What is your gender?

(1) Male

(2) Female

2. What is your age?

Age (in years)

3. What is your zip code?

Zip code

4. Do you live alone?
(1) Yes
(0) No

5. What is your current marital status?
(1) Single - never married
(2) Married
(3) Separated
(4) Divorced
(5) Widowed
(6) Rather not say

6. What is your occupation? (specific occupation and not just an employer's name.)

If retired, what did you do for a living before you retired?

If you did not work outside the home and you are widowed, married, or separated, what did/does your spouse do for a living?

7. What is the highest level of education you have completed?
(1) Less than High School
(2) High School/GED
(3) Vocational/Technical School (2 year)
(4) Some College
(5) 2-Year College Degree (Associates)
(6) 4-Year College Degree (BA, BS)
(7) Master's Degree
(8) Doctoral Degree
(9) Professional Degree (MD, JD, etc.)
(10) Other - Please

print 
8. Are you of Hispanic, Latino, or Spanish origin?
(0) No, not of Hispanic Latino, or Spanish origin
(1) Yes, Mexican, Mexican American, Chicano
(2) Yes, Puerto Rican
(3) Yes, Cuban
(4) Yes, another Hispanic, Latino, or Spanish Origin

9. What is your race? (Mark all that apply).
(1) White
(2) Black, African American, or Negro
(3) American Indian or Alaska Native
(4) Asian
(5) Native Hawaiian/Pacific Islander
(6) Some other race- Print race:

10. Overall, how satisfied are you with your mobility (your ability to get where you want to, when you need to)?

$\square(1)$ Very unsatisfied

(2) Somewhat unsatisfied

(3) Neither satisfied nor dissatisfied

(4) Somewhat satisfied

(5) Very satisfied

11. (Item removed)

12. Has a doctor ever told you that you have cataracts?

Yes (if yes, proceed to question 13)

No (if no, proceed to question 14)

13. Have you had corrective surgery for cataracts?

$\square$ Yes

14. Has a doctor ever told you that you have either Glaucoma or Macular

Degeneration?

$\square$ Yes (if yes, proceed to question 15)

$\square$ No (if no, proceed to question 16)

15. When were you diagnosed with either Glaucoma or Macular Degeneration?
Within the past month
Within the past 6 months
Within the past year
More than 1 year ago

16. Has a doctor ever told you that you have Parkinson's disease? 
Yes (if yes, proceed to question 17)

No (if no, proceed to question 18)

17. Are you currently taking medication to control your Parkinson's disease?

$\square$ Yes

18. Has a doctor ever told you that you have severe arthritis?

$\square$ Yes (if yes, proceed to question 19)

$\square$ No (if no, proceed to question 20)

19. Have you had adjustments or modifications made to your car because of arthritis (such as a steering wheel handgrip, etc.)?

$\square$ Yes

20. Has a doctor ever told you that you have had a Stroke or Cerebrovascular accident (CVA)?

$\square$ Yes (if yes, proceed to question 21)

$\square$ No (if no, proceed to question 23)

21. When did you first experience a Stroke or Cerebrovascular accident?
Within the past month
Within the past 6 months
Within the past year
More than 1 year ago

22. Before resuming driving after your Stroke or Cerebrovascular accident, did your doctor conduct a formal screening?
$\square$ Yes
No

23. Has a doctor ever told you that you have Sleep Apnea?

Yes (if yes, proceed to question 24)

No (if no, proceed to question 25)

24. Have you been treated by your doctor for Sleep Apnea?

$\square$ Yes

25. Has a doctor ever told you that you have any form of Dementia?

$\square$ Yes (if yes, proceed to question 26)

$\square$ No (if no, proceed to question 27)

26. When were you diagnosed with Dementia?

Within the past month

Within the past 6 months 


\section{Within the past year}

More than 1 year ago

27. Has a doctor ever told you that you have either type of Diabetes?

$\square$ Yes (if yes, proceed to question 28)

No (if no, proceed to question 29)

28. When were you diagnosed with diabetes?
Within the past month
Within the past 6 months
Within the past year
More than 1 year ago

29. Has a doctor ever told you that you have any other medical condition that may impair your driving?

$\square$ Yes

If yes, what was/were the condition(s)?

$\square$ No

30. What type of mobility challenges (e.g., walking) do you currently have? - or expect to encounter as you age?

31. What type of driving challenges do you currently have? -or expect to encounter as you age?

32. If you drive a car, what type of car is it?

$$
\text { Year }
$$

Make (e.g., Toyota) Model (e.g., Camry)

33. During the PAST MONTH, that is, since $\{1$-month ref. date $\}$, ABOUT how many days did illness or injury keep you in bed more than half of the day (include days while an overnight patient in a hospital)?

34. During the PAST SIX MONTHS, that is, since $\{6-$ month ref. date $\}$, ABOUT how many days did illness or injury keep you in bed more than half of the day (include days while an overnight patient in a hospital)? 
MOBILE AGING

35. How would you rate your overall health at the present time?

(4) $\square$ Excellent (3) $\square$ Good (2) $\square$ Fair (1) $\square$ Poor

36. How is your health compared to what it was like five years ago?

(3) $\square$ Better (2) $\square$ About the Same (1) $\square$ Worse

37. How much do your health troubles stand in the way of doing the things you want to do?

(3) $\square$ Not at all (2) $\square$ A little or some (1) $\square$ A great deal 
Appendix C

Carr's Measure (Carr et al., 2011): Includes 3 measures.

\section{Clock Drawing Task (CDT)}

Participant Instructions: "Subjects are verbally instructed to draw a clock, put all the numbers in, and set the time at 10 minutes after 11 . This time is reported to be the most sensitive for detecting neurocognitive dysfunction. The instruction is also written at the top of the page in 16-point font. Instructions may be repeated verbatim as needed. No cues are allowed. Self-correction is permitted" (Freund et al., 2005, p. 240).

\section{Scoring}

Table 1. Freund CDT Scoring Scale

\begin{tabular}{cl}
\hline \hline Time & One hand points 2 (or symbol representative of 2) \\
(3 points) & Exactly two hands \\
& Absence of intrusive marks, e.g., writing or \\
& hands indicating incorrect time, hand points \\
& to number $10 ;$ tic marks, time written in text \\
& $(11: 10 ;$ ten after eleven) \\
& Numbers are inside the clock circle \\
& All numbers $1-12$ are present, no duplicates \\
Numbers & or omissions \\
(2 points) & Numbers spaced equally or nearly equally \\
from each other & Numbers spaced equally or nearly equally from \\
(2 points) & the edge of the circle \\
\hline
\end{tabular}

\section{Trail Making Test Part A}

Participant Instructions: Participant should draw lines to connect the numbers in ascending order. The participant should be instructed to connect the circles as quickly as possible, without lifting the pen or pencil from the paper. Time the participant as he or she connects the "trail." If the participant makes an error, point it out immediately and allow the participant to correct it. Errors affect the participant's score only in that the correction of errors is included in the completion time for the task. It is unnecessary to continue the test if the participant has not completed after five minutes have elapsed. 
MOBILE AGING

\section{Trail Making Test Part A}

Patient's Name:

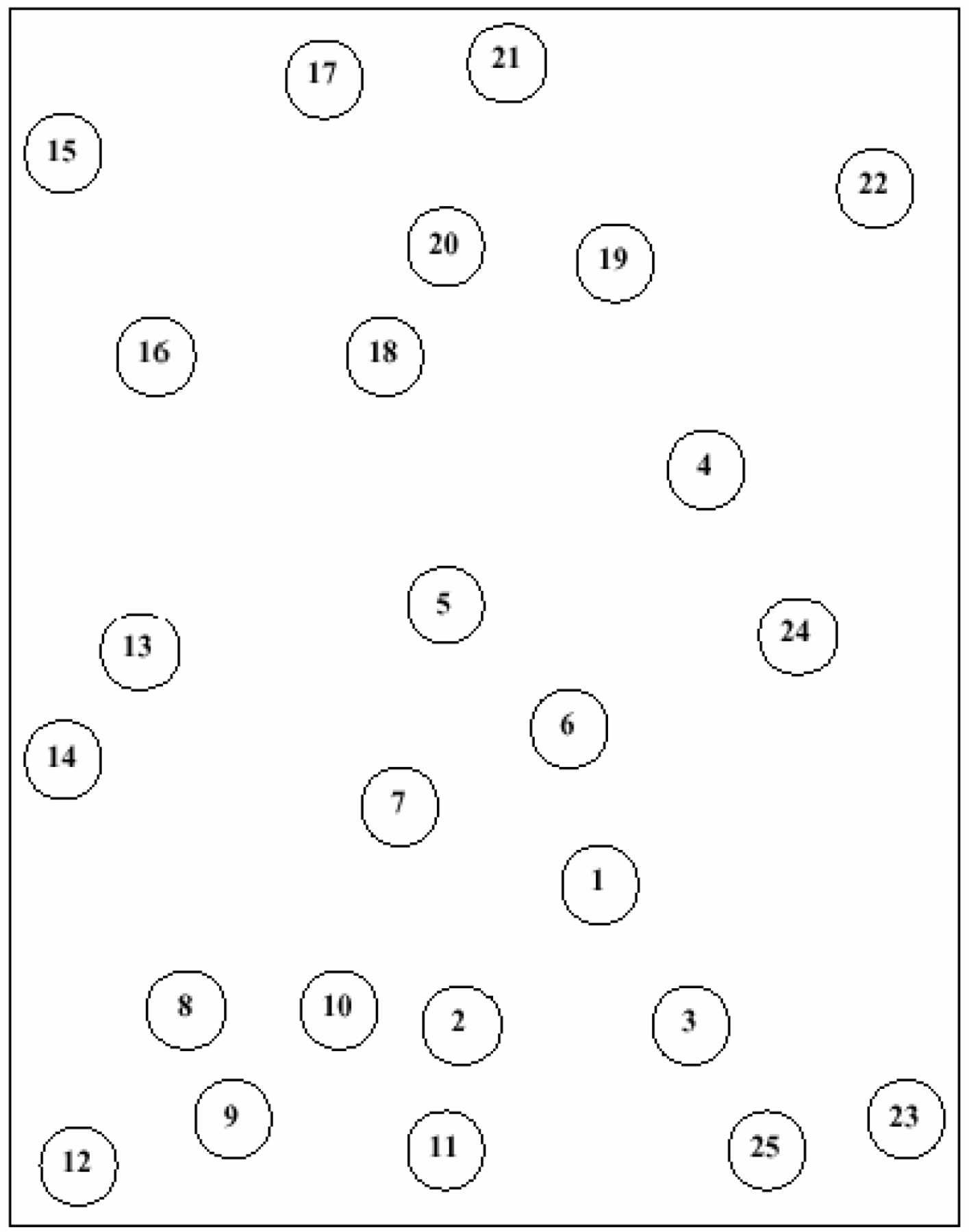


AD8 Dementia Screening Interview (Galvin et al., 2005).

\begin{tabular}{|l|l|l|l|}
\hline $\begin{array}{l}\text { Remember, 'Yes, a change' indicates that there } \\
\text { has been a change in the last several years } \\
\text { caused by cognitive (thinking and memory) } \\
\text { problems }\end{array}$ & $\begin{array}{l}\text { Yes, A } \\
\text { change }\end{array}$ & $\begin{array}{l}\text { No, No } \\
\text { Change }\end{array}$ & $\begin{array}{l}\text { N/A, } \\
\text { Don't } \\
\text { Know }\end{array}$ \\
\hline $\begin{array}{l}\text { 1. Problems with judgment (e.g., problems making } \\
\text { decisions, bad financial decisions, problems with } \\
\text { thinking) }\end{array}$ & & & \\
\hline $\begin{array}{l}\text { 2. Less interest in hobbies/activities } \\
\text { 3. Repeats the same things over and over } \\
\text { (questions, stories, or statements) }\end{array}$ & & & \\
\hline $\begin{array}{l}\text { 4. Trouble learning how to use a tool, appliance, } \\
\text { gadget (e.g., VCR, computer, microwave, remote } \\
\text { control) }\end{array}$ & & & \\
\hline 5. Forgets the correct month or year & & & \\
\hline $\begin{array}{l}\text { 6. Trouble handling complicated financial affairs } \\
\text { (e.g., balancing checkbook, income taxes, paying } \\
\text { bills) }\end{array}$ & & & \\
\hline 7. Trouble remembering appointments & & & \\
\hline $\begin{array}{l}\text { TOTAL AD8 SCORE } \\
\text { Paily problems with thinking and/or memory }\end{array}$ & & & \\
\hline
\end{tabular}




\section{The AD8 Administration and Scoring Guidelines}

A spontaneous self-correction is allowed for all responses without counting as an error.

The questions are given to the respondent on a clipboard for self-administration or can be read aloud to the respondent either in person or over the phone. It is preferable to administer the AD8 to an informant, if available. If an informant is not available, the AD8 may be administered to the patient.

When administered to an informant, specifically ask the respondent to rate change in the patient.

When administered to the patient, specifically ask the patient to rate changes in his/her ability for each of the items, without attributing causality.

If read aloud to the respondent, it is important for the clinician to carefully read the phrase as worded and give emphasis to note changes due to cognitive problems (not physical problems). There should be a one second delay between individual items.

No timeframe for change is required.

The final score is a sum of the number items marked "Yes, A change".

Interpretation of the AD8 (Adapted from Galvin JE et al, The AD8, a brief informant interview to detect dementia, Neurology 2005:65:559-564)

A screening test in itself is insufficient to diagnose a dementing disorder. The AD8 is, however, quite sensitive to detecting early cognitive changes associated many common dementing illness including Alzheimer disease, vascular dementia, Lewy body dementia and frontotemporal dementia.

Scores in the impaired range (see below) indicate a need for further assessment. Scores in the "normal" range suggest that a dementing disorder is unlikely, but a very early disease process cannot be ruled out. More advanced assessment may be warranted in cases where other objective evidence of impairment exists.

Based on clinical research findings from 995 individuals included in the development and validation samples, the following cut points are provided:

- $0-1$ : Normal cognition

- 2 or greater: Cognitive impairment is likely to be present

Administered to either the informant (preferable) or the patient, the AD8 has the following properties:

- Sensitivity $>84 \%$

- Specificity $>80 \%$

- Positive Predictive Value $>85 \%$

- Negative Predictive Value $>70 \%$

- Area under the Curve: $0.908 ; 95 \% \mathrm{Cl}: 0.888$ 0.925

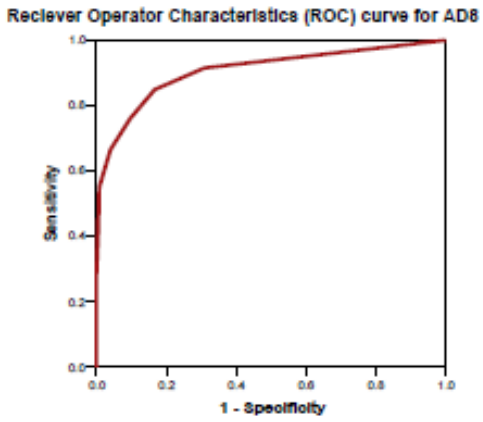

Adapted from Galvin JE et al, The AD8, a brief informant interview to detect dementia, Neurology 2005:65:559-564 Copyright 2005. The AD8 is a copyrighted instrument of the Alzheimer's Disease Research Center, Washington University, St. Louis, Missouri. All Rights Reserved. 
MOBILE AGING

Appendix D

Driving Habits Questionnaire (DHQ).

Owsley et al. (1999). Please note that some items on the DHQ are altered for contextual relevance (e.g.,

"Alabama" was changed to "Missouri" in item 33).

Interviewer: "Now l'm going to ask you some questions about driving."

Current Driving

1. Do you currently drive?

$\square$ (1) yes (go to question \#4) $\square$ (0) no (go to question \#2 and \#3 only)

2. Why did you stop driving?

(Wait for the subject's spontaneous reply; write it in space below.)

3. When is the last time you drove? (month/year)

(If within 1 year, go to question \#10)

4. Do you wear a seatbelt when you drive? Would you say: *

$\square$ (1) Always $\square$ (2) Sometimes $\square$ (3) Never

5. Which way do you prefer to get around? *

$\square$ (3) Drive yourself $\square$ (2) Have someone drive you

$\square$ (1) Use public transportation or a taxi

6. How fast do you usually drive compared to the general flow of traffic? Would you say: *

$\square$ (5) Much faster $\square$ (4) Somewhat faster $\square$ (3) About the same

(2) Somewhat slower $\square$ (1) Much slower

7. Has anyone suggested over the past year that you limit your driving or stop driving?

$\square$ (1) Yes $\square$ (0) No

8. How would you rate the quality of your driving? Would you say: *
(5) Excellent
(4) Good
(3) Average
(2) Fair

(1) Poor

9. If you had to go somewhere and didn't want to drive yourself, what would you do?

Would you: *

a. $\square$ (1) Ask a friend or relative to drive you

b. $\square$ (2) Call a taxi or take the bus

c. $\square$ (3) Drive yourself regardless of how you feel

d. $\square$ (4) Cancel or postpone your plans and stay home

e. $\square$ (5) Other (specify): 


\section{Crashes and Citations}

10. How many accidents have you been involved in over the past year when you were the driver? Please tell me the number of all accidents, whether or not you were at fault. accidents

11. How many accidents have you been involved in over the past year when you were the driver where the police were called to the scene? accidents

12. How many times in the past year have you been pulled over by the police, regardless of whether you received a ticket? times

13. How many times in the past year have you received a traffic ticket (other than a parking ticket) where you were found to be guilty, regardless of whether or not you think you were at fault? times

\section{Driving Space}

14. During the past year, have you driven in your immediate neighborhood?
(1) $\square$ yes
(0) $\square$ no

15. During the past year, have you driven to places beyond your neighborhood?
(1) $\square$ yes
(0) $\square$ no

16. During the past year, have you driven to neighboring towns?
(1) $\square$ yes
(0) $\square$ no

17. During the past year, have you driven to more distant towns?
(1) $\square$ yes
(0) $\square$ no

18. During the past year, have you driven to places outside the state of Missouri?
(1) $\square$ yes
(0) $\square$ no

19. During the past year, have you driven to places outside the mid-west region?

(1) $\square$ yes

(0) $\square$ no 


\section{Appendix E}

Older Americans Resources and Services - Subjective Health Status Items (Fillenbaum, 1982; 1988)

1. How would you rate your overall health at the present time?

(3) $\square$ Excellent (2) $\square$ Good (1) $\square$ Fair (0) $\square$ Poor

2. How is your health compared to what it was like five years ago?

(2) $\square$ Better (1) $\square$ About the Same (0) $\square$ Worse

3. How much do your health troubles stand in the way of doing the things you want to do?

(2) $\square$ Not at all (1) $\square$ A little or some (0) $\square$ A great deal 


\section{Appendix F}

Self-reported bed days due to illness or injury.

Item asked at Baseline and T3 measurement periods:

During the PAST SIX MONTHS, that is, since \{6-month ref. date $\}$, ABOUT how many days did illness or injury keep you in bed more than half of the day (include days while an overnight patient in a hospital)?

Item asked at T2 measurement period:

During the PAST MONTH, that is, since $\{1$-month ref. date $\}$, ABOUT how many days did illness or injury keep you in bed more than half of the day (include days while an overnight patient in a hospital)? 


\section{Appendix G}

\section{Manchester Driving Behavior Questionnaire (DBQ).}

\section{Manchester Driving Behavior Questionnaire (DBQ) HOW OFTEN DO YOU DO EACH OF THE FOLLOWING? \\ No one is perfect. Even the best drivers make mistakes, do foolish things, or bend the rules at some time or another. Some of these behaviors are trivial, but some are potentially dangerous. For each item below you are asked to indicate HOW OFTEN, if at all, this kind of thing has happened to you. Base your judgments on what you remember of your driving over, say, the last year. Please indicate your judgments by checking ONE of the columns in the grid next to each item. These columns are headed by numbers between 0 and 5 . These mean the following: $\mathbf{0}=$ Never $\mathbf{1}=$ Hardly Ever $\mathbf{2}=$ Occasionally $3=$ Quite Often $4=$ Frequently $5=$ Nearly All The Time}

\section{**Use answer cards for every question**}

1. Attempt to overtake someone that you hadn't noticed to be signaling a left turn

2. Stay in a lane that you know will be closed ahead until the last minute before forcing your way into another lane

3. Miss 'Stop' or 'Yield' signs and narrowly avoid colliding with traffic having right of way

4. Pull out of an intersection so far that the driver with right of way has to stop and let you out

5. Fail to notice that pedestrians are crossing when turning into a side street from a main road

6. Drive especially close to the car in front as a signal to its driver to go faster or get out of the way

7. Sound your horn to indicate your annoyance to another driver

8. While waiting to turn left onto a main road, you pay such close attention to the mainstream of traffic that you nearly hit the car in front

9. Cross an intersection knowing that the traffic lights have already turned against you

10. On turning right nearly hit a cyclist who has come up on your inside

11. Disregard the speed limit on a highway

12. Fail to check your rear-view mirror before pulling out, changing lanes, etc.

13. Become angered by a certain type of driver and indicate your hostility by whatever means you can

14. Become impatient with a slow driver in an outer lane and pass on the right

15. Underestimate the speed of an oncoming vehicle when passing

16. Race away from the traffic lights with the intention of beating the driver next to you

17. Brake too quickly on a slippery road, or steer the wrong way in a skid

18. Drive even though you suspect you may be over the legal blood-

alcohol limit

19. Disregard the speed limit on a residential road

20. Become angered by another driver and give chase with the intention of giving him/her a piece of your mind 


\section{Appendix $\mathrm{H}$}

Fitness-to-Drive Screening Measure (FTDS; Classen, 2012).

Read prior to beginning: "Please base your answers to the following questions off of observations of __Participant's Name_driving during the past four months. If you haven't observed___ Participant's Name___ driving during the past four months, please use your best judgment to rate the difficulty the driver would have."

\section{0 = Not difficult; 1 = A little Difficult; 2 = Somewhat Difficult; 3 = Very Difficult}

\begin{tabular}{|c|c|c|c|}
\hline \multirow{2}{*}{ 1. Stay in the proper lane? } & 0 & 2 & 3 \\
\hline & & & \\
\hline $\begin{array}{l}\text { 2. Check for a clear path when backing out from a driveway or } \\
\text { parking space? }\end{array}$ & & & \\
\hline $\begin{array}{l}\text { 3. Use the car controls (such as the turn signals, emergency } \\
\text { brake, windshield wipers, or headlights)? }\end{array}$ & & & \\
\hline 4. Check car mirrors when changing lanes? & & & \\
\hline $\begin{array}{l}\text { 5. Read road signs far enough in advance to react (such as } \\
\text { make a turn)? }\end{array}$ & & & \\
\hline $\begin{array}{l}\text { 6. Obey varied forms of traffic lights (such as green arrow for } \\
\text { turn lane or flashing lights)? }\end{array}$ & & & \\
\hline $\begin{array}{l}\text { 7. Drive and hold a conversation with one or more } \\
\text { passengers? }\end{array}$ & & & \\
\hline $\begin{array}{l}\text { 8. Drive with a passenger who is providing driving directions } \\
\text { or assistance? }\end{array}$ & & & \\
\hline 9. Drive in light rain? & & & \\
\hline $\begin{array}{l}\text { 10. Drive on a highway with two or more lanes in each } \\
\text { direction? }\end{array}$ & & & \\
\hline 11. Keep up with the flow of traffic? & & & \\
\hline 12. Keep distance from other vehicles when changing lanes? & & & \\
\hline 13. Change lanes in moderate traffic? & & & \\
\hline $\begin{array}{l}\text { 14. Drive cautiously (to avoid collisions) in situations when } \\
\text { others are driving erratically (such as speeding, road rage, } \\
\text { crossing lane lines or driving distracted)? }\end{array}$ & & & \\
\hline $\begin{array}{l}\text { 15. Brake at a stop sign so car stops completely before the } \\
\text { marked line? }\end{array}$ & & & \\
\hline
\end{tabular}


16. Maintain lane when turning (not cut corner or go wide)?

17. Back out of parking spot?

18. Enter the flow of traffic when turning right?

19. Share the road with vulnerable road users such as bicyclists, scooter drivers, motorcyclists?

20 . Drive on graded (unpaved) road?

21. Check blind spots before changing lanes?

22. Drive with surrounding tractor trailers (transport trucks)?

23. Merge onto a highway?

24. Use a paper map while driving?

25. Make a left hand turn crossing multiple lanes and entering traffic (with no lights of stop signs)?

26. Parallel Park?

27. Stay within the lane markings unless making a lane change?

28. Stay within proper lane in the absence of road features such as clearly marked lane lines, reflectors or rumble strips?

29. Keep distance between his or her car and others (allow time to react to hazards)?

30. Look left and right before crossing an intersection?

31. Drive in a construction zone?

32. Drive in dense traffic (such as rush hour)?

33. Pass (overtake) a car in the absence of a passing lane?

34. Pass (overtake) a larger vehicle such as a RV, tractortrailer (transport truck), or dump truck in the absence of a passing lane?

35. Drive in an unfamiliar urban area?

36. Control his or her car when going down a steep hill?

37. Exit an expressway, or inter-state from a left-hand lane?

38. Drive in a highly complex situation (such as a large city with high-speed traffic, multiple highway interchanges and several signs)? 


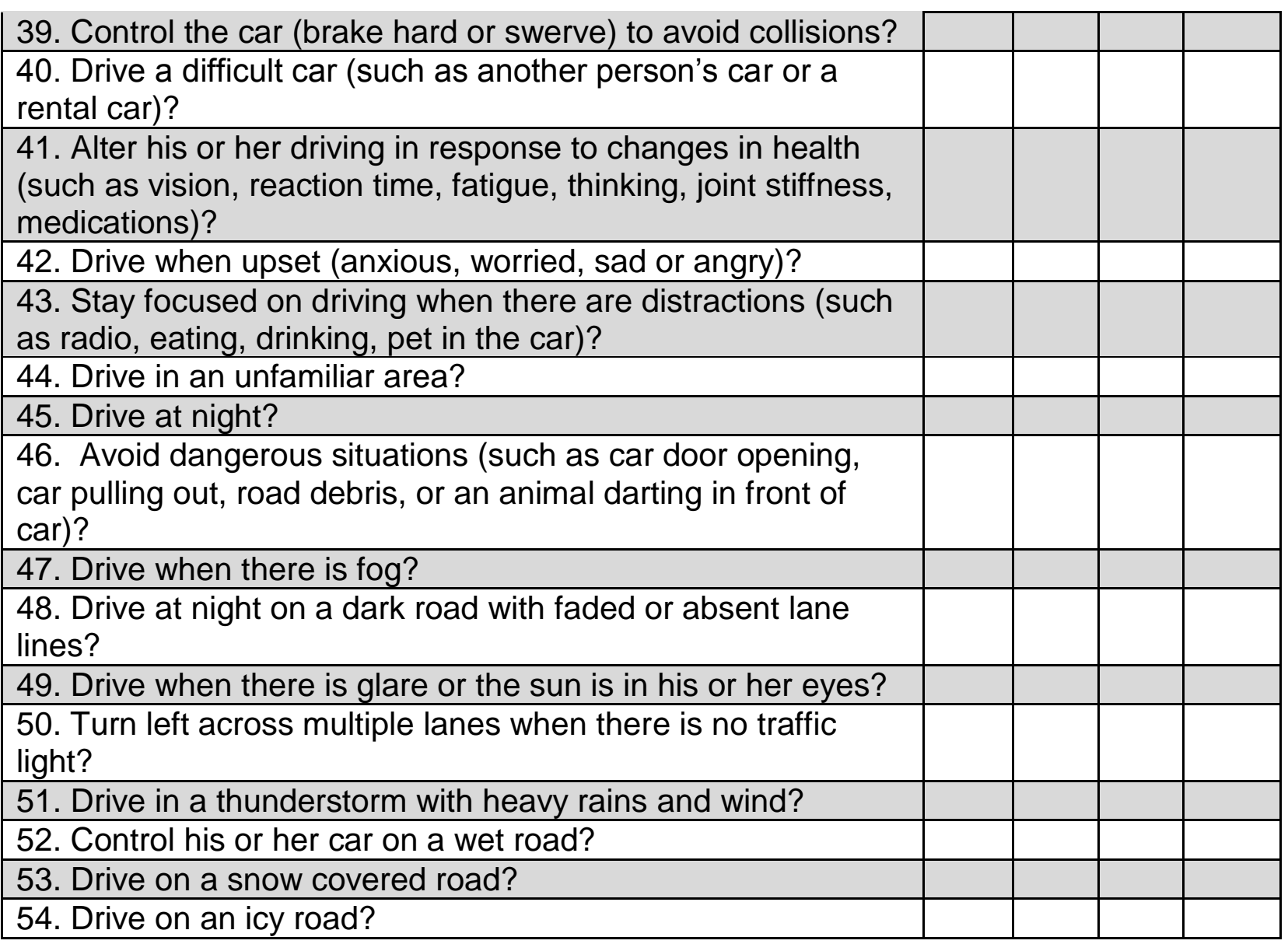


MOBILE AGING

\section{Appendix I}

Assessment of Readiness for Mobility Transition (ARMT). 

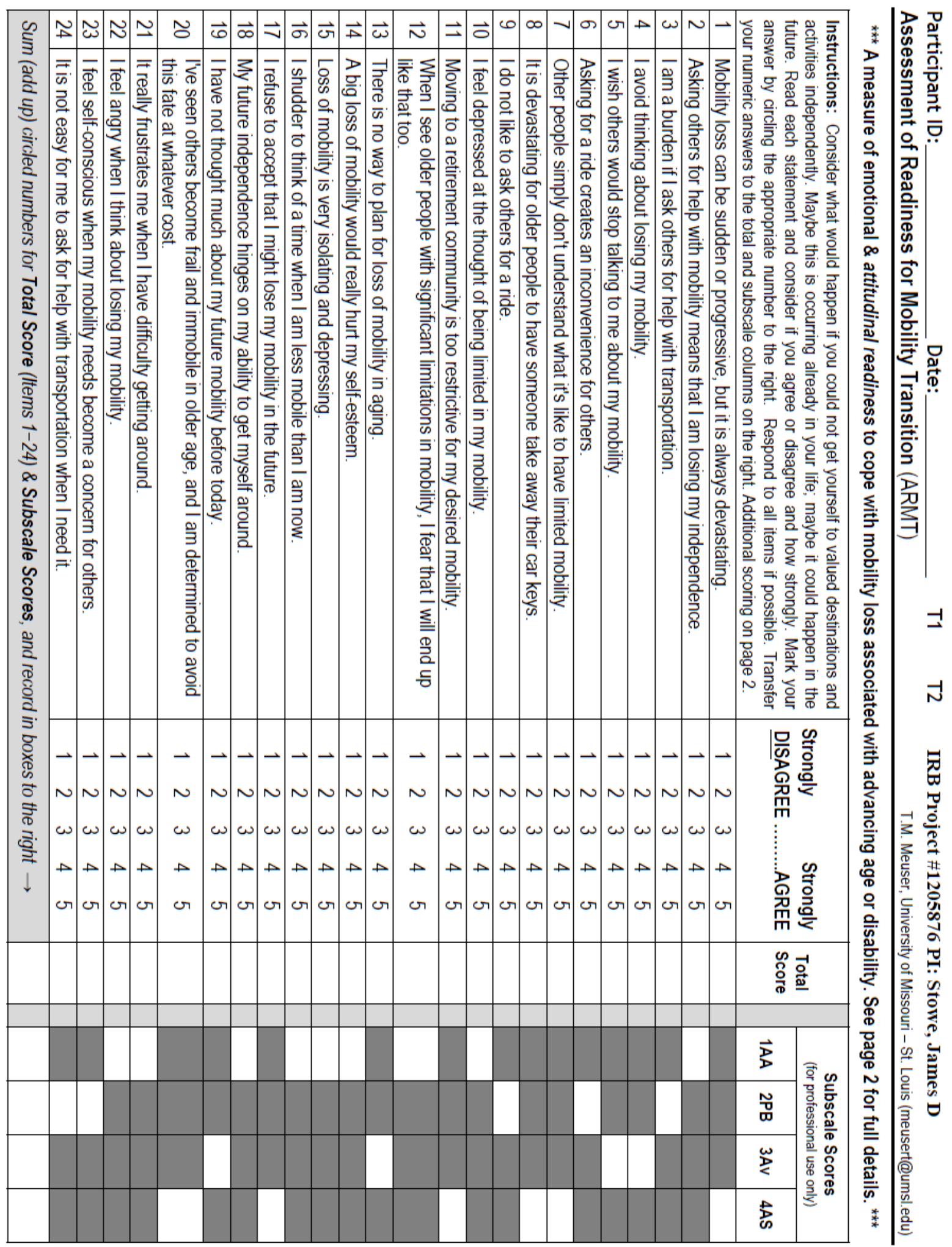


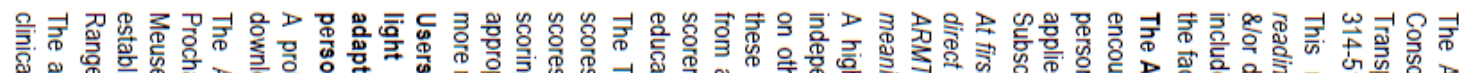

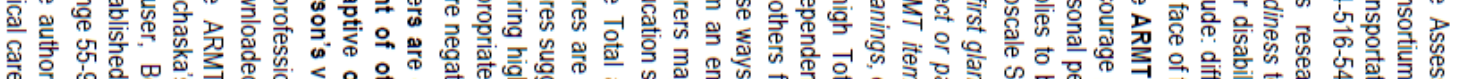

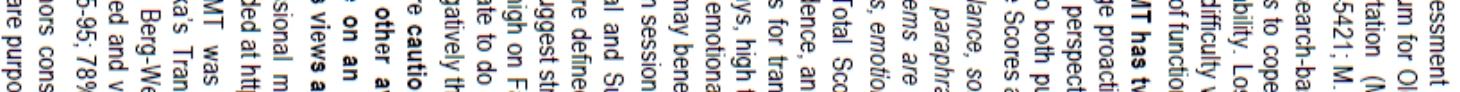

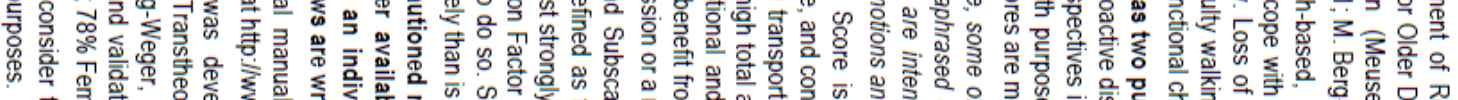

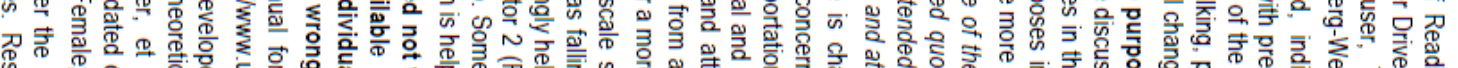

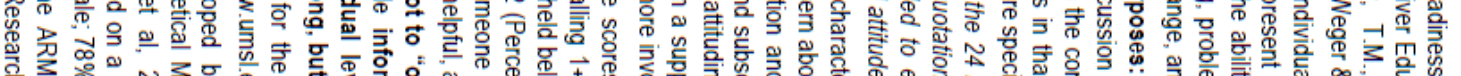

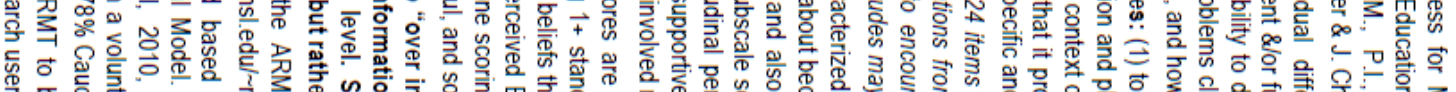

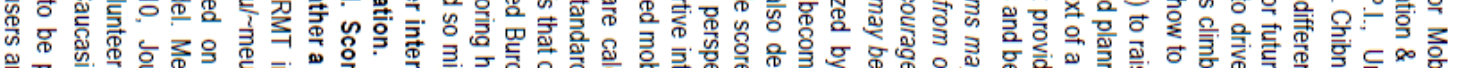

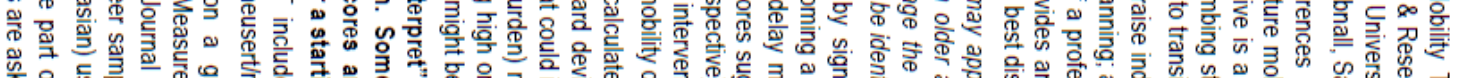

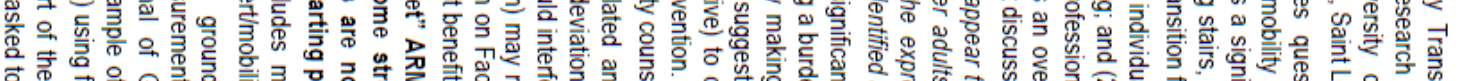

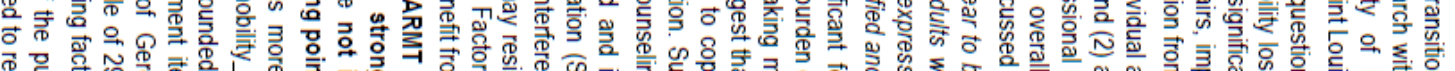
兽

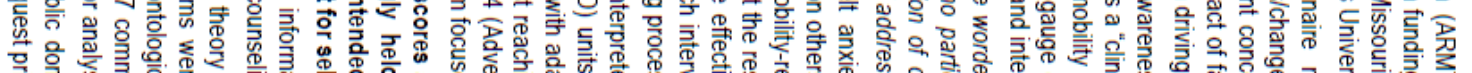

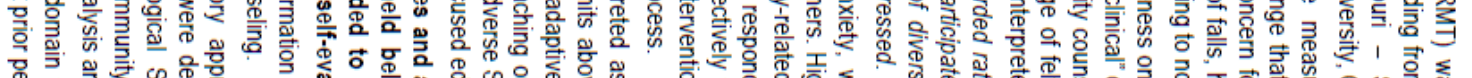

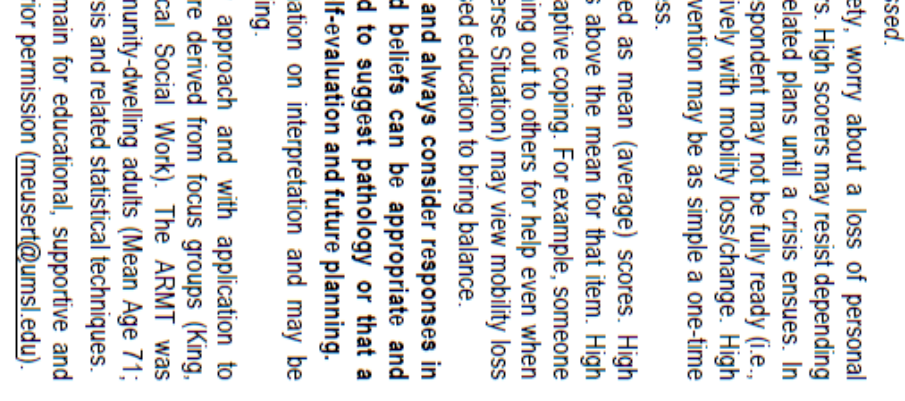

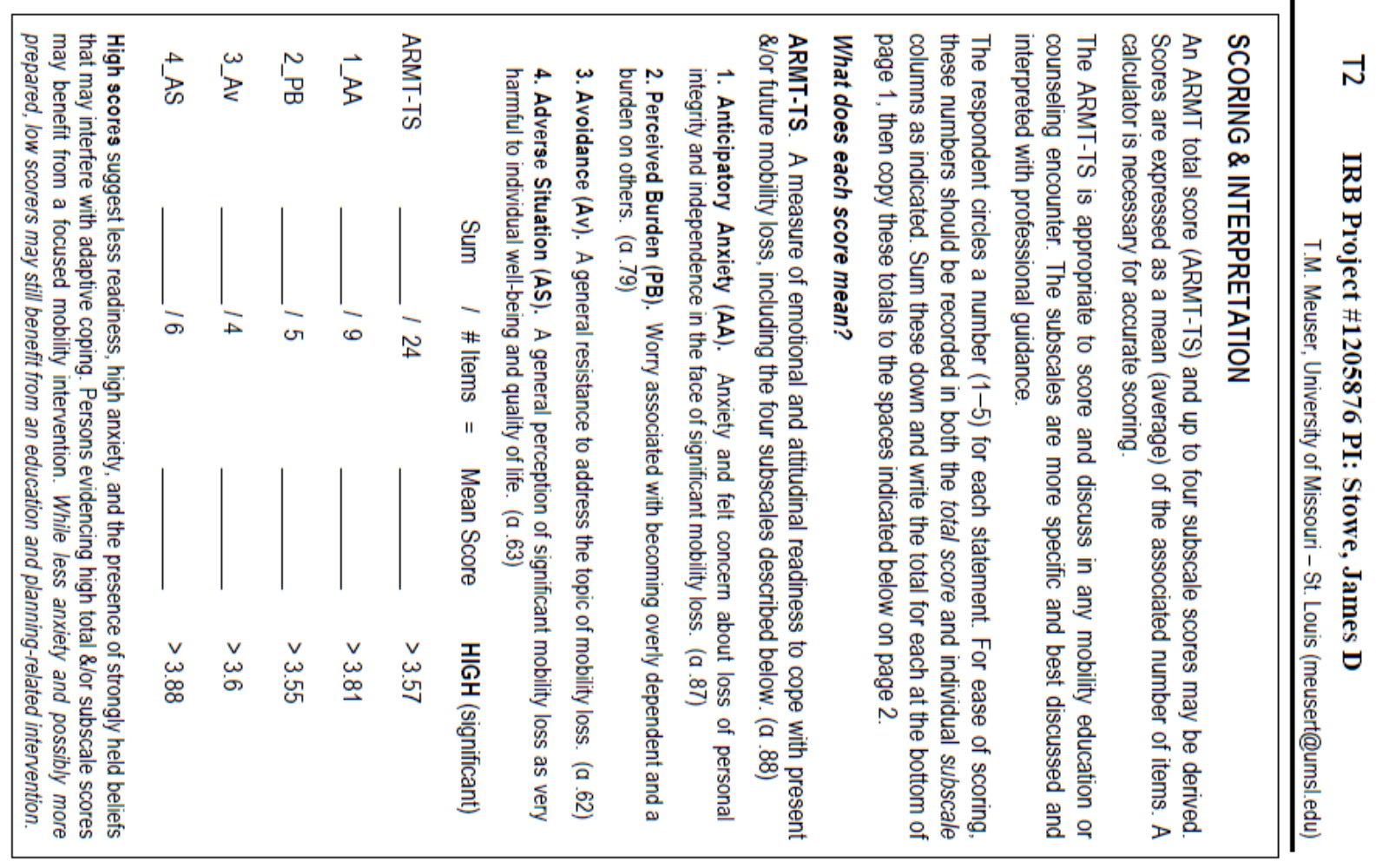


Appendix J

Informed consent documents.

\section{Consent Form to Participate in a Research Study}

\section{Investigator's Name: James Stowe Project \#}

\section{Study Title: MobileAge}

\section{Introduction}

This consent may contain words that you do not understand. Please ask the investigator or the study staff to explain any words or information that you do not clearly understand.

You are being asked to participate in this research study to help us investigate mobility transitions of older adults because you are an older adult who currently drives. Research studies include only people who choose to participate. As a study participant you have the right to know about the procedures that will be used in this research study so that you can make the decision whether or not to participate. The information presented here is simply an effort to make you better informed so that you can decide to participate in this research study or not.

Please take your time to make your decision and discuss it with your family and friends.

In order to participate in this study, it will be necessary to give your written consent.

\section{Why Is This Study Being Done?}

You are invited to participate in a study of mobility of older adults being conducted by James Stowe, of the University of Missouri Hospital. The purpose of this study is to investigate mobility transitions in older adults.

\section{How Many People Will Take Part In The Study?}


About 90 people will take part in this study. Those 90 people will be asked to find a family member or friend to help them with the study. Therefore, there will be 180 individuals in the study. Finally, we will recruit 5 peers to help with various aspects of the study.

\section{What Is Involved in the Study?}

You will be "randomized" into one of the study groups described below. Randomization means that you are put into a group by chance. It is like flipping a coin. You don't choose what group you will be in. The researcher doesn't choose what group you will be in. You will have an equal chance of being placed in any group.

If you agree to participate, we will ask you to speak with us about your mobility. One group in this study uses "peers," who are study volunteers that understand aging, and can likely relate to your circumstances. The other group only interacts with study staff.

You will be interviewed up to five times and each interview will take a maximum of 75 minutes. Some of these interviews will be with study staff, and some of the interviews will be with the peers. Also, in between interviews, you will be contacted regularly by phone.

You will also need to choose a friend or family member who knows you well and knows about your driving to be in the study with you. We will ask this person questions about you over the phone. Finally, we will gather information about whether or not you are admitted to a hospital or nursing home during the study period (please see the "HIPAA Authorization form" for more information).

Audio recordings of conversations will be taken to assist in quality control and for qualitative data analyses. Audio recordings will be de-identified and transcribed by professional University of Missouri transcriptionists. 


\section{How Long Will I Be in the Study?}

We think you will be in the study for 6 months. We may contact you after the study is over to follow up on study results. You can stop being in the study at any time. Your decision to stop being in the study will not affect in any way your medical care and/or benefits.

\section{What Are the Risks of the Study?}

The study methods have little known risks, but participation may cause you some discomfort due to the topics we will discuss. However, these risks are no greater than discussing sensitive issues with friends and family in an everyday setting. If you experience any problems as a result of being in the study, your participation in the study will be stopped and a list of supportive services will be provided to you. You will be encouraged to contact James Stowe with any problems or concerns. He is in charge of the study.

\section{Are There Benefits to Taking Part in the Study?}

The benefit of participation is that you can contribute to knowledge about how older adults adapt to mobility changes.

There is also a chance you will enjoy thinking about and discussing this issue.

\section{What about Confidentiality?}

Information produced by this study will be stored in James Stowe's file and identified by a code number only. The code key connecting your name to specific information about you will be kept in a separate, secure location. Information contained in your records may not be given to anyone unaffiliated with the study in a form that could identify you without your written consent, except as required by law. The investigator conducting this study must obtain your permission before contacting your doctor for information about your past medical history or to inform them that you are in this trial. 
It is possible that your medical and/or research record, including sensitive information and/or identifying information, may be inspected and/or copied by federal or state government agencies, Health Sciences IRB, or hospital accrediting agencies, in the course of carrying out their duties. If your record is inspected or copied by the study sponsor (and/or its agents), or by any of these agencies, the hospital will use reasonable efforts to protect your privacy and the confidentiality of your medical information.

The results of this study may be published in a journal or used for teaching purposes. However, your name or other identifying information will not be used in any publication or teaching materials without your specific permission.

In addition, you must give special written permission for us to use audiotapes that were taken during the study that could identify you. If you want, you will be given the opportunity to listen to the audiotapes before you give your permission for their use.

\section{Will I be Paid for Participating in the Study?}

In return for your time and inconvenience, you will receive compensation of approximately $\$ 20.00$ if you complete the full study. If you are unable, or choose not to complete the study, you will receive $\$ 10.00$ after the second time measures are taken.

\section{What Are My Rights as a Participant?}

Participation in this study is voluntary. You do not have to participate in any part of this study, and you are free to stop participating at any time. There are no penalties for stopping. If you decide to participate, you can change your mind and drop out of the study at any time without affecting your present or future care in the hospital. Leaving the study will not result in any penalty or loss of benefits to which you are entitled. In addition, the investigator of this 
study may decide to end your participation in this study at any time after he has explained the reasons for doing so and has helped arrange for your continued care by your own doctor, if needed.

You will be informed of any new findings discovered during the course of this study that might influence your health, welfare, or decision to continue participation in this study.

\section{Whom Do I Call if I Have Questions or Problems?}

If you have any questions regarding your rights as a participant in this research and/or concerns about the study, or if you feel under any pressure to enroll or to continue to participate in this study, you may contact the University of Missouri Health Sciences Institutional Review Board (which is a group of people who review research studies to protect participants' rights) at (573) 882-3181.

You may ask more questions about the study at any time. For questions about the study, contact James Stowe at (573) 884-6381or stowejd@health.missouri.edu A copy of this consent form will be given to you to keep.

Name of Informant (family member/friend) you wish to be contacted:

Name

Relationship 
Phone Number

\section{Signature}

I confirm that the purpose of the research, the study procedures, the possible risks and discomforts as well as potential benefits that I may experience have been explained to me. Alternatives to my participation in the study also have been discussed. I have read this consent form and my questions have been answered. My signature below indicates my willingness to participate in this study.

Subject/Patient

Date

\section{Signature of Study Representative}

I have explained the purpose of the research, the study procedures, identifying those that are investigational, the possible risks and discomforts as well as potential benefits and have answered questions regarding the study to the best of my ability.

Study Representative

Date 


\section{Consent Form to Participate in a Research Study PEER FORM}

\section{Investigator's Name: James Stowe \\ Project \# \\ Study Title: MobileAge}

\section{Introduction}

This consent may contain words that you do not understand. Please ask the investigator or the study staff to explain any words or information that you do not clearly understand.

You are being asked to participate in this research study to help us investigate mobility transitions of older adults because you are an older person who is familiar with the aging process. Research studies include only people who choose to participate. As a study participant you have the right to know about the procedures that will be used in this research study so that you can make the decision whether or not to participate. The information presented here is simply an effort to make you better informed so that you can decide to participate in this research study or not.

Please take your time to make your decision and discuss it with your family and friends.

In order to participate in this study, it will be necessary to give your written consent.

\section{Why Is This Study Being Done?}

You are invited to participate in a study of mobility of older adults being conducted by James Stowe, of the University of Missouri Hospital. The purpose of this study is to investigate mobility transitions in older adults.

\section{How Many People Will Take Part In The Study?}

About 5 peers will take part in this study. There will be 90 participants in the study, and each one of those participants 
will ask a family member or friend to help them with the study.

\section{What Is Involved in the Study?}

You will be asked to consult with older adults who are at risk for needing to make a mobility transition about planning and preparing for that transition.

If you agree to participate, we will ask you to speak with other older adults about their mobility. You will determine the number of interviews that you conduct. Also, in between interviews, you will be asked to contact study participants regularly by phone or email. Additionally, we will gather information about your mobility to see if it changes over time.

Moreover, you will be asked to participate in training sessions that will serve to familiarize you with the topic of mobility and aging. You will participate in at least two training sessions, but may request additional one-on-one training with the study staff.

Audio recordings of conversations will be taken to assist in quality control and for qualitative data analyses. Audio recordings will be de-identified and transcribed by professional University of Missouri transcriptionists.

\section{How Long Will I Be in the Study?}

We think you will be in the study for 8 months. We may contact you after the study is over to follow up on study results. You can stop participating at any time. There are no negative consequences for stopping.

\section{What Are the Risks of the Study?}

The study methods have little known risks, but participation may cause you some discomfort due to the topics discussed. However, these risks are no greater than discussing sensitive issues with friends and family in an everyday setting. If you experience any problems as a result of participating in the study, your participation in the study will be stopped 
immediately and a list of supportive services will be provided to you. You will be encouraged to contact the principal investigator (James Stowe) with any problems or concerns.

\section{Are There Benefits to Taking Part in the Study?}

The benefit of participation is that you can contribute to knowledge about how older adults adapt to mobility changes.

There is also a chance you will enjoy thinking about and discussing this issue. Finally, the study process and results may benefit vulnerable older adults in the community.

\section{What about Confidentiality?}

Information produced by this study will be stored in James Stowe's file and identified by a code number only. The code key connecting your name to specific information about you will be kept in a separate, secure location. Information contained in your records may not be given to anyone unaffiliated with the study in a form that could identify you without your written consent, except as required by law. If the investigator conducting this study is not your primary, or regular doctor, he must obtain your permission before contacting your regular doctor for information about your past medical history or to inform them that you are in this trial.

It is possible that your medical and/or research record, including sensitive information and/or identifying information, may be inspected and/or copied by federal or state government agencies, Health Sciences IRB, or hospital accrediting agencies, in the course of carrying out their duties. If your record is inspected or copied by the study sponsor (and/or its agents), or by any of these agencies, the hospital will use reasonable efforts to protect your privacy and the confidentiality of your medical information.

The results of this study may be published in a journal or used for teaching purposes. However, your name or other 
identifying information will not be used in any publication or teaching materials without your specific permission.

In addition, you must give special written permission for us to use audiotapes that were taken during the study that could identify you. If you want, you will be given the opportunity to listen to the audiotapes before you give your permission for their use.

\section{Will I be Paid for Participating in the Study?}

In return for your time and inconvenience, you will receive compensation of approximately $\$ 20.00$.

\section{What Are My Rights as a Participant?}

Participation in this study is voluntary. You do not have to participate in any part of this study, and you are free to stop participating at any time. There are no penalties for stopping. If you decide to participate, you can change your mind and drop out of the study at any time without affecting your present or future care in the hospital. Leaving the study will not result in any penalty or loss of benefits to which you are entitled. In addition, the investigator of this study may decide to end your participation in this study at any time after he has explained the reasons for doing so and has helped arrange for your continued care by your own doctor, if needed.

You will be informed of any new findings discovered during the course of this study that might influence your health, welfare, or decision to continue participation in this study.

\section{Whom Do I Call if I Have Questions or Problems?}

If you have any questions regarding your rights as a participant in this research and/or concerns about the study, or if you feel under any pressure to enroll or to continue to participate in this study, you may contact the University of Missouri Health Sciences Institutional Review Board (which 
is a group of people who review research studies to protect participants' rights) at (573) 882-3181.

You may ask more questions about the study at any time.

For questions about the study, contact James Stowe at (573) 884-6381or stowejd@health.missouri.edu

A copy of this consent form will be given to you to keep.

\section{Signature}

I confirm that the purpose of the research, the study procedures, the possible risks and discomforts as well as potential benefits that I may experience have been explained to me. Alternatives to my participation in the study also have been discussed. I have read this consent form and my questions have been answered. My signature below indicates my willingness to participate in this study.

Subject/Patient

Date

\section{Signature of Study Representative}

I have explained the purpose of the research, the study procedures, identifying those that are investigational, the possible risks and discomforts as well as potential benefits and have answered questions regarding the study to the best of my ability.

Study Representative

Date 


\section{WAIVER OF DOCUMENTATION OF CONSENT}

\section{INVESTIGATOR's NAME: JAMES D. STOWE \\ Project \#}

Hi, I'm [investigator's name] from the University of Missouri Hospital, and [participant's name] referred you to me because you may be able to help out with a study that involves research and is being conducted by James Stowe. Participation is voluntary and your decision not to participate will not involve any penalty or loss of benefits. You can stop being in the study at any time.

For this study, we will call you up to 3 times over a period of about 6 months to answer brief questions about [participant's name] related to mobility. The purpose of our study is to look into mobility of older adults. We are asking approximately 90 subjects to participate in this study and those subjects will be asked to recruit someone like you to help them with the study, which is another 90 individuals. Finally, we are recruiting 5 peers who will help with certain aspects of the study. The study staff may withdraw you from the study at any time after explaining to you the reason for withdrawal.

During the study, you are at risk for potential discomfort when discussing the topic of mobility and aging. You should discuss this with the investigator. If you agree to take part in this study, there may be no direct benefits to you or you may enjoy discussing and thinking about mobility. You may expect to benefit from taking part in this research to the extent that you are contributing to medical knowledge that may help vulnerable older adults in the community.

Audio recordings of phone conversations will be taken to assist in quality control. Audio recordings will be de-identified and transcribed by professional University of Missouri transcriptionists.

If you choose to participate, any information you provide to us is confidential, and no one will be able to tell that you were in the study from any published results.

Moreover, there are no costs to you to participate in this study.

If you have any questions regarding your rights as a participant in this research and/or concerns about the study, or if you feel under any pressure to enroll or to continue to participate in this study, you may contact the University of Missouri Health Sciences Institutional Review Board (which is a group of people who review the research studies to protect participants' rights) at (573) 882-3181. Also, if you have any problems or questions, you may contact James Stowe at 573884-6381. If you have any questions right now, I would be happy to answer them. If you need some time to think about participating we will call you back at a later time. Would you like some more time to decide? 
MOBILE AGING

\section{Bibliography}

Adler, G., \& Rottunda, S. (2006). Older adults' perspectives on driving cessation. Journal of Aging Studies, 20, 227-235. doi:10.1016/j.jaging.2005.09.003

Anstey, K. J., Wood, J., Lord, S., \& Walker, J. G. (2005). Cognitive, sensory and physical factors enabling driving safety in older adults. Clinical Psychology Review, 25, 45-65. doi:10.1016/j.cpr.2004.07.008

Baird, S., Hill, L., Rybar, J., Concha-Garcia, S., Coimbra, R., \& Patrick, K. (2010). Agerelated driving disorders: Screening in hospitals and outpatients settings. Geriatrics and Gerontology International, 10, 288-294. doi:10.1111/j.14470594.2010.00622.x

Ball, K. K., Roenker, D. L., Wadley, V. G., Edwards, J. D., Roth, D. L., McGwin, G. Jr., ... Dube, T. (2006). Can high-risk older drivers be identified through performancebased measures in a department of motor vehicles setting? Journal of the American Geriatrics Society, 54, 77-84. doi:10.1111/j.1532-5415.2005.00568.x

Berg-Weger, M., Meuser, T. M., \& Stowe, J. D. (2013). Addressing individual differences in Mobility Transition Counseling with older adults. Journal of Gerontological Social Work, 56, 201-218. doi:10.1080/01634372.2013.764374

Buerhaus, P. I., Donelan, K., Ulrich, B. T., Norman, L., DesRoches, C. \& Dittus, R. (2007). Impact of the nurse shortage on hospital patient care: Comparative perspectives, Health Affairs, 26, 853-862. doi:10.1377/hlthaff.26.3.853

Carr, D. B., Barco, P. P., Wallendorf, M. J., Snellgrove, C. A., \& Ott, B. R. (2011). Predicting road test performance in drivers with dementia. Journal of the American Geriatrics Society, 59, 2112-2117. doi:10.1111/j.1532-

5415.2011.03657.x 


\section{MOBILE AGING}

Carr, D. B., \& Ott, B. R. (2010) The older adult driver with cognitive impairment: "It's a very frustrating life." Journal of the American Medical Association, 303, 16321641. doi:10.1001/jama.2010.481

Chapin, R. K., Sergeant, J. F., Landry, S., Leedahl, S. N., Rachlin, R., Koenig, T., \& Graham, A. (2013). Reclaiming joy: Pilot evaluation of a mental health peer support program for older adults who receive Medicaid. The Gerontologist, 53 doi:10.1093/geront/gns/120.

Cicchino, J. B., \& McCartt, A. T. (2014a). Trends in older driver crash involvement rates and fragility: An update. Arlington, VA: Insurance Institute for Highway Safety.

Cicchino, J. B., \& McCartt, A. T. (2014b). Trends in older driver crash involvement rates and survivability in the United States: An update. Accident Analysis and Prevention, 72, 44-54. doi:10.1016/j.aap.2014.06.011

Classen, S. (2012, November). The Safe Driving Behavior Measure for at-risk older drivers: Steps in translation. Presented at the meeting of the Gerontological Society of America, San Diego, CA.

Classen, S., Velozo, C., Winter, S., Wang, Y., \& Lanford, D. (2012). Validity and usability of a safe driving behavior measure for older adults. (Florida Department of Transportation Final Report on project No. BDK77-977-17). Gainsville, FL: University of Florida.

Crane-Okada, R., Freeman, E., Ross, M., Kiger, H., \& Giuliano, A. E. (2010). Training senior peer counselors to provide support for newly diagnosed breast cancer survivors. Journal of Cancer Education, 25, 174-179. doi:10.1007/s13187-0090028-7

Cox, D.J., Penberthy, J.K., Zrebiec, J., Weinger, K., Aikens, J.E., Frier, B. ... Clarke, W. (2003). Diabetes and driving mishaps: Frequency and correlations from a 


\section{MOBILE AGING}

multinational survey. Diabetes Care, 26, 2329-2334.

doi:10.2337/diacare.26.8.2329

Cummings, P., Koepsell, T. D., \& Mueller, B. A. (1995). Methodological challenges in injury epidemiology and injury prevention research. Annual Review of Public Health, 16, 381-400. doi:10.1146/annurev.pu.16.050195.002121

Curl, A. L., Proulx, C. M., Stowe, J. D., \& Cooney, T. M. (in press). Productive and social engagement following driving cessation: A couple-based analysis. Research on Aging. doi:10.1177/0164027514527624

Curl, A. L., Stowe, J. D., Cooney, T. M., \& Proulx, C. M. (2014). Giving up the keys: How driving cessation affects engagement in later life. The Gerontologist, 54, 423433. doi:10.1093/geront/gnt037

Davey, J. A. (2007). Older people and transport: Coping without a car. Ageing \& Society, 27, 49-65. doi:10.1017/S0144686X06005332

Dellinger, A. M., Sehgal, M., Sleet, D. A., \& Barrett-Connor, E. (2001). Driving cessation: What older former drivers tell us. Journal of the American Geriatrics Society, 49 , 431-435. doi:10.1046/j.1532-5415.2001.49087.x

Dickerson, A.E., Molnar, L.J., Eby, D.W., Adler, G., Bedard, M. Berg-Weger, M. ... Trujillo, L. (2007). Transportation and aging: A research agenda for advancing safe mobility. The Gerontologist, 47, 578-590. doi:10.1093/geront/47.5.578

Edwards, J. D., Perkins, M., Ross, L. A., \& Reynolds, S. L. (2009). Driving status and three-year mortality among community-dwelling older adults. Journals of Gerontology: Biological Sciences and Medical Sciences, 64A, 300-305. doi:10.1093/gerona/gln019

Elder, R. W., Voas, R., Beirness, D., Shults, R. A., Sleet, D. A., Nichols, J. L., \& Compton, R. (2011). American Journal of Preventative Medicine, 40I, 362-376. doi:10.1016/j.amepre.2010.11.012 


\section{MOBILE AGING}

Fillenbaum, G. G. (1982). Social context and self-assessments of health among the elderly. Journal of Health and Social Behavior, 20, 45-51. Retrieved from http://www.jstor.org/stable/2136478

Fillenbaum, G. G. (1988). Multidimensional functional assessment of older adults: The Duke Older Americans Resources and Services procedures. Hillsdale, NJ: Erlbaum.

Freeman, E.F., Gange, S.J., Munoz, B., \& West, S.K. (2006). Driving status and risk of entry into long-term care in older adults. American Journal of Public Health, 96, 1254-1260. doi:10.2105/AJPH.2005.069146

Freund, B., Colgrove, L. A., Petrakos, D., \& McLeod, R. (2008). In my car the brake is on the right: Pedal errors among older drivers. Accident Analysis and Prevention, 40, 403-409. doi:10.1016/j.aap.2007.07.012

Freund, B., Gravenstein, S., Ferris, R., Burke, B., \& Shaheen, E. (2005). Drawing clocks and driving cars. Journal of General Internal Medicine, 20, 240-244. doi:10.1111/j.1525-1497.2005.40069.x

Ganong, L. M., Coleman, M., Benson, J., Snyder-Rivas, L., Stowe, J. D., \& Porter, E. (2013). An intervention to help older adults maintain independence safely. Journal of Family Nursing, 19, 146-170. doi:10.1177/1074840712471900

Galvin, J. E., Roe, C. M., Powlishta, K. K., Coats, M. A., Muich, S. J., Grant, E. ... Morris, J. C. (2005). The AD8: A brief informant interview to detect dementia, Neurology, 65, 559-564. doi:10.1212/01.wnl.0000172958.95282.2a

Galvin, J. E., Roe, C. M., Xiong, C., \& Morris, J. C. (2006). Validity and reliability of the AD8 informant interview in dementia. Neurology, 67, 1942-1948.

doi:10.1212/01.wnl.0000247042.15547.eb 


\section{MOBILE AGING}

Gentzler, M. D., \& Smither, J. A. (2012). A literature review of major perceptual, cognitive, and/or physical test batteries for older drivers, Work, 41, 5381-5383. doi:10.3233/WOR-2012-0825-5381

Haddon, W. (1968). The changing approach to the epidemiology, prevention, and amelioration of trauma: The transition to approaches etiologically rather than descriptively based. American Journal of Public Health, 58, 1431-1438. doi:10.2105/AJPH.58.8.1431

Hanninen, T., Hallikainen, M., Tuomainen, S., Vanhanen, M., \& Soininen, H. (2002). Prevalence of mild cognitive impairment: A population-based study in elderly subjects. Acta Neurologica Scandinavica, 106, 148-154. DOI: 10.1034/j.16000404.2002.01225.x

Hansotia, P. \& Broste, S. K. (1991). The effect of epilepsy or diabetes mellitus on the risk of automobile accidents. The New England Journal of Medicine, 324, 22-26. doi:10.1056/NEJM199101033240105

Huebner, K. D., Porter, M. M., \& Marshall, S. C. (2006). Validation of an electronic device for measuring driving exposure. Traffic Injury Prevention, 7, 76-80. doi:10.1080/15389580500413067

Idler, E. L., \& Benyamini, Y. (1997). Self-rated health and mortality: A review of twentyseven community studies. Journal of Health and Social Behavior, 38, 21-37. Insurance Institute for Highway Safety (IIHS) (2007). Special issue: Older drivers. Status Report, 42(3), 1-8.

Jang, Y., Poon, L. W., \& Martin, P. (2004). Individual differences in the effects of disease and disability on depressive symptoms: The role of age and subjective health. The International Journal of Aging and Human Development, 59, 125-137. doi:10.2190/RT1W-2HD7-KG5X-K1FB 


\section{MOBILE AGING}

Kaczorowski, J., Chambers, L. W., Karwalajtys, T., Dolovich, L., Farrell, B. ... McDonough, B. (2008). Cardiovascular Health Awareness Program (CHAP): A community cluster-randomized trial among elderly Canadians. Preventive Medicine, 46, 537-544. doi:10.1016/j.ypmed.2008.02.005

Kaczorowski, J., Chambers, L. W., Dolovich, L., Paterson, J. M., Karwalajtys, T., ... Gierman, T. (2011). Improving cardiovascular health at population level: 39 community cluster randomized trial of Cardiovascular Health Awareness Program (CHAP). British Medical Journal, 342, np. doi:10.1136/bmj.d442

Kate, L., Ritter, P., Stewart, A. L., Sobel, D. S., William Brown, B., Bandura, A., ... Holman, H. R. (2001). Chronic disease self-management program: 2-year health status and health care utilization outcomes. Medical Care, 39, 1217-1223.

Koepsell, T., Wolf, M. \& McCloskey, L. (1994). Medical conditions and motor vehicle collision injuries in older adults. Journal of the American Geriatrics Society, 42, 695-700.

Kostyniuk, L. P., Shope, J. T., \& Molnar, L. J. (2000). Reduction and cessation of driving among older drivers in Michigan: Final report (University of Michigan Transportation Research Institute Report No. UMTRI-2000-06). Ann Arbor, MI: UMTRI.

LaJunen, T., Parker, D., \& Summala, H. (2004). The Manchester Driver Behaviour Questionnaire: A cross-cultural study. Accident Analysis and Prevention, 36, 231238.

Langford, J. (2008). Usefulness of off-road screening tests to licensing authorities when assessing older driver fitness to drive. Traffic Injury Prevention, 9, 328-335. doi:10.1080/15389580801895178 


\section{MOBILE AGING}

Lawton, M. P., \& Nahemow, L. (1973). Ecology and the aging process. In C. Eisdorfer \& M. P. Lawton (Eds.), The psychology of adult development and aging, (619-674). Washington, DC: American Psychological Association. doi:10.1037/10044-000 Liddle, J., Haynes, M., Pachana, N. A., Mitchell, G., McKenna, K., \& Gustafsson, L. (2014). Effect of a group intervention to promote older adults' adjustment to driving cessation on community mobility: A randomized controlled trial. The Gerontologist, 54, 409-422. doi:10.1093/geront/gnt019

Liddle, J., Reaston, T., Pachana, N., Mitchell, G., \& Gustafsson, L. (2014). Is planning for driving cessation critical for the well-being and lifestyle of older drivers? International Psychogeriatrics, 26, 1111-1120. doi:10.1017/S104161021400060X

Liddle, J., Turpin, M., Carlson, G., \& McKenna, K. (2008). The needs and experiences related to driving cessation for older people. British Journal of Occupational Therapy, 71, 379-388.

Logan, P. A., Gladman, J. R. F., Avery, A., Walker, M. F., Dyas, J., \& Groom, L. (2004). Randomised controlled trial of an occupational therapy intervention to increase outdoor mobility after stroke. British Medical Journal, 329, 1372-1374. doi:10.1136/bmj.38264.679560.8F

Lyman, S., Ferguson, S., Braver, E., \& Williams, A. (2002). Older driver involvements in police reported crashes. Injury Prevention, 8, 116-120. doi:10.1136/ip.8.2.116

Marottoli, R., Mendes de Leon, C., Glass, T., Williams, C., Cooney, L., Berkman, L., \& Tinetti, M. (1997). Driving cessation and increased depressive symptoms: Prospective evidence from the New Haven EPESE. Journal of the American Geriatrics Society, 45, 202-206.

Marottoli, R., Mendes de Leon, C., Glass, T., Williams, C., Cooney, L. \& Berkman, L. (2000). Consequences of driving cessation: Decreased out-of-home activity 


\section{MOBILE AGING}

levels. Journals of Gerontology: Psychological Sciences \& Social Sciences, 55, S334-S339. doi:10.1093/geronb/55.6.S334

Mathias, J. L., \& Lucas, L. K. (2009). Cognitive predictors of unsafe driving in older drivers: A meta-analysis. International Psychogeriatrics, 21, 637-653.

Doi10.1017/S104161029009119

Mattsson, M. (2012) Investigating the factorial invariance of the 28-item DBQ across genders and age groups: An exploratory Structural Equation Modeling study. Accident Analysis and Prevention, 48, 379-396. doi:10.1016/j.aap.2012.02.009

McGwin, G. Jr., Sims, R. V., Pulley, L. \& Roseman, J.M. (2000). Relations among chronic medical conditions, medication, and automobile crashes in the elderly: A population-based case-control study. American Journal of Epidemiology, 152, 424-431. doi:10.1093/aje/152.5.424

McGwin, G. Jr., Xie, A., Mays, A., Joiner, W., DeCarlo, D. K., Hall, T. A., \& Owsley, C. (2005). Visual field defects and the risk of motor vehicle collisions among patients with glaucoma. Investigative Ophthalmology \& Visual Science, 46, 44374441. doi:10.1167/iovs.05-0750

Meindorfner, C., Körner, Y., Möller, J. C., Stiasny-Kolster, K., Oertel, W. H., \& Krüger, H. P. (2005). Driving in Parkinson's disease: Mobility, accidents and sudden onset of sleep at the wheel. Movement Disorders, 20, 832-842. doi:.1002/mds.20412 Meuser, T. M. (2011, November). Assessing readiness for mobility transitions. In T. M. Meuser (Chair), Integrated assessment and mobility counseling for older adults. Symposium conducted at the meeting of the Gerontological Society of America, Boston, MA.

Meuser, T. M., Berg-Weger, M., Chibnall, J. C., Harmon, A. \& Stowe, J. D. (2013). Assessment of Readiness for Mobility Transition (ARMT): A tool for mobility 


\section{MOBILE AGING}

transition counseling for older adults. Journal of Applied Gerontology, 54, 201 218. doi:10.1080/01634372.2013.764374

National Center for Health Statistics. (2012). Summary health statistics for U.S. adults: National Health Interview Survey, 2011 (DHHS Publication No. (PHS) 20131584). Hyattasville, Maryland: Centers for Disease Control and Prevention.

National Highway Transportation Safety Administration. (2013). Countermeasure that work: A highway safety countermeasure guide for state highway safety offices (DOT Report No. DOT HS 811 727). Washington, DC: United States Department of Transportation.

Naumann, R., Dellinger, A., Zaloshnja, E., Lawrence, B., \& Miller, T. (2010). Incidence and total lifetime costs of motor vehicle-related fatal and nonfatal injury by road user type, United States, 2005. Traffic Injury Prevention, 11, 353-360. doi:10.1080/15389588.2010.486429

Older Americans Act, Public Law 109-365 § IIIB (2006).

Oswald, F., Wahl, H.-W., Schilling, O., Nygren, C., Fange, A., Sixsmith, A. ... Iwarsson, S. (2007). Relationships between housing and healthy aging in very old age. The Gerontologist, 47, 96-107. doi:10.1093/geront/47.1.96

Owsley, C., McGwin, G., \& Ball, K. (1998). Vision impairment, eye disease, and injurious motor vehicle crashes in the elderly. Ophthalmic Epidemiology, 5, 101-113. doi:10.1076/opep.5.2.101.1574

Owsley, C., McGwin, G., Phillips, J. M., McNeal, S. F., \& Stalvey, B. T. (2004). Impact of an educational program on the safety of high-risk, visually impaired, older drivers. American Journal of Preventive Medicine, 26, 222-229.

doi:10.1016/j.amepre.2003.12.005 


\section{MOBILE AGING}

Owsley, C., Stalvey, B. T., \& Phillips, J. M. (2003). The efficacy of an educational intervention in promoting self-regulation among high-risk older drivers. Accident Analysis \& Prevention, 35, 393-400. doi:10.1016/S0001-4575(02)00016-7

Owsley, C., Stalvey, B. T., Wells, J., \& Sloane, M. E. (1999). Older drivers and cataract: Driving habits and crash risk. Journals of Gerontology: Medical Sciences, 54A, M203-M211. doi:10.1093/gerona/54.4.M203

Pachana, N. A., \& Petriwskyj, A. M. (2006). Assessment of insight and self-awareness in older drivers. Clinical Gerontologist, 30, 23-38. doi:10.1300/J018v30n01_03

Petersen, R. C., Stevens, J. C., Ganguli, M., Tangalos, E. G., Cummings, J. L., \& DeKosky, S. T. (2001). Early detection of dementia: Mild cognitive impairment (an evidence-based review): Report of the Quality Standards Subcommittee of the American Academy of Neurology. Neurology, 56, 1133-1142.

Pillemer, K., \& Suitor, J. J. (2002). Peer support for Alzheimer's caregivers: Is it enough to make a difference? Research on Aging, 24, 171-192. doi:10.1177/0164027502242001

Pinquart, M. (2001). Correlates of subjective health in older adults: A meta-analysis. Psychology and Aging, 16, 414-426. doi:10.1037/0882-7974.16.3.414

Prochaska, J. O., \& DiClemente, C. C. (1983). Stages and processes of self-change of smoking: Toward an integrative model of change. Journal of Consulting and Clinical Psychology, 51, 390-395. doi:10.1037/0022.006X.51.3.390

Reason, J., Manstead, A., Stradling, S., Baxter, J., \& Campbell, K. (1990). Errors and violations on the roads: A real distinction? Ergonomics, 33, 1315-1332. doi:10.1080/00140139008925335

Royall, D. R., Mulroy, A. R., Chiodo, L. K., \& Polk, M. J. (1999). Clock drawing is sensitive to executive control: A comparison of six methods. Journal of Geriatrics: Psychological Sciences, 5, 328-333. doi:10.1093/geronb/54B.5.P328 


\section{MOBILE AGING}

Russell, K. F., Vandermeer, B., \& Hartling, L. (2011). Graduated driver licensing for reducing motor vehicle crashes among young drivers. Cochrane Database of Systematic Reviews, 2011. doi:10.1002/14651858.CD003300.pub3

Samton, J. B., Ferrando, S. J., Sanelli, P., Karimi, S., Raiteri, V., \& Barnhill, J.W. (2005). The clock drawing test: Diagnostic, functional and neuroimaging correlates in older medically ill adults. Journal of Neuropsychiatry and Clinical Neuroscience, 17, 533-540. doi:10.1176/appi.neuropsych.17.4.53

Salzberg, P. \& Moffat, J. (1998). The Washington State Department of Licensing Special Exam Program: An Evaluation. Olympia, WA: Washington Traffic Safety Commission.

Schulz, K. F., \& Grimes, D. A. (2002). Generation of allocation sequences in randomised trials: Chance, not choice. Lancet, 359, 515-518. doi:10.1016/S01406736(02)07683-3

Scheidt, R. J., \& Norris-Baker, C. (2003). The general ecological model revisited: Evolution, current status, and continuing challenges. In H.-W. Wahl, R. Scheidt, \& P. Windley (Eds.), Environments, gerontology and old age. Annual review of gerontology and geriatrics 2003 (pp. 34-58). New York: Springer.

Sinclair, A. J., Conroy, S. P., Davies, M., \& Bayer, A. J. (2005). Post-discharge homebased support for older cardiac patients: A randomized controlled trial. Age and Ageing, 34, 338-343.

Siren, A., Hakamies-Blomqvist, L., \& Lindeman, M. (2004). Driving cessation and health in older women. Journal of Applied Gerontology, 23, 58-69. doi:10.1177/0733464804263129

Siren, A., \& Meng, A. (2013). Older drivers' self-assessed driving skills, driving-related stress and self-regulation in traffic. Transportation Research Part F: Traffic Psychology \& Behavior, 17, 88-97. doi:10.1016/j.trf.2012.10.004 


\section{MOBILE AGING}

Stapleton, T. (2012, November). Formative factors influencing the clinical decision to refer for driving-assessment following stroke. Presented at the $65^{\text {th }}$ Annual Scientific Meeting of the Gerontological Society of America, San Diego, CA.

Staplin, L., \& Freund, K. (2013). Policy prescriptions to preserve mobility for seniors - a dose of realism. Accident Analysis and Prevention, 61, 212-221. doi:10.1016/j.aap.2013.02.014

Staplin, L., Lococo, K. H., Martell, C., Stutts, J. (2012). Taxonomy of older driver behaviors and crash risk (National Highway Traffic Safety Administration Report No. DOT HS 811-468A). Washington, DC: NHTSA.

Staplin, L., Lococo, K.H. Steward, J., \& Decina, L.E. (1999). Safe Mobility for Older People Notebook. National Highway Traffic Safety Administration Model Driver Screening and Evaluation program. DOT (HS 808 853).

Starkstein, S. E., Jorge, R., Mizrahi, R., \& Robinson, R. G. (2006). A diagnostic formulation for anosognosia in Alzheimer's disease. Journal of Neurology Neurosurgery and Psychiatry, 77, 719-725. doi:10.1136/jnnp.2005.08537s

Stowe, J. D. (2011, November). Heightening older adults' awareness of mobility preparedness using Multiple Segment Factorial Vignettes. In T. M. Meuser (Chair), Intervention, assessment, and mobility counseling for older adults. Symposium conducted at the meeting of the Gerontological Society of America, Boston, MA.

Stowe, J. D., Niewoehner, P., Meuser, T. M., \& Berg-Weger, M. (2013, November). Encounters with medically-impaired older license seekers. Presented at the $66^{\text {th }}$ Annual Scientific Meeting of the Gerontological Society of America, New Orleans, LA. 


\section{MOBILE AGING}

Strunin, L., Stone, M., \& Jack, B. (2007). Understanding rehospitalization risk: Can hospital discharge be modified to reduce recurrent hospitalization? Journal of Hospital Medicine, 2, 297-304.

Tabachnick, B. G., \& Fidell, L. S. (2007). Using multivariate statistics ( $5^{\text {th }}$ ed.) Boston, MA: Allyn \& Bacon.

Truncali, A., Dumanovsky, T., Stollman, H., \& Angell, S. Y. (2010) Keep on Track: A volunteer-run community-based intervention to lower blood pressure in older adults. Journal of the American Geriatrics Society, 58, 1177-1183. doi:10.1111/j.1532-5415.2010.02874.x

Tuokko, H., Tallman, K., Beattie, L.B., Cooper, P. \& Wier, J. (1995). An examination of driving records in a dementia clinic. The Journals of Gerontology: Psychological Sciences and Social Sciences, 50, S173-S186. doi:10.1093/geronb/50B.3.S173

Utts, J. M. and Heckard, R. F. (2012). Mind of statistics, $6^{\text {th }}$ ed. Boston: Brooks/Cole Cengage Learning.

Van Houtven, G., Honeycutt, A. A., Gilman, B., McCall, N. T., Throneburg, W. W., \& Sykes, K. E. (2008). Costs of illness among older adults: An analysis of six major health conditions with significant environmental risk factors (Research Triangle Institute publication no. RR-0002-0809). Research Triangle Park, NC: RTI International.

Wahl, H. W., Iwarsson, S., \& Oswald, F. (2012). Aging well and the environment: Toward an integrative model and research agenda for the future. The Gerontologist, 52, 306-316. doi:10.1093/geront/47.1.78

Warnes, A. M., \& Fraser, D. A. (1993). Car driving as a social skill. Gerontology \& Geriatrics Education, 13, 103-127. 


\section{MOBILE AGING}

Waters, D. L., Hale, L. A. Robertson, L., Hale, B. A., \& Herbison, P. (2011). Evaluation of a peer-led falls prevention program for older adults. Archives of Physical Medicine and Rehabilitation, 92, 1581-1586. doi:10.1016/j.apmr.2011.05.014

West, D. S., Bursac, Z., Cornell, C. E., Felix, H. C., Fausett, J. K. ... Krukowski, R. A. (2011). Lay health educators translate a weight-loss intervention in senior centers: A randomized controlled trial. American Journal of Preventive Medicine, 41, 385-391. doi:10.1016/j.amepre.2011.06.041

Wong, Y., Smith, S. S., \& Sullivan, A. (2012). The relationship between cognitive ability, insight, and self-regulatory behaviors: Findings from the older driver population. Accident Analysis and Prevention, 49, 316-321. doi:10.1016/j.aap.2012.05.031

Zuin, D., Ortiz, H., Boromei, D. \& Lopez, O.L. (2002). Motor vehicle crashes and abnormal driving behaviors in participants with dementia in Mendoza, Argentina. European Journal of Neurology, 9, 29-34. doi:10.1046/j.14681331.2002.00296.x. 


\section{VITA}

James Daniel Stowe was born in Manhattan, Kansas. After graduating from Manhattan High School in 2003, he attended Drury University in Springfield, Missouri before transferring to Kansas State University. He received a Bachelor of Arts with a major in Political Science from Kansas State University in December 2006. After a brief stint in the Political Science graduate program at Kansas State University, he transferred to Gerontology and received a Master of Science in July 2009. In August 2009, he entered graduate school at the University of Missouri. 